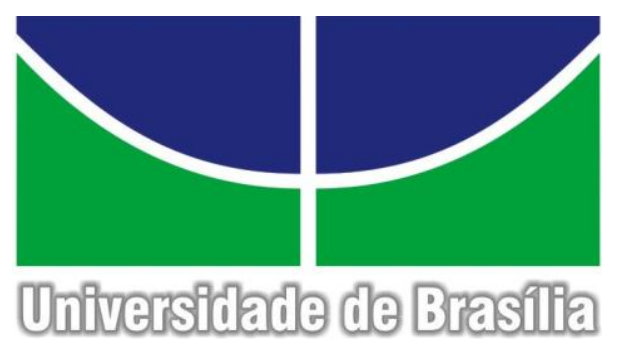

Universidade de Brasília

Faculdade de Educação Física

Programa de Pós-Graduação em Educação Física

\title{
ANÁLISE DO ALCANCE MANUAL DE LACTENTES PRÉ-TERMO COM BAIXO E MUITO BAIXO PESO
}

Ana Letícia de Souza Oliveira

Brasília - DF 


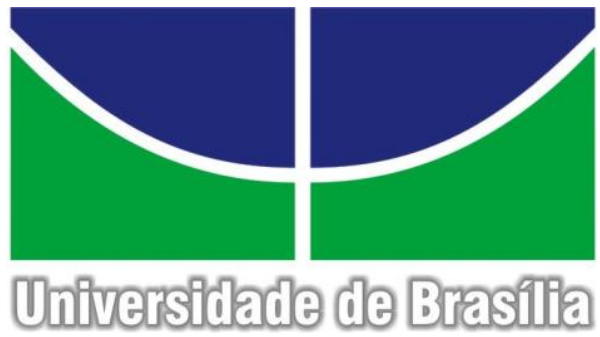

ANA LETÍCIA DE SOUZA OLIVEIRA

Análise do alcance manual de lactentes pré-termo com baixo e muito baixo peso

Orientadora: Profa. Dra. Aline Martins de Toledo

Pesquisa apresentada ao Programa de Pós Graduação em Educação Física da Universidade de Brasília como parte dos requisito para obtenção do Título de Mestre em Educação Física.Linha de Pesquisa: Aspectos Biológicos Relacionados ao Desempenho e a Saúde.Tema: Análise do Movimento Infantil

\section{Brasília - DF}


A todas as pessoas que de alguma maneira me ajudaram concluir esse trabalho, a minha família e ao Carlos por todo incentivo e força para realização desse sonho. 


\section{AGRADECIMENTOS}

A Deus e meu anjo da aguarda (que trabalhou muito nesses anos), por não me fazer vacilar nos momentos difíceis e me inspirar nos momentos que me encontrei encurralada.

A minha família, por ter me ajudado a tomar essa decisão de realizar um sonho que vem desde a graduação, por ter me incentivado nos momentos que tive que tomar difíceis decisões. Especialmente à minha irmã, Ana Luísa, que teve ser por muitas vezes um ouvido amigo e achar sempre palavras de motivação.

Ao Carlos, meu eterno companheiro e cúmplice, por ter paciência comigo, compreender minhas ausências, tentar me ajudar da melhor maneira que estava ao seu alcance, por ter orgulho de mim e reconhecer sempre meus esforços. Por ter o abraço e o carinho que me acalmam que me fazem sentir simplesmente ampara e segura. Eu te amo.

Ao Paulo, por sua toda sua incansável ajuda nas análises de dados, tentando compreender e solucionar todos os desafios e idéias mirabolantes que tivemos.

À minha querida orientadora, Aline, por simplesmente ter confiado em mim e me aceitado de braços abertos para essa caminhada. Pessoa que me inspira pela renomada carreira, na qual não mede esforços para ser sempre melhor. Mas me inspira ainda mais pela pessoa que é, por sua essência, sua doçura, sua garra, sua personalidade e suas virtudes. Me ensinou muito mais do que só conhecimentos científicos (que foram muitos!), me ensinou através de suas atitudes como ser e buscar cada vez mais ser uma pessoa melhor. Se fosse repetir essa jornada mil vezes, todas teriam que te ter como orientadora, outra não serviria. Por me incentivar, me ensinar tantas coisas, acreditar em mim e me adotar como "filha", meu eterno muito obrigada!

Ao Rodrigo, por nunca se recusar a nos ajudar, dispondo sempre de seu tempo e atenção para tentar solucionar nos problemas, motivando e dando bronca quando precisamos. Obrigada!

Especialmente, à minha companheira, parceira e cúmplice amiga Mariana, por ter enfrentado mais essa jornada comigo. Obrigada pela companhia, pelo ombro amigo, pelas conversas, por me incentivar quando precisei, por dividir comigo todas as dificuldades, por me compreender. E, principalmente, pelas risadas e por tentar dar leveza aos nossos desafios. Sem dúvidas, não teria conseguido sem você. É o fim de um grande caminhada, desde nosso TCC de faculdade. Sempre sentirei saudades de você nos meus dias, mas terei sempre na memória um árduo caminho de sucesso ao seu lado. Obrigada, acima de tudo, por ser minha amiga!

Como dizem que nossos orientadores são como pais, eu fui ainda mais sortuda, pois ganhei uma família completa: uma mãe, um pai e uma irmã! 


\section{LISTA DE FIGURAS}

Figura 1. Fluxograma de Perda Amostral do grupo Baixo Peso.................................36

Figura 2. Fluxograma de Perda Amostral do grupo de Muito Baixo Peso ..................36

Figura 3. Calibração do Sistema Qualysis ................................................................... 38

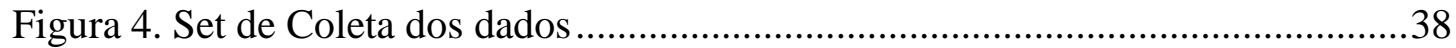

Figura 5. Local de avaliação da Alberta Infant Motor Scale (AIMS) .........................41

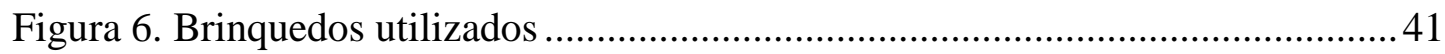

Figura 7. Posicionamento dos Marcadores ............................................................... 44

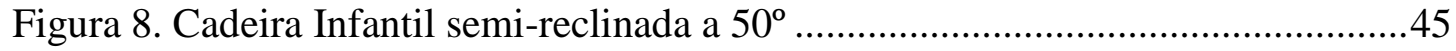

Figura 9.Faixa de tecido para estabilidade de tronco...............................................45

Figura 10. Índice de Retidão em cada grupo dividido por peso ao nascer ..................53

Figura 11. Unidade de Movimento em cada grupo dividido por peso ao

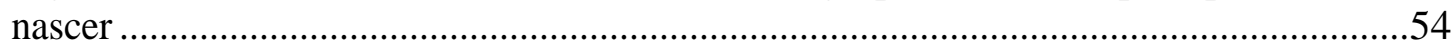

Figura 12. Índice de Ajuste em cada grupo dividido por peso ...ao nascer. $\quad$.............54

Figura 13. Velocidade Inicial em cada grupo dividido por peso ...ao nascer.

Figura 14. Velocidade de Pico em cada grupo dividido por peso ao nascer ................56

Figura 15. Velocidade Média em cada grupo dividido por peso ...ao nascer.

Figura 16. Comportamento Motor em cada grupo dividido por peso...ao nascer

Figura 17. Índice de Retidão em cada grupo dividido por idade gestacional $\quad \ldots 60$

Figura 18. Unidade de Movimento em cada grupo dividido por idade gestacional $\quad \ldots 61$

Figura 19. Índice de Ajuste em cada grupo dividido por idade gestacional $\quad \ldots 61$

Figura 20. Velocidade Inicial em cada grupo dividido por idade gestacional.............62 


\section{LISTA DE TABELAS}

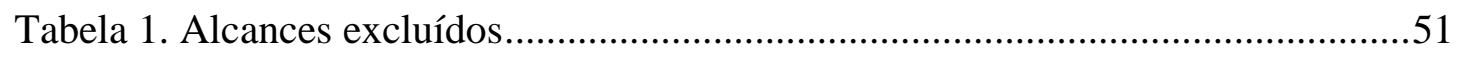

Tabela 2. Alcances analisados nos grupos estratificados pelo peso ao nascimento ....51

Tabela 3. Alcances analisados nos grupos estratificados pela idade gestacional ........52

Tabela 4. Caracterização das intervenções neonatais dos grupos estratificados

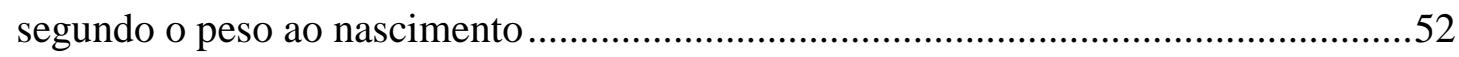

Tabela 5. Risco Relativo, grupo Baixo Peso ao nascer.............................................58

Tabela 6. Risco Relativo, grupo Muito Baixo Peso ao nascer.....................................58

Tabela 7. Caracterização das intervenções neonatais dos grupo estratificados pela

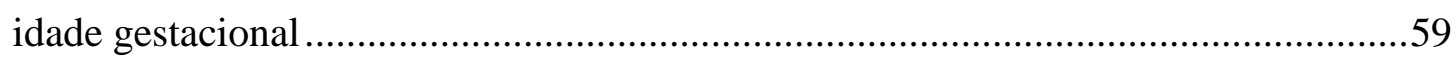

Tabela 8. Risco Relativo, grupo Prematuro Tardio ...................................................63

Tabela 9. Risco Relativo, grupo Muito Prematuro ....................................................64 


\section{LISTA DE ANEXOS}

ANEXO 1 - Termo de Consentimento Livre e Esclarecido.

.95

ANEXO 2 - Escala AIMS (Alberta Infant Motor Scale).

97

ANEXO 3 - Aprovação do Comitê de ética em Pesquisa.............................. 103 


\section{LISTA DE APÊNDICES}

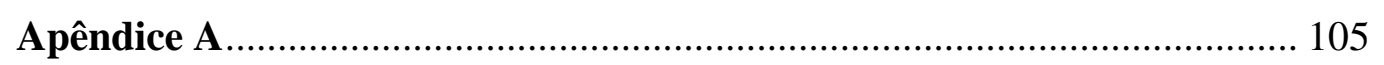

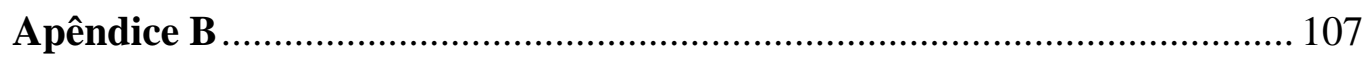




\section{RESUMO}

OLIVEIRA, A.L.S. Análise do alcance manual de lactentes pré-termo com baixo e muito baixo peso ao nascer. 2015. Dissertaçao (Mestrado) - Universidade Brasília, Brasilia, DF

O alcance manual é uma importante habilidade a ser estudada pois é uma das aquisições motoras voluntárias iniciais e é através dele que os lactentes desenvolvem habilidades mais complexas. Algumas restrições intrinsecas, como a prematuridade e o baixo peso ao nascer influenciam o comportamento motor geral de lactentes. No entanto, não foram encontrados estudos que abordassem a influencia especificamente do prematuro com baixo peso ao nascer no alcance manual. Desta forma, o objetivo do presente estudo foi analisar a influência do peso ao nascer e da prematuridade no alcance manual de lactentes aos 6 meses de idade corrigida. Afim de contemplar este objetivo foi realizado um estudo transversal, com uma amostra de 57 lactentes divididos em 3 grupos: a) 21 prematuros com Baixo Peso ao nascer $(<2500 \mathrm{~g})(\mathrm{GBP})$; b) 15 prematuros com Muito Baixo peso $(<1500 \mathrm{~g})(\mathrm{GMBP})$; c) 21 lactentes a termo com Peso Adequado ao nascimento (>2500g) (GPA), para compor o grupo controle; estes mesmos lactentes foram redistribuidos conforme a idade gestacional, formando 3 grupos: a) 25 Prematuros Tardios (32 a 36 semanas) (GPT); b) 11 Muito Prematuro (28 e 32 semanas) (GMP); c) 21 lactentes A termos (>37 semanas) (GAT). O alcance foi analisado cinematicamente por meio do Sistema Qualysis (QTM - Qualisys Track Manager). As variaveis analisadas foram índice de retidão, índice de ajuste, velocidade inicial, média e de pico, unidades de movimento. Além disso, também foi avaliado o comportamento motor grosso dos lactentes por meio da escala Alberta Infant Motor Scale (AIMS). A analise dos dados foi realizada por meio dos testes não-paramétricos. Para verificar a diferença entre os grupos estratificados pelo peso ao nascimento e posteriormente pela idade gestacional foi utilizado o teste KruskallWallys, quando as diferenças foram observadas realizou-se o teste Mann-Whitney para identificar em cada dois grupos em quais isto ocorreu, adotando para este último p<0,017 e para as demais significância de 5\%. Por fim foi calculado o Risco Relativo do atraso motor dos grupos. Na comparação entre os grupos estratificados pelo peso ao nascer, observou-se que entre o GPA e GBP, o GPA apresentou maior Índice de Retidão $(\mathrm{p}<0,000)$ e menores de Unidades de Movimento $(\mathrm{p}<0,001)$ e de Índice de Ajuste ( $\mathrm{p}=0,001$ ); entre os grupos GPA e GMBP, o Índice de retidão foi maior nos 
GPA $(\mathrm{p}<0,000)$ e as velocidades Inicial $(\mathrm{p}=0,001)$ e de Pico $(\mathrm{p}=0,005)$ o GMBP apresentou maiores valores; e entre os grupos GBP e GMBP o GMBP mostrou maiores velocidades Média $(\mathrm{p}=0,006)$ e de Pico $(\mathrm{p}=0,009)$ e menores valores na escala AIMS $(\mathrm{p}=0,009)$. Quanto a analise de Risco relativo observou-se que e o GMBP apresentou Risco Relativo positivo para atraso motor. Na estratificação quanto a idade gestacional, a comparação entre os grupos GAT e GPT a variavel Índice de Retidão ( $\mathrm{p}=0,001)$ apresentou-se maior no grupo GAT; já as Unidade de Movimento $(\mathrm{p}<0,000)$ e Índice de Ajuste ( $\mathrm{p}=0,001)$ foram maiores no GPT; entre os grupos GAT e os GMP, o Índice de Retidão $(\mathrm{p}<0,000)$ foi maior no GAT enquanto sua Velocidade Inicial $(p=0,017)$ foi menor; entre os prematuros em: Índice de Ajuste $(p<0,000)$ apresentou-se maior no GPT. Na análise de Risco, pode-se observar que o grupo

GMP apresentou risco relativo positivo para atraso motor. É possível concluir a partir dos presentes resultados que os lactentes de Baixo Peso e Prematuros Tardios possuem o movento de alcance semelhante, possivelmente consequente a déficits de massa muscular e sensorias. Os lactentes de Muito Baixo Peso apresentaram um movimento de alcance mais rápido, pouco fluente e sem ajustes durante a trajetória, fato consequente a déficits importante de massa magra, do subsenvolvimento cerebelar e por hipertonia de cintura escapular. Fato similar ocorreu com o grupo Muito Prematuro, que também apresentou velocidade inicial alta e movimento pouco fluente, o que pode ter sido causado pela restrições intrínsecas de baixa massa magra e déficits de ação de cerebelo. Quanto ao comportamento motor, os grupos de lactentes de Muito Baixo Peso e Muito Prematuros tiveram um risco relativo alto para atrasos motores, determinado pelas restrições intrínsecas desses lactentes e pelas intervenções neonatais sofridas devido ao uso de oxigênio suplementar e da ventilação mecânica.

Palavras-chaves: Alcance manual, Peso ao nascer, Prematuridade, Destreza motora 


\begin{abstract}
OLIVEIRA, A.L.S. Analysis the reaching of infants pre-term low and very low birth weight. 2015. Dissertation (MSc) - University of Brasília, Brasilia, DF
\end{abstract}

Reaching is an important skill to be studied because it is one of the initial voluntary motor skills and it is through him that infants develop more complex skills. Some intrinsic restrictions, such as prematurity and low birth weight influence the overall motor behavior. However, there are no studies about the influence of preterm with low birth weight in reaching. Thus, the aim of this study was to analyze the influence of birth weight and prematurity in the reaching of infants at 6 months of corrected age. In order to reflect this objective were performed a cross-sectional study with a sample of 57 infants divided in 3 groups: a) 21 preterm infants with low weight at birth $(<2500 \mathrm{~g})(\mathrm{LWB})$; b) 15 preterm infants with very low weight $(<1500 \mathrm{~g})$ (VLWB); c) 21 full-term infants birth with appropriate weight (> 2500g) (AWB), to form the control group; these same infants were redistributed according to gestational age, forming three groups: a) 25 Late Preterm (32-36 weeks) (LP); b) 11 Very Premature (28 and 32 weeks) (VP); c) Full-term 21 infants (> 37 weeks) (FT). The reaching was analyzed cinematically through Qualysis System (QTM - Qualisys Track Manager). The variables analyzed were righteousness index, set index, initial speed, average and peak, motion units. Furthermore, it was also evaluated gross motor behavior of infants using Alberta Infant Motor Scale (AIMS). The data analysis was performed using non-parametric tests. To detect differences between groups stratified by birth weight and then by gestational age, we used the Kruskal-Wallys test, when differences were observed was used the Mann-Whitney test to identify in two groups in which this occurred, adopting for the latter $\mathrm{p}<0.017$ and for the remaining 5\% significance. Finally we calculated the Relative Risk of motor delay groups. Comparing the groups stratified by birth weight, it was observed that between the AWB and LWB, GPA had a higher Righteousness Index ( $\mathrm{p}<0.000)$ and lower Movement Units $(\mathrm{p}<0.001)$ and Adjustment Ratio ( $\mathrm{p}=0.001)$; between the AWB and VLWB groups, Righteousness Index was higher in AWB $(\mathrm{p}<0.000)$ and the Initial Speed $(p=0.001)$ and Peak $(p=0.005)$ the VLWB showed higher values; groups and between LWB and the VLWB, VLWB showed higher Average speeds (p 
$=0.006)$ and Peak $(p=0.009)$ and the lower values on the AIMS scale $(p=0.009)$. As for risk analysis relating it noted that the VLWB and presented positive risk relative to motor delay. Stratification as gestational age, the comparison between FT and LP groups the variable Righteousness Index $(\mathrm{p}=0.001)$ was higher in FT group; already the Movement Unit ( $\mathrm{p}<0.000)$ and Adjustment Index ( $=0.001)$ were higher in the LP; between the FT and the VP groups Righteousness Index ( $\mathrm{p}<0.000)$ was higher in FT as its Initial Speed $(\mathrm{p}=0.017)$ was lower; among premature infants: Adjustment index $(\mathrm{p}<0.000)$ was higher in LP. The risk analysis, it can be seen that the VP group showed positive relative risk for motor delays. It can be concluded from the present results that infants Low Birth Weight and Preterm Late have the similar reaching motion possibly resulting muscle mass and sensory deficits. The Very Low Birth Weight infants showed a faster reaching motion, rather fluently and without adjustments during the course, the important fact consequent deficits in low muscle mass, cerebellar underdevelopment and shoulder increased muscle tone. Similar incident occurred with the group Very Premature, which also showed initial high speed and little flowing movement, which can be caused by intrinsic restrictions of low lean mass and cerebellum action deficits. As for the engine behavior, groups of Very Low Birth Weight and Preterm infants Moderates had a relatively high risk for motor delays determined by the intrinsic limitations of these infants and the neonatal interventions suffered, use of supplemental oxygen and mechanical ventilation.

\section{Keywords: Reaching, Birth Weight, Prematurity, Motor Skills}




\section{SUMÁRIO}

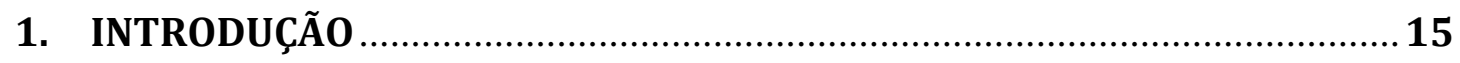

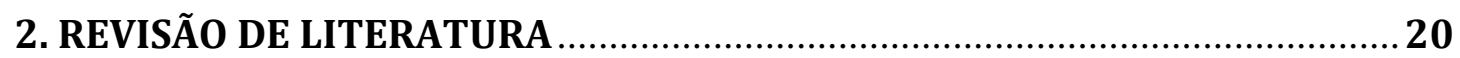

2.1 Abordagens Teóricas ………………………………………………………...20

2.1.1 Teoria Neuromaturacional ...............................................................................22

2.1.2 Perspectiva de Bernstein ......................................................................................2

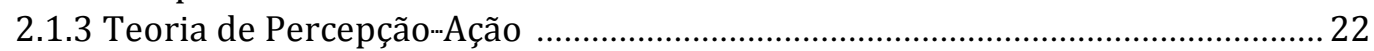

2.1.4 Abordagem dos Sistemas Dinâmicos .............................................................. 22

2.2 A influencia das restrições intrínsecas no desenvolvimento motor infantil 25

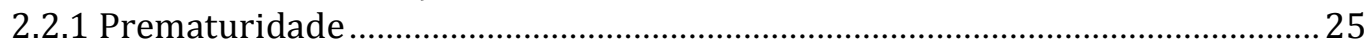

2.2.2 Peso ao nascimento...................................................................................... 26

2.3 Diferenças do desenvolvimento motor nas populações com restrições

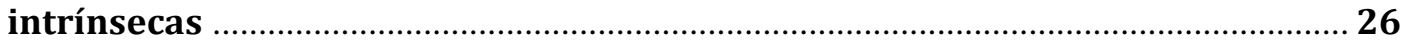

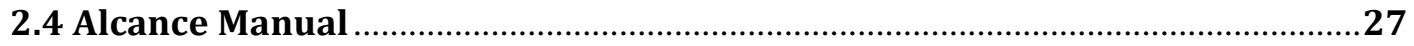

2.3.1 Alcance Manual em populações com restrições intrínsecas............................ 28

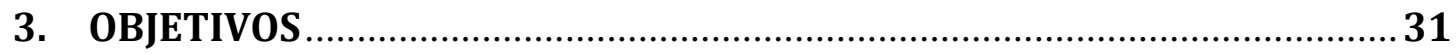

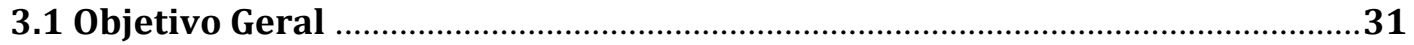

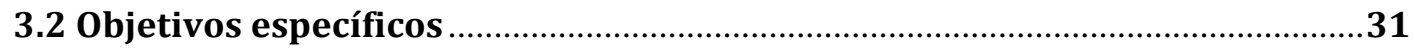

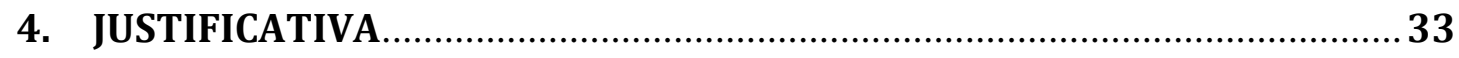

5. MÉTODO

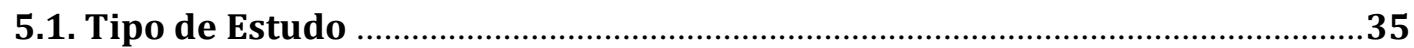

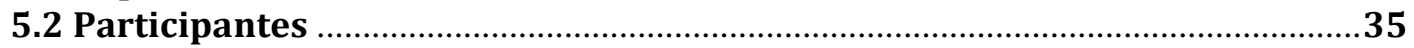

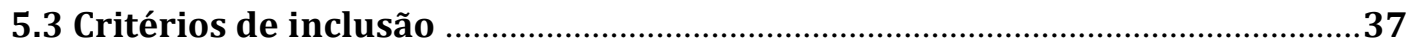

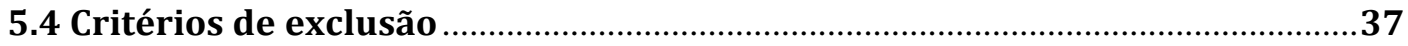

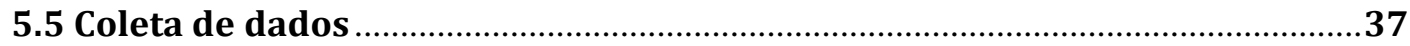

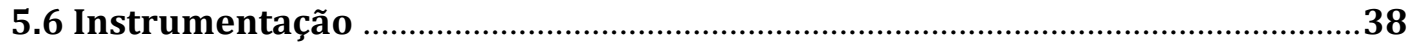

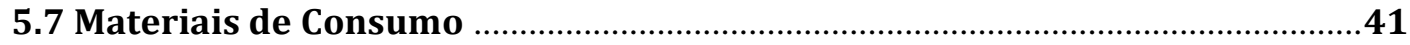

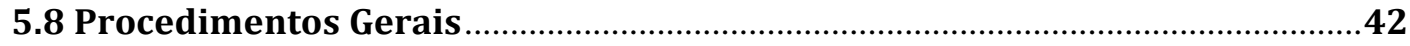

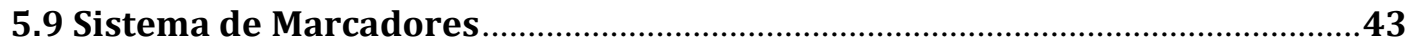

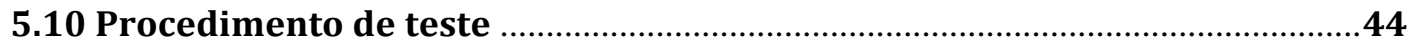

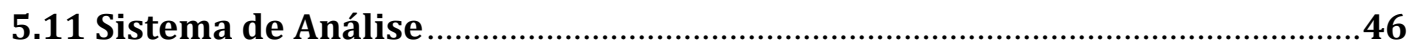

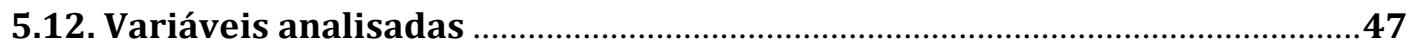

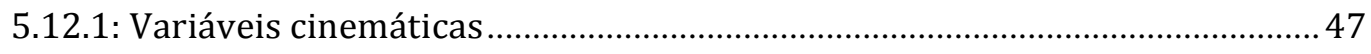

5.12.2. Variáveis do comportamento motor ........................................................... 47

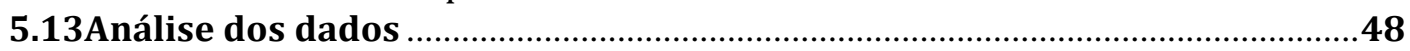

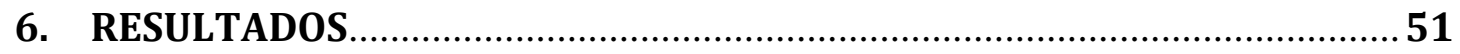

6.1. Comparação entre os grupos divididos por peso ao nascer...........................52

6.1.1. Comparações entre os Grupos................................................................... 52

6.2. Comparação entre os grupos divididos por idade gestacional ......................58

6.2.1 Comparações entre os Grupos ditribuidos pela idade gestacional..................59

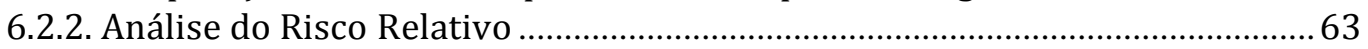

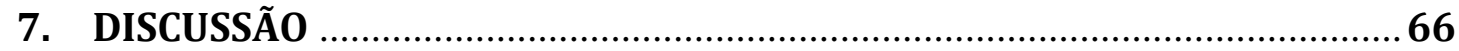

8. CONCLUSÃO

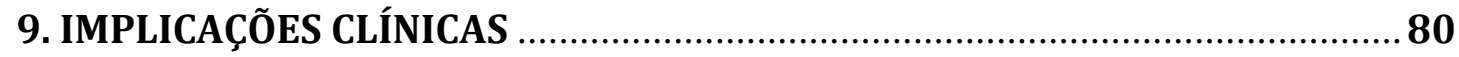

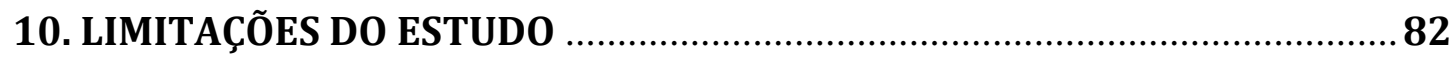

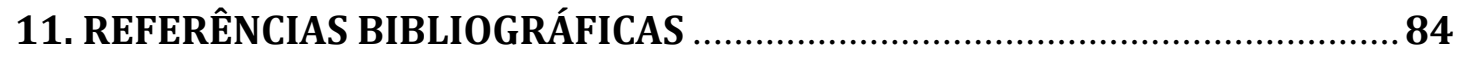


INTRODUÇÃO 


\section{INTRODUÇÃO}

O desenvolvimento infantil é tema que desperta interesse de estudiosos de diferentes áreas do conhecimento, a fim de entendermos cada vez mais como ocorre o processo de estruturação e amadurecimento nos diferentes sistemas do organismo. O estudo do desenvolvimento motor é importante tanto pela necessidade de se conhecer como e quando ocorrem os marcos motores dos lactentes, como controle cervical, o alcance, o engatinhar, a marcha, quanto para entender como tais habilidades são influenciadas pelas restrições intrínsecas e extrínsecas a criança. Entende-se por restrições intrínsecas aquelas relacionadas às características do próprio indivíduo, como tamanho da mão, nível de controle postural e exposição a condições de riscos à saúde, como prematuridade, lesão encefálica e síndromes genéticas. E extrínsecas são aquelas impostas pelo ambiente e pela tarefa à ação motora, como por exemplo a gravidade e as propriedades físicas de um objeto oferecido ao lactente (CAMPOS; ROCHA; SAVELSBERGH, 2009; CAMPOS et. al., 2011; FRÔNIO et. al., 2011; GUIMARÃES, 2013).

O alcance manual, considerado um dos marcos motores do desenvolvimento, é umas das primeiras habilidades motoras adquiridas na infância e fundamental para a funcionalidade humana (FALLANG et. al., 2003; CARVALHO; TUDELLA, 2004; TOLEDO; TUDELLA, 2008; ARIAS et. al., 2010; TOLEDO; SOARES; TUDELLA, 2012). A partir da aquisição do alcance, os lactentes podem desenvolver outras habilidades mais complexas e fundamentais, como uso de ferramentas e alimentação (CARVALHO; TUDELLA, 2004;CORBETTA, 1998).

A maioria dos estudos que investiga a habilidade do alcance utilizam a avaliação cinemática para caracterizar seu desenvolvimento, fornecendo dados relacionados por exemplo a velocidade média, índice de retidão (trajetória da mão até o toque no objeto), unidades de movimentos (fluência do movimento da mão), entre outros (FALLANG et. al., 2003; CARVALHO; TUDELLA, 2004; GRAAF-PETERS et. al., 2007; TOLEDO; TUDELLA, 2008; TOLEDO; SOARES; TUDELLA, 2012). Populações como lactentes a termo, ou seja, aqueles nascidos de 37 semanas a 42 semanas completas (OMS, 2013) apresentam as características do desenvolvimento do alcance manual documentadas na literatura. Nestes lactentes, sabe-se que a 
aquisição do alcance se inicia por volta dos 3-4 meses de idade. A princípio apresenta trajetória da mão não retilínia, tortuosa, com várias acelerações e desacelerações durante o movimento e com velocidades ainda não bem definidas, além de ser executado com menor precisão (THELEN; CORBETTA ESPENCER, 1996; GRECO; SOARES E TUDELLA, 2013). Aos 4-5 meses de idade eles são capazes de ajustar as mãos conforme as propriedades físicas do objeto de interesse, como por exemplo pelo seu tamanho e rigidez. E aos 6 meses sabe-se que iniciam os alcances unimanuais e apresentam uma melhora da qualidade cinemática do movimento, provavelmente por apresentarem um melhor recrutamento e controle da musculatura de tronco e membro superior (GRAAF-PETERS et. al, 2007; ARIAS et. al., 2010; SILVA et. al., 2011; TOLEDO; SOARES;TUDELLA,2011).

Poucos estudos com populaçoes apresentando restrições intrinsecas, como, os lactentes nascidos prematuros, com menos de 37 semanas de gestação, e com baixo risco peri e neonatal para lesões neurológicas demonstraram que o desenvolvimento do alcance comporta-se diferente nestes lactentes quando comparado a lactentes a termos. Esta habilidade ocorre de forma menos retilínea, com mais acelerações e desacelerações e com menor sucesso na preensao dos objetos (TOLEDO; TUDELLA, 2008). Além disso, estes lactentes apresentaram pior regulação de força muscular dos membros superiores durante as atividades manuais (PLANTINGA; PERDOCK; E DE GROOT, 1997).

Além dos prematuros de baixo risco, outras populações tem sido estudadas, com o intuito de analisar a influência dos fatores intrínsecos no alcance manual, como lactentes com Paralisia Cerebral (HADDERS-ALGRA et al., 1999; CORBETTA et al., 2006), Síndrome de Down (CADORET; BEUTER, 1994) e agenesia do corpo caloso (SACCO et al., 2006). Estes estudos demonstram que as restrições intrínsecas são determinantes para o desenvolvimento desta habilidade, pois estes lactentes apresentaram pior desempenho do alcance quando comparados aos lactentes a termos, apresentando atraso no início dessa habilidade, movimentos mais lentos e tortuosos, menor sucesso de apreensão e em tarefas de coordenação bimanual (CAMPOS; ROCHA; SAVELSBERGH; 2009).

Outra restrição intrínseca que parece influenciar o desenvolvimento motor, apesar de não ter sido analisada sua influencia no alcance manual, é o baixo peso ao nascer. 
Nos últimos anos tem aumentado a incidência de lactentes prematuros com baixo peso ao nascer como consequência da melhora técnica dos cuidados intensivos pósnatais dos últimos 30 anos (CAMPBELL; KOLOBE; LINACR, 2002; GOLDENBERG; CULHANE, 2007). O nascimento com peso inferior a 2.500 gramas leva ao aumento da prevalência de morbidades neonatais como a morte neonatal e pós-natal, morbidades de curto prazo como síndrome do desconforto respiratório e enterocolite necrosante, e morbidades de longo prazo, tais como cegueira, surdez, hidrocefalia, retardo mental e paralisia cerebral (GOLDENBERG; CULHANE, 2007).

Mesmo que esses lactentes nascidos em condições desfavoráveis de peso e idade gestacional possam não sofrer desfechos irreversíveis como os citados anteriormente, sabe-se que apresentam altos riscos de déficits e de atrasos nos diferentes aspectos do desenvolvimento, sendo eles cognitivos, comportamentais, sensoriais e/ou motores (CAÇOLA; BOBBIO, 2010). Especificamente em relação ao desenvolvimento motor, estes lactentes apresentam alterações, como aquisições motoras mais atrasadas, que por sua vez, são dependentes de quão baixo foi o peso da criança ao nascer (CAÇOLA; BOBBIO, 2010). Alguns estudos utilizaram a Alberta Infant Motor Scale (AIMS) para avaliar o desenvolvimento motor grosso e observaram que os lactentes nascidos a termo obtiveram pontuações mais altas quando comparados aos prematuros com baixo peso e com muito baixo peso sugerindo que estes apresentam desenvolvimento motor atrasado (SANTOS et. al., 2004; CHARITOU; ASONITOU; KOUTSOUKI, 2010; WANG et. al., 2013). Além disso, demonstrou-se também que déficits e alterações nas habilidade motoras iniciais destes lactentes nascidos com baixo peso geram repercussões em idades mais avançadas como na idade pré-escolar e na adolescência (EVENSEN et. al., 2003; SANTOS et. al., 2004 KIEVIET et. al., 2009 CHARITOU; ASONITOU; KOUTSOUKI, 2010). Dentre as habilidades com pior desempenho nessas populações estão as que envolvem destreza manual e atividades visuo-motoras (KIEVIET et. al., 2009; CAÇOLA E BOBBIO, 2010; WANG et. al., 2014).

Apesar destes inquestionáveis riscos de atraso no desenvolvimento motor, cognitivo e sensorial, não foram encontrados na literatura estudos que verificaram como o baixo peso e o muito baixo peso ao nascer influenciam o alcance manual dos 
lactentes.Como o alcance é uma habilidade adquirida precocemente no desenvolvimento motor, se obtivermos o conhecimento sobre possíveis atrasos ou desvios do seu desenvolvimento nesses lactentes atípicos será possível identificá-los e viabilizar o processo de intervenção precoce, agindo terapeuticamente de forma preventiva e/ou de estimulação imediata, além de traçar estratégias mais eficazes de tratamento para essa população. 
REVISÃO DE LITERATURA 


\section{REVISÃO DE LITERATURA}

\subsection{Abordagens Teóricas}

A história do desenvolvimento motor teve início a partir do interesse dos estudiosos pelas mudanças observadas no comportamento motor das crianças, visto que as alterações que ocorrem, principalmente no primeiro ano de vida, são dramaticamente visíveis.

A partir de então, houve a preocupação em descrever o movimento e em entender quais os processos que propiciam a emergência desse movimento e dos comportamentos observados.

$\mathrm{Na}$ tentativa de se estabelecer fundamentação teórica para as mudanças que estavam sendo observadas, o desenvolvimento motor recebeu abordagens distintas de interpretação a essas mudanças. As principais abordagens teoricas serão apresentadas a seguir.

\subsubsection{Teoria Neuromaturacional}

Nas décadas de 20 a 40 surgiram os primeiros estudos sobre o desenvolvimento motor, os primeiros pesquisadores, como Gesell (1938) e McGraw(1943), descreveram que padrões e sequências de movimentos surgiam por uma progressão e maturação do sistema nervoso central e que estas eram a causa exclusiva do ganho de controle dos movimentos ao longo da vida. Ou seja, de acordo com as propriedades intrínsecas do individuo sem interferência ambiental (LOCKMAN E THELEN, 1993; THELEN, 1995; HADDERS-ALGRA, 2000).

Segundo esta teoria, o controle motor reflete diretamente as mudanças no cérebro, onde de maneira hierárquica vertical, há um progressivo aumento do controle cortical sobre os reflexos dos níveis mais baixos (THELEN, 1995). Sendo assim, o centro superior planeja, controla e delega o programa motor para os centros inferiores, em que estes são exclusivamente subordinados a executarem. O comando dos níveis inferiores são estereotipados e incapazes de se modificarem (NEWTON, 1994).

Baseando-se nas evoluções neuromaturacionais, segundo os estudiosos, o comportamento motor dos bebês são incialmente "reflexos", determinados pela imaturidade do córtex cerebral, que evoluem juntamente com o sistema nervoso central para movimentos voluntários e intencionais (MACGRAW, 1945). 
No entanto, estudos posteriores demonstraram que os bebês ainda pequenos são capazes de discriminar e modificar ações segundo estímulos ambientais, o que tornou a explicação das mudanças comportamentais exclusivamente dependentes da maturação neural controverso. Esta teoria perdurou por 30 anos e serviu de base para outras pesquisas e teorias (ROCHAY E SENDERS, 1991).

\subsubsection{Perspectiva de Bernstein}

Berntein (1967) foi um fisiologista russo que realizou um trabalho pioneiro sobre o movimento humano, pois foi o primeiro a definir a coordenação do movimento e a interação de diversas partes do corpo para a produção de um movimento unificado. Sua questão priordial era: entender como um organismo que possui milhares de músculos, bilhões de nervos e diversas combinações possíveis de segmentos corporais que sofrem influências da posição corporal e das forças externas poderia desenvolver e coordenar seus movimentos exclusivamente pela maturação do sistema nervoso central (THELEN, 1995). Esta perspectiva percebeu que para compreender o controle do movimento deve-se considerar as características de um sistema como um todo, suas forças externas e internas, ou seja, passou-se a considerar a ação dos músculos, do sistema esquelético e articular, a força da gravidade, a inercia (BERNSTEIN, 1967).

Para explicar o controle e a coordenação dos movimentos, Bernstein identificou dois principais problemas: os graus de liberdade e a variabilidade condicionada ao contexto. Entende-se como graus de liberdade os grande número de variáveis que devem ser controladas para realizar um movimento, como por exemplo músculos, ossos e articulações (BERNSTEIN, 1967). A variabilidade condicionada ao contexto refere-se às circunstâncias em que o movimento ocorre, ou seja, o movimento acontece em um ambiente que está mudando constantemente e gera influencia nesse controle, como as forças externas, por exemplo a gravidade e a inercia (TURVEY et. al., 1982). Um exemplo das restrições impostas pelo ambiente sobre os graus de liberdade é a locomoção humana. Esta sofre modificações, por exemplo, dependendo da superfície em que se deseja andar, ou das propriedades externas do ambiente, como a gravidade, uma vez que nana lua os astronautas tiveram que saltar devido a ausência da gravidade (THELEN, 1995). 
A consequência dessas novas teorias foi chamar a atenção sobre a multicausalidade do movimento, incluindo os aspectos físicos e fisiológicos (THELEN, 2995). Porém, observou-se que um mesmo impulso pode produzir movimentos diferentes e isto levou a questionar ambas teorias (neuromaturacional e Perspectiva de Bernstein) por não considerarem o feedback necessário para que um sistema produza um movimento apropriado para o contexto do momento.

\subsubsection{Teoria de Percepção-Ação}

O tema central desta teoria é a explicação para a percepção e ação na geração e aprimoramento de novas habilidades. Teve inspiração nas teorias de EJ Gibson e JJ Gibson, os quais demontraram que desde o início as crianças são continuamente instigadas a coordenar seus movimentos conforme as novas informações de percepção simultânia e assim modificar seu controle motor para a execução das habilidades. Para investigar e entender esta linha é necessário compreender o que Gibson denominou como affordance, ou seja, a relação recíproca ou "ajuste" entre o indivíduo e o ambiente que é necessário realizar para a adequada execução do movimento. Como exemplo podemos citar as diferentes superfícies para caminhar (instáveis ou rígidas) ou quando um objeto esta dentro do campo de alcance (GIBSON, 1982; THELEN, 1995).

O que se evidencia é que, desde o início, há uma percepção multimodal contínua sobre o mundo. Em todo instante a criança percebe durante seus movimentos as sesações de visão, audição, paladar, olfato e sentimento, além de obterem informações também de seus receptores musculares, articulares e da pele que detectam a posição do corpo, força e as mudanças no organismo ativo. Portanto, compreende-se que o sistema nervoso é capaz de integrar todo esse fluxo de informação e modificar as ações motoras (THELEN, 1995).

Considerando tais aspectos e na tentativa de explicar a fundo essa integração e aprimorar outras explicações sobre o desenvolvimento infantil, surgiu a Abordagem do Sistemas Dinâmicos, que será apresentada a seguir.

\subsubsection{Abordagem dos Sistemas Dinâmicos}

A Abordagem dos Sistemas Dinâmicos surgiu na década de 60 a fim de compreender como ocorrem as mudanças do comportamento moto ao longo do 
tempo. Baseia-se no fato que o movimento é mais que músculos e motoneurônios agindo, todos os elementos do corpo participam para um melhor resultado motor, como por exemplo os elementos sensoriais, respiração, função cardíaca, questões anatômicas (THELEN E FISCHER, 1982; KAMM et. al., 1990; THELEN, 1995). Esta teoria tem embasado atualmente os estudos sobre a aquisição e o refinamento das habilidades motoras.

Esta abordagem se baseia em diversos conceitos físicos, matemáticos e biológicos que são aplicados ao desenvolvimento motor (ROCHA E TUDELLA, 2003). E para tanto engloba alguns principios que serão conceituados a seguir.

\subsubsection{Princípio das restrições}

O comportamento motor é emergente a partir da interação de diferentes elementos: o organismo, o ambiente e a tarefa. De acordo com Newell (1986), as restrições são, os fatores que influenciam ou delineiam a realização de determinado comportamento motor. As restrições podem ser classificadas em intrinsecas, como aquelas relacionadas as influências do organismo, e extrinsecas, como aquelas relacionadas as influências do ambiente e da tarefa. É importante destacar que apesar de serem denominadas de "restrições", estas não referem-se apenas a fatores que limitam a execuçao de um movimento. As restrições, de uma forma geral, influenciam o comportamento motor, seja de forma positiva ou negativa, favorecendo ou limitando o mesmo.

Compreende-se como restrições do organismo, àquelas limitações impostas pelas características neurológicas e físicas da criança (NEWELL, 1986). Como por exemplo, o tamanho da mão, peso ao nascimento, lesões neurológicas, a maturidade neurologica.

As restrições ambientais, são as que estão presentes fora do organismo em que os movimentos estão sendo realizados (NEWELL, 1986), como por exemplo a açao da gravidade, o posicionamento do corpo, a temperatura. Estas restrições envolvem, inclusive os aspectos econômicos e socioculturais, como os costumes da sociedade que a criança está inserida (ROCHA E TUDELLA, 2003).

As restrições da tarefa, por sua vez, são as relacionadas a tarefa específica, ao que precisa ser motoramente executado para que o objetivo da tarefa seja alcançado (NEWELL, 1986). Por exemplo, características de um objeto que se deseja alcançar e apreender. 


\subsubsection{Princípio da exploração-seleção}

O principio da exploraçao-seleçao refere-se ao o processo de repetidos ciclos de percepção e ação em relação a uma tarefa estabelecida, ou seja, baseia-se na idéia que o ser humano esta sempre percebendo e participando do movimento através de informações sensoriais e assim a criança busca receber informações periféricas e modificam sua ação de acordo com a percepção que recebeu (THELEN, 1995).

Toda nova habilidade esta associada à maturação do sistema nervoso central e a um contínuo processamento de informações aferentes sensoriais de exploração, que geram gradualmente uma seleção de padrão de movimento mais eficientes e refinados (HADDERS-ALGRA, 2000).

Dessa maneira, infere-se que cada novo marco motor abre novas oportunidades de descobertas perceptuais e sensoriais, gerando novas seleções de movimento (ROCHA E TUDELLA, 2003). Assim, o refinamento do movimento ocorre pela repetição da tarefa em relação ao objetivo, por meio de ciclos de exploração seleção.

\subsubsection{Princípio da Auto-Organização}

O principio da auto-organizaçao afirma que o movimento ou desenvolvimento não se assume em programas pré-estabelecidos. O organismo evolui para um estado mais organizado por meio da reunião entre os diversos subsistemas (como muscular, esquelético, nervoso, circulatório, entre outros) que agem em cooperação para que novos comportamentos sejam iniciados (KAMM et. al., 1990). Portanto, diferente da teoria neuromaturacional, não se baseia somente no fator do tempo como componente de controle motor, e sim que o sistema se molda conforme as restrições impostas ao indivíduo e tarefa (WALTER et. al., 1998).

Ao longo do tempo e desenvolvimento, o organismo humano se mostra um sistema dinâmico em que alguns padrões de comportamento são preferidos em alguns momentos e agem como um "estado atrator" (THELEN, 1995). Como exemplo podemos citar a habilidade de engatinhar que em algumas circuntâncias e fases do desenvolvimento da criança esta habilidade é preferida ao invés da marcha. Nesta visão dinâmica do sistema auto-organizado, o evolução motora é vista como 
transições de fases entre um padrão "atrator" para um outro ainda mais estável e adaptativo (THELEN et. al., 1987; THELEN, 1995)

\subsection{A influencia das restrições intrínsecas no desenvolvimento motor infantil}

Como abordado anteriormente, restrições intrínsecas são, as características relacionadas a um indivíduo, ou seja, ao organismo individual. Algumas restrições intrinsecas, como as condições de nascimento (peso ao nascer ou prematuridade) influenciam diretamente o desenvolvimento infantil e devem ser estudadas mais profundamente a fim de entender como ocorre sua influência em habilidades motoras especificas, no intuito de estimular precocemente tal hablidade. A seguir tais condições serão revisadas assim como sua influencia no comportamento motor geral de lactentes.

\subsubsection{Prematuridade}

A prematuridade é uma restrição intrínseca que tem aumentado a incidência nos últimos anos e que acarreta diversas características específicas ao lactente, além de alterações e desvios do seu desenvolvimento (VanHAASTERT et. al., 2006).

Segundo a Organização Mundial de Saúde (OMS), nascimento prematuro é aquele que ocorre com menos de 37 semanas completas ou 259 dias de gestação (OMS, 2013).

Os lactentes prematuros podem ser classificados como tardios, como aqueles que nascem entre 32 e 36 semanas e 6 dias de gestação, muito prematuros como aqueles que nascem entre 28 e 31 semanas e 6 dias e prematuro extremo os que nascem como menos de 28 semanas (OMS, 2013).

Estudos tem demonstrado que os lactentes prematuros apresentam diferenças na aquisição de diversas habilidades motoras que possuem características peculiares a suas condições de nascimento e ao tempo de permanencia intra-útero. Tais diferenças serão apresentadas posteriormente nesta revisão. 


\subsubsection{Peso ao nascimento}

Nos últimos anos, outra restrição intrínseca que tem aumentado a incidência são os lactentes nascidos com baixo peso. Tal fato deve-se a consequente melhora técnica dos cuidados intensivos pós-natais dos últimos 30 anos (CAMPBELL; KOLOBE; LINACR, 2002; GOLDENBERG; CULHANE, 2007).

Segundo a OMS, o peso ao nascer é a primeira medida de peso do feto ou recém-nascido obtida após o nascimento. É classificado como baixo peso aqueles nascidos entre 1500 e 2500 gramas, muito baixo peso se tiveram ao nascimento peso entre 1000 e 1500 gramas e extremo baixo peso os que nasceram com menos de 1000 gramas (GOLDENBERG; CULHANE, 2007; BARON; REY-CASSERLY, 2010; OMS, 2015).

Tem sido observadas as repercurssões do nascimento com peso inferior a 2500 gramas no desenvolvimento motor de lactentes, os quais, apresentam nitidas diferenças quando comparado ao lactente típico. Essas diferenças serão apresentas em seguida.

\subsection{Diferenças do desenvolvimento motor nas populações com restrições intrínsecas}

Estudos demonstraram que a prematuridade e o nascimento com menos de 2500 gramas acarretam desvios e atrasos no desenvolvimento motor infantil (GABRIEL et. al., 2009; KIEVIET et. al., 2009; CAÇOLA; BOBBIO, 2010; ZWICKER et. al., 2013). E ainda, a literatura tem demonstrado que o atraso no desenvolvimento motor esta relacionado ao quão prematuro e baixo peso foi $\mathrm{o}$ lactente, ou seja, quanto mais prematuro e mais baixo peso ao nascer piores são os desempenhos motores e maiores são os atrasos (KIEVIET et. al., 2009; WATKINS et. al., 2014)

Estudos que avaliaram o desenvolvimento motor grosso por meio da escala Alberta Infant Motor Scale (AIMS) observaram que os lactentes nascidos a termo obtiveram pontuações mais altas quando comparados aos prematuros com baixo peso e com muito baixo peso, sugerindo que estes apresentam desenvolvimento motor atrasado (SANTOS et. al., 2004; CHARITOU; ASONITOU; KOUTSOUKI, 2010; WANG et. al.,2013). Já foi demonstrado também que déficits e alterações em 
habilidade motoras iniciais destes lactentes nascidos com baixo peso podem ter repercussões até em idades mais avançadas como na idade pré-escolar e na adolescência (EVENSEN et. al., 2003; (SANTOS et. al., 2004 KIEVIET et. al., 2009 CHARITOU; ASONITOU; KOUTSOUKI, 2010). Dentre as habilidades com pior desempenho nessas populações de prematuros nascidos com baixo peso estão as que envolvem destreza manual e atividades visuo-motoras, estas últimas estão relacionadas aos déficits sensoriais de propriocepção e visão também encontrados nesses lactentes (KIEVIET et. al., 2009; CAÇOLA E BOBBIO, 2010; WANG et. al., 2014).

\subsection{Alcance Manual}

O alcance manual é uma importante habilidade motora que surge nas primeiras etapas do desenvolvimento motor voluntário infantil (FALLANG et. al., 2003; CARVALHO; TUDELLA, 2004; TOLEDO; TUDELLA, 2008; ARIAS et. al., 2010; TOLEDO; SOARES; TUDELLA, 2012). Sua importância se dá por ser um movimento base para diversas funções do ser humano, como alimentação, uso de ferramentas, escrita e tantas outras atividades do cotidiano (CARVALHO; TUDELLA, 2004;CORBETTA, 1998).

Os estudos que se propõem a estudar o alcance manual utilizam, na sua maioria, a análise cinemática. Esta analise permite verificar por meio de variaveis como velocidade média, índice de retidão e unidades de movimento a velocidade, retidão e fluencia do movimento dos membros superiores durante o movimento destes em direçao ao alvo. Apesar da inquestionável importância do alcance manual, o estudo desta habilidade ainda necessita ser melhor explorado com o intuito de verificar como ocorre o desenvolvimento do alcance, principalmente em populações atípicas.

Em lactentes típicos, a termo, estudos foram realizados com o intuito de investigar como ocorre o surgimento e o desenvolvimento do alcance manual. Sabe-se que o surgimento do alcance nesta população ocorre em quatro etapas: a primeira o lactente percebe a mão e a olha com interesse, mas não é capaz de mantê-la em seu campo visual por ainda não apresentarem força e controle motor adequado; a segunda é o momento em que o lactente olha a mão havendo um aumento na atividade muscular dos dedos e alterações de deslocamento do membro superior para que a mão 
permaneça mais tempo no campo visual; na terceira fase já consegue realizar alcance desde que a mão e o objeto sejam vistos simultaneamente em seu campo visual; e na quarta e última etapa caracteriza-se pela integração entre os movimentos das mãos e informações visuais e os primeiros alcances sem que o lactente esteja visualizando a mão, por volta dos 4 meses de idade (CARVALHO E TUDELLA, 2004; ARIAS ET. AL., 2010; ARAÚJO ET. AL., 2011).

Nos lactentes a termos os primeiros movimentos de alcance ocorrem de forma tortuosa, com várias unidades de movimento, ou seja, apresentando diversos picos de aceleraçao e desaceleraçao da mão; baixo índice de retidão, demontrando uma trajetoria pouco direta ao alvo; e com um perfil de velocidade nao definido (THELEN; CORBETTA ESPENCER, 1996; GRECO; SOARES E TUDELLA, 2013). A partir dos 4-5 meses de idade, esses lactentes ajustam a abertura da mão conforme as diferentes propriedades do objeto, utilizando informações visuais, táteis e proprioceptivas para realizarem o alcance de acordo com o tamanho e rigidez do objeto. Aos 6 meses, se inicia o alcance unimanual, quando o lactente adquire o sentar e há um maior recrutamento da musculatura de cabeça e ombro, o que também se relaciona a uma maior qualidade cinemática do movimento (GRAAF-PETERS et. al, 2007; ARIAS et. al., 2010; SILVA et. al., 2011; TOLEDO; SOARES;TUDELLA,2011).

\subsubsection{Alcance Manual em populações com restrições intrínsecas}

Alguns estudos na literatura tem apresentado a influência de fatores intrínsecos no desenvolvimento do alcance manual. Sabe-se que lactentes nascidos prematuros e considerados de baixo risco peri e neonatal para alterações neurológicas, desenvolvem o alcance e interagem com os objetos diferentemente dos a termos (TOLEDO; TUDELLA, 2008; GUIMARÃES et. al., 2013). O alcance destes lactentes ocorre com menor número de sucessos nas primeiras tentativas, trajetória menos retilínea e com mais correções, movimentos com menor velocidade e com maior número de unidades de movimento (TOLEDO; TUDELLA, 2008; GUIMARÃES et. al., 2013), além de fraco desempenho na regulação da força muscular dos membros superiores durante a função da mão (PLANTINGA; PERDOCK; E DE GROOT, 1997). Provavelmente, todas estas diferenças estão relacionadas aos déficits de informações sensoriais, coordenação global e viso-motora 
$\begin{array}{llll}\text { apresentadas } & \text { pelos lactentes } & \text { prematuros }\end{array}$ 2000;HEATHCOCK;LOBO;GALLOWAY, 2008;TOLEDO; TUDELLA, 2008) ou ainda a baixa ativação muscular postural e aumento na extensão de tronco, consideradas como distonias transitórias nestes lactentes (FALLANG et. al., 2003). Fallang et al (2003) afirmam ainda que estas modificações são necessárias devido a falta de planejamento e coordenação do movimento de alcance, demonstrando uma incapacidade de modular a atividade motora eferente por parte dos prematuros (FALLANG et. al., 2003). De acordo com Toledo e Tudella (2008), devido as alteraçoes apresentadas pelos lactentes prematuros, estes necessitaram modificar seus parâmetros cinemáticos de velocidade do braço para terem mais tempo para processar e utilizar a informação visual e, por fim, tocar o objeto e apreende-lo com sucesso.

O desenvolvimento do alcance de outras populações com restrições intrinsecas tambem são encontradas na literatura. Estas envolvem lactentes com Paralisia Cerebral (HADDERS-ALGRA et. al., 1999; CORBETTA et al., 2006), Síndrome de Down (CADORET; BEUTER, 1994), agenesia do corpo caloso (SACCO et al., 2006) e exposição in útero a cocaína (LAGASSE et al., 1998; SCHUETZE et al., 2003; TRONICK et al., 2004). Os resultados destes estudos sugerem que as condições intrínsecas influenciam o desempenho no alcance manual de forma heterogênea, apresentando de forma geral variabilidade na idade de aquisição dessa habilidade. Além disso, a severidade e a condição de risco que o lactente se encontra são determinantes para o desenvolvimento da habilidade. Com exceção dos lactentes expostos a cocaína no período intra-útero que não apresentaram diferenças no movimento de alcance em relação aos lactentes a termos, todos os demais grupos de risco apresentaram desempenho inferior aos lactentes a termos nesta aquisição motora, como atraso no início dessa habilidade, movimentos mais lentos e tortuosos, menor sucesso de apreensão e em tarefas de coordenação bimanual (CAMPOS; ROCHA; SAVELSBERGH; 2009).

Com base nos estudos apresentados, é evidente que a restrição intrínseca influencia de forma negativa o desenvolvimento e aprimoramento do alcance manual. No entanto, ainda existem lacunas na literatura quanto a influencia de fatores de risco, como o peso ao nascer no desenvolvimento desta habilidade. Baseado no fato da influencia do peso ao nascer em habilidades motoras gerais, como citadas anteriormente, acredita-se que o mesmo ocorrerá com o alcance manual. 


\section{OBJETIVOS}




\section{OBJETIVOS}

\subsection{Objetivo Geral:}

Analisar a influência do peso ao nascer (baixo peso e muito baixo peso) e da prematuridade no alcance manual de lactentes aos 6 meses de idade corrigida.

\subsection{Objetivos específicos:}

- Comparar as variáveis cinemáticas (índice de retidão, velocidade média, índice de ajuste, unidade de movimento, velocidade inicial e velocidade de pico) do alcance entre os diferentes grupos distribuidos pelo peso ao nascimento: lactentes nascidos com peso adequado, com Baixo Peso e com Muito Baixo Peso.

- Comparar as varáveis cinemáticas do alcantes entre os diferentes grupos distribuidos pela idade gestacional: lactentes a termos, prematuros tardios e muito prematuros

- Comparar o comportamento motor grosso dos lactentes nascidos com as diferentes faixas de peso e os a termos nascidos com peso adequado por meio dos escores e percentis da AIMS (Alberta Infant Motor Scale).

- Comparar o comportamento motor grosso dos lactentes nascidos nas diferentes faixas de idade gestacional e os a termos, por meio dos escores e percentis da AIMS (Alberta Infant Motor Scale).

- Verificar qual o Risco Relativo dos lactentes nascidos com menos de 2500 gramas e nascidos prematuros em apresentar atraso motor global (segundo a AIMS). 
JUSTIFICATIVA 


\section{JUSTIFICATIVA}

Sabe-se que a incidência de sobrevivência dos prematuros nascidos com peso inferior ao mínimo esperado para um recém-nascido, ou seja 2.500 gramas, vem aumentando como resultado do aperfeiçoamento de técnicas e de cuidados médicos intensivos. Esta sobrevivência, porém, vem acompanhada de restrições intrínsecas aquiridas por essas condições de nascimento que geram diversas alterações no desenvolvimento neuropsicomotor desses lactentes. E, apesar dessa ser uma população de lactentes que vem ocupando cada vez mais os espaços de reabilitação pediátrica, as pesquisas sobre seu desenvolvimento ainda são incipientes.

Sendo o alcance uma importante habilidade motora, devido a sua complexidade biomecânica e por ser considerada como base para o desenvolvimento funcional manual futuro do ser humano, conhecer seu comportamento nos prematuros nascidos com uma restrição intrínseca, como o baixo peso, auxiliará na formação de bases teóricas para estabelecer os padrões típicos do seu desenvolvimento nesta população. E assim, definir precocemente o momento de intervenção ideal e auxiliar na seleção de estratégias terapêuticas, evitando possíveis atrasos funcionais e sensoriais e favorecendo a eficácia da fisioterapia.

Diante do exposto, ressalta-se a necessidade de contribuir para os avanços dos estudos cinesiológicos do alcance e suas características nos lactentes que possuem como restrições intrínsecas a prematuridade e o baixo peso ao nascer, para estabelecer seus padrões e, assim, detectar precocemente atrasos e alterações do desenvolvimento. 


\section{MÉTODO}




\section{MÉTODO}

\subsection{Tipo de Estudo}

Trata-se de um estudo transversal correlacional-causal, na qual foi realizada a coleta de dados em um único momento, buscando determinar relações entre categorias (SAMPIERI; COLLADO; LUCIO, 2013)

\subsection{Participantes}

A amostra foi por conveniência, contatados através do ambulatório de acompanhamento de bebês de risco do Hospital Regional de Ceilândia. Foram formados três grupos de lactentes, sendo dois de lactentes com peso abaixo de 2.500 gramas. Os grupos foram divididos conforme a faixa de peso de seu nascimento: a) Grupo Baixo Peso ao nascer (GBP): composto por 21 lactentes com peso ao nascer entre 1500g a 2500g; b) Grupo Muito Baixo Peso (GMBP): formado por 15 lactentes nascidos com peso entre 1000g a 1500g (GOLDENBERG; CULHANE, 2007; BARON; REY-CASSERLY, 2010; OMS, 2015); e c) Grupo com Peso Adequado (GPA): considerado como o grupo controle, composto de 21 lactentes a termos, com peso ao nascer maior que $2500 \mathrm{~g}$. Totalizando 57 lactentes participantes da pesquisa..

Com o intuito de analisar a influencia da idade gestacional no alcance manual, os mesmos lactentes foram também redistribuídos em grupos considerando sua idade gestacional. As categorias de idade gestacional consideradas no atual trabalho baseouse na Organização mundial de Saúde (2013), a qual classifica lactentes a termo como aqueles nascidos com mais de 37 semanas de gestação, prematuro tardio aquele nascido entre 32 e 36 semanas e 6 dias de gestação e muito prematuro aquele nascido entre 28 e 32 semanas de gestação. Para esta dissertação os lactentes foram divididos em três grupos conforme a idade gestacional: a) Prematuro Tardio (GPT): composto por 25 lactentes; b) Muito Prematuro (GMP): composto por 11 lactentes; e c) Grupo A termo (GAT): composto por 21 lactentes e que foi considerado o grupo controle. A perda amostral está ilustrada no fluxograma abaixo (Figuras 1 e 2), sendo que o grupo Peso Adequado não apresentou perda amostral. 


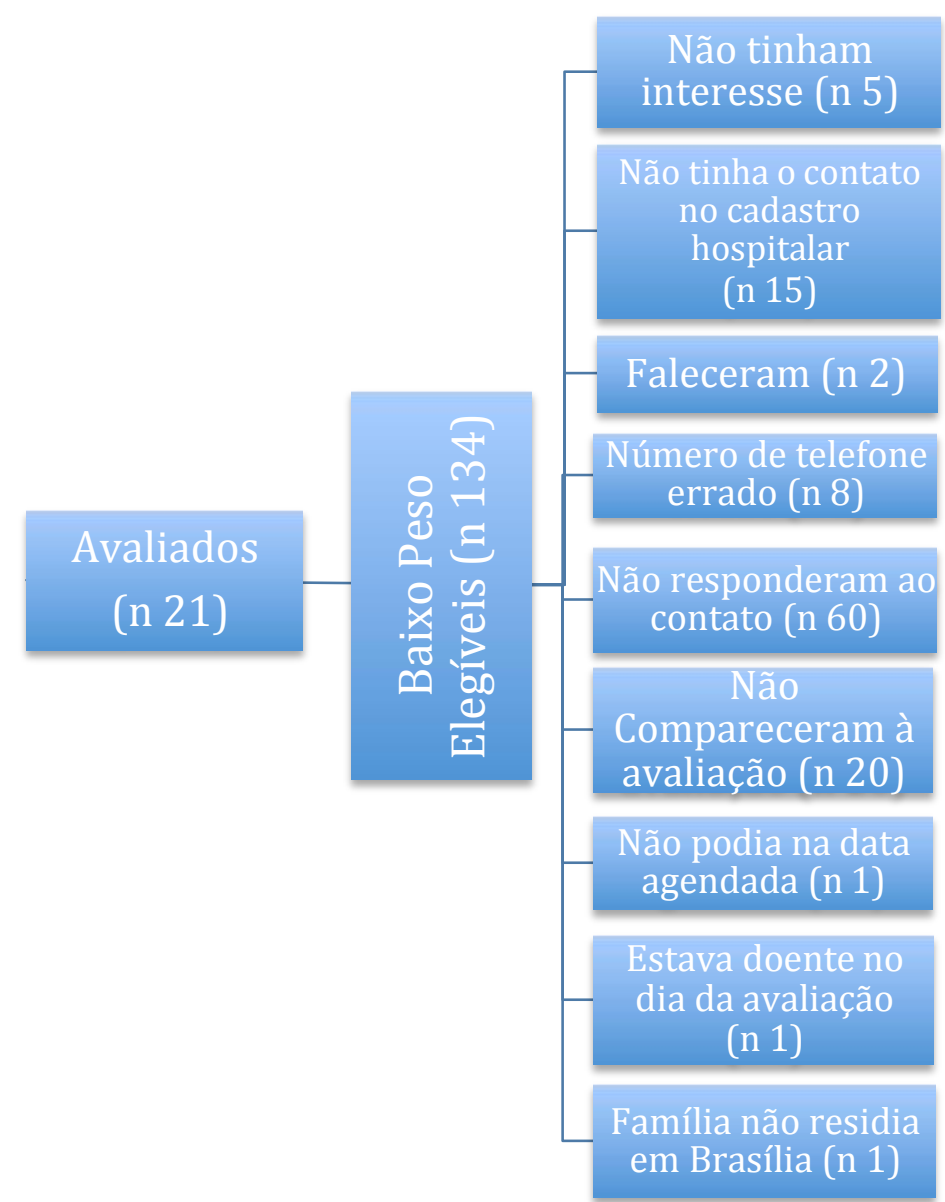

Figura 4. Fluxograma de Perda Amostral do grupo Baixo Peso

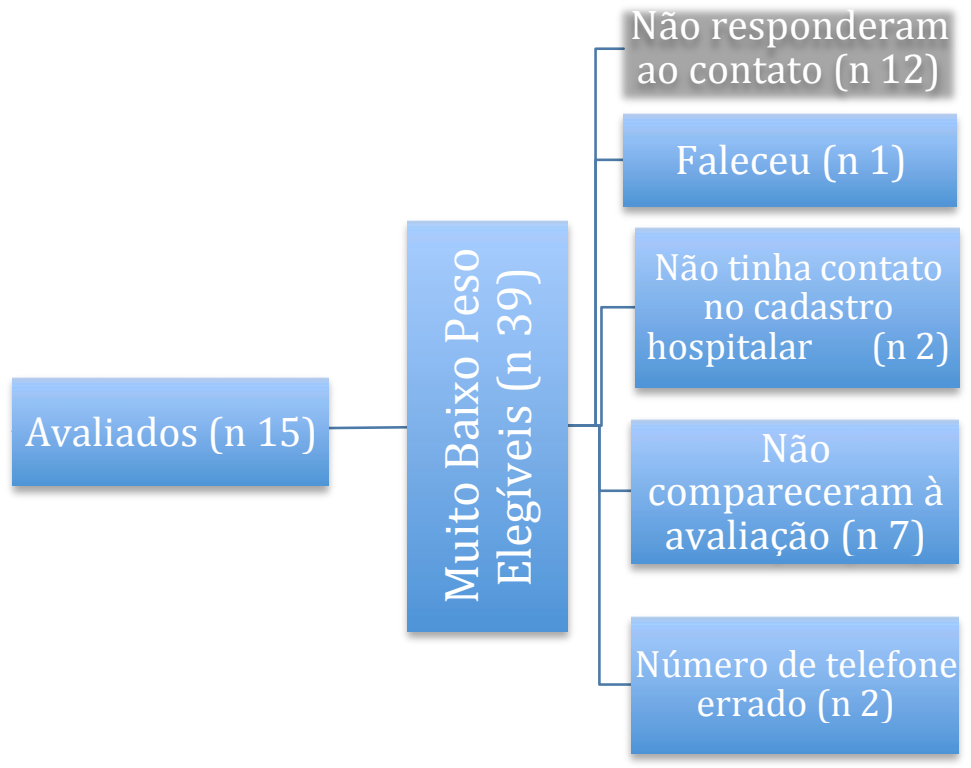

Figura 5. Fluxograma de Perda Amostral do grupo de Muito Baixo Peso 
Os lactentes foram avaliados quando completaram 6 meses de vida com uma tolerância de 7 dias para mais ou para menos, sendo que os prematuros foram avaliados com a idade corrigida. A idade corrigida é calculada subtraindo-se a idade gestacional que o lactente nasceu pelo número de semanas de uma gestação a termo (40 semanas), em seguida é subtraído da idade cronológica da criança o resultado obtido (Idade Corrigida $=$ Idade cronológica $-(40$ semanas - Idade gestacional $)$ (RESTIFFE; GHERPELLI, 2006).

\subsection{Critérios de inclusão}

Foram incluídos neste estudo lactentes com idade gestacional e peso ao nascer compatíveis com os grupos apresentados no item participantes e, lactentes cujo pais ou responsáveis autorizaram a participação de seus (as) filhos (as) assinando o Termo de Consentimento Livre e Esclarecido (ANEXO 1).

\subsection{Critérios de exclusão}

Crianças nascidas com síndromes (por exemplo, Síndrome de Down), malformações congênitas neurológicas (como exemplo, mielomeningocele) ou ortopédicas (como exemplo, pé torto congênito), diagnosticadas com Paralisia Cerebral e aquelas com deficiência visual grave. Além disso, foram excluídos do estudo aqueles lactentes que apresentaram intercorrências que pudessem comprometer o desenvolvimento neuro-sensório-motor normal no momento da avaliação (por exemplo: pneumonias recorrentes, infecção renal e intestinal) ou que choraram sem controle durante a avaliação não permitindo a analise do movimento de alcance.

\subsection{Coleta de dados}

Inicialmente ocorreu o levantamento dos prontuários dos lactentes. Este foi realizado por meio do projeto de extensão da Universidade de Brasília de follow up de bebê de risco no Hospital Regional da Ceilândia. Cada prontuário foi analisado cautelosamente no intuito de garantir os critérios de inclusão e de exclusão apresentados previamente. A avaliação do movimento de alcance e do comportamento global dos lactentes ocorreu no Laboratório de Análise do Movimento, no Campus da Ceilândia da Universidade de Brasília. 
A coleta de dados iniciou-se em setembro de 2013 e foi finalizada em dezembro de 2014. Todos os procedimentos foram executados somente pelas duas pesquisadoras e examinadoras principais.

\subsection{Instrumentação}

A análise cinemática dos membros superiores durante a trajetória do alcance foi realizada por meio do Sistema Qualysis (QTM - Qualisys Track Manager). Este sistema verifica as posições absolutas dos marcadores retro reflexivos fixados no membro durante toda a trajetória do movimento, os quais foram identificados pelas câmeras do próprio sistema posicionadas ao redor do lactente.

Incialmente foi necessário realizar a calibração do sistema para que os sensores configurassem as coordenadas $\mathrm{X}, \mathrm{Y}$ e Z no sistema QTM para posteriormente reconstruir diretamente as posições tridimensionais dos membros superiores em movimento (Figura 3) (ZHOU; HUOSHENG; HARRIS, 2005).

O método de calibração utilizado foi por Frame (QTM - User Manual, 2011), que consiste em utilizar marcadores reflexivos em posições conhecidas e fixas. Para a realização deste método foi configurada uma calibração com no máximo 1000 frames que foram regularmente distribuídos em todo espaço calibrado e utilizou-se o Kit do tipo Ward Kit 300mm (pequeno) (Figura 3).

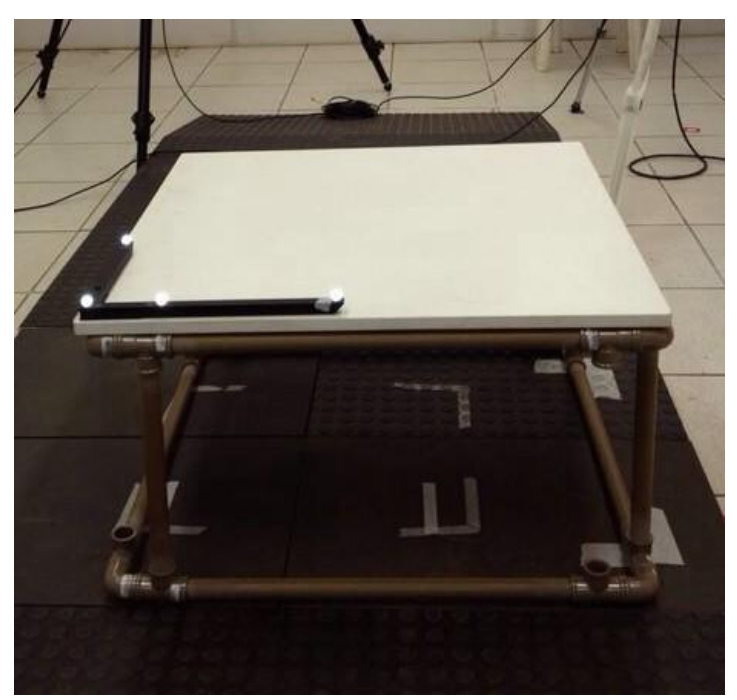

Figura 6. Calibração do Sistema Qualysis 
A frequência de captura das câmeras foi de $200 \mathrm{Hertz}(\mathrm{Hz})$ por segundo. O set de coleta (Figura 4) consta de 8 câmeras, das quais utilizou-se para o presente estudo apenas 7. Uma das câmeras foi desativada por estar posicionada atrás do encosto da cadeira do lactente, impossibilitando a visualização dos marcadores durante a coleta. Além das câmeras do Sistema Qualysis uma câmera webcam foi posicionada a frente e a direita do lactente.

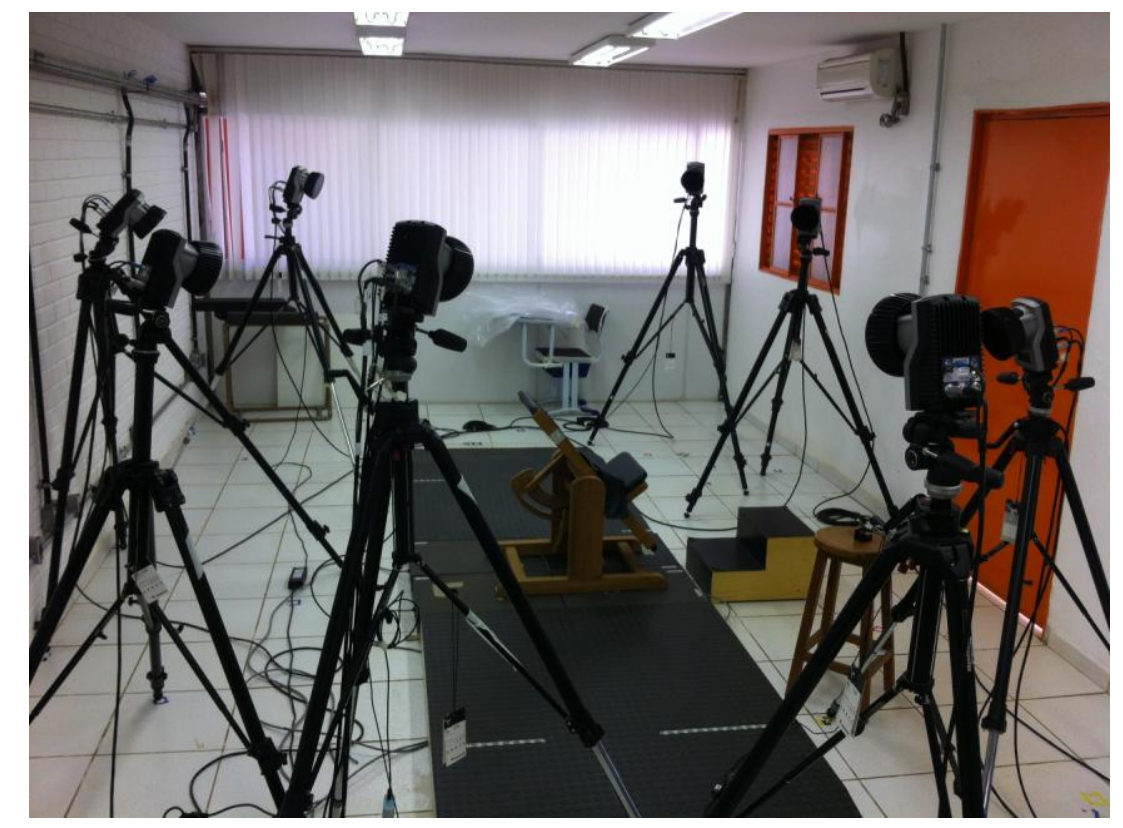

Figura 7. Set de Coleta dos dados

Para avaliação do comportamento motor global dos lactentes utilizou-se a escala Alberta Infant Motor Scale-AIMS (ANEXO 2 ).

A Alberta Infant Motor Scale (AIMS) é uma escala padronizada, desenvolvida por Piper et. al. (1992), foi criada como objetivo avaliar e monitorar o desenvolvimento motor grosso de lactentes por meio da observação da atividade motora espontânea, desde o nascimento até os 18 meses de vida ou até a aquisição da marcha independente. Esta escala também pode ser usada com o propósito de identificar quais lactentes possuem risco de desenvolver disfunções neuromotoras decorrentes de restrições intrínsecas como a prematuridade, baixo peso ao nascer, displasia broncopulmonar, meningite bacteriana, entre outros (PIPER et. al., 1992).

A atividade motora ampla é quantificada pela AIMS por meio de um escore bruto, levando em consideração três critérios relacionados à qualidade do movimento: 
distribuição de peso, postura e movimentos anti-gravitacionais. Trata-se de uma escala observacional, de fácil aplicabilidade, de baixo custo e não exige manuseio excessivo do lactente (PIPER; DARRAH, 1994).

A escala é composta por 58 itens no total, sendo que 21 são observados em posição prona, 9 em supino, 12 sentado e 16 em pé. O escore é atribuído pela avaliação de cada item como observado (escore 1) ou não-observado (escore zero). Os itens observados em cada uma das sub-escalas são somados resultando em quatro subtotais (prono, supino, sentado e de pé). O escore total do teste (0-58 pontos) é a soma dos subtotais obtidos em cada sub-escala. Além da representação pelo escore bruto, o comportamento motor é classificado de acordo com o percentil apresentado na escala (percentis: abaixo de 5, 5, 10, 25, 50, 75, 90 ou acima de 90). Para a obtenção do percentil, utiliza-se uma curva oferecida pela escala, na qual visualiza-se no seu eixo horizontal a idade da criança na data de avaliação (idade corrigida para os lactentes prematuros) e no eixo vertical os escore total (ANEXO 2). O ponto de intersecção desses dois dados (idade e escore total) fornece uma estimativa de um percentil contínuo individual da criança, além de indicar qual a faixa percentílica que o lactente se encontra. (PIPER; DARRAH, 1994).

A partir da obtenção do percentil, o lactente pode ser classificado de acordo com os seguintes critérios: desempenho motor normal/esperado: acima de $25 \%$ da curva percentílica (acima do percentil 25); desempenho motor suspeito: entre $25 \%$ e $5 \%$ da curva percentílica (entre os percentis 25 e 5); desempenho motor anormal: abaixo de 5\% da curva percentílica (abaixo do percentil 5) (PIPER et al, 1992; PIPER; DARRAH, 1994).

As avaliações dos lactentes prematuros foram realizadas por uma fisioterapeuta com conhecimento sobre o desenvolvimento motor infantil e treinada para aplicação do instrumento. Para a aplicação da AIMS, o lactente foi posicionado em um tapete de E.V.A e objetos foram utilizados para estimular o aparecimento das habilidades motoras do mesmo (Figura 5). No momento da avaliação os lactentes permaneceram apenas de fraldas e deveriam estar em estado de alerta inativo, ou seja, estado 3 (olhos abertos, sem choro, não exibindo movimentos grosseiros), ou em estado de alerta ativo, ou seja, estado 4 (olhos abertos, sem choro, exibindo movimentos grosseiros), segundo a Escala Comportamental de Prechtl e Beintema (1964). Para a avaliação, os neonatos estavam acordados e despidos. 


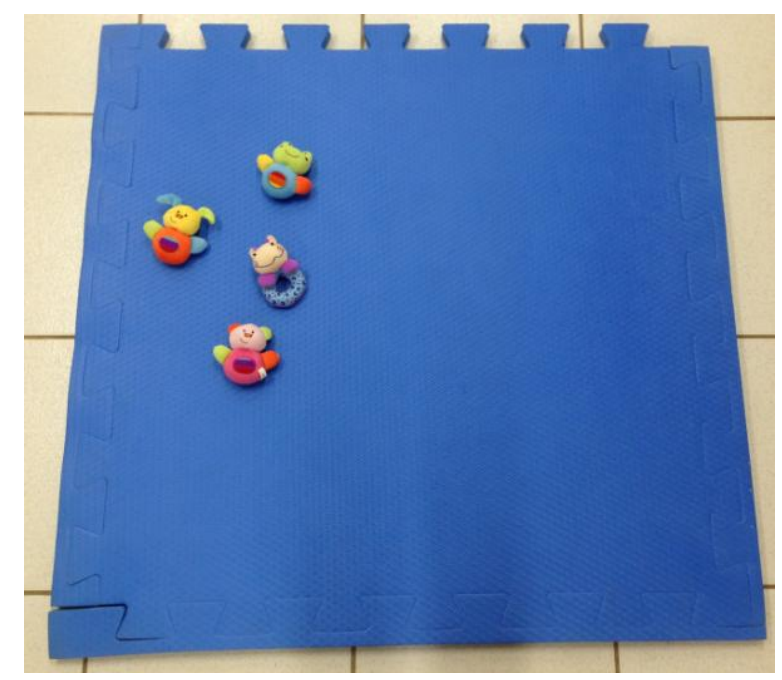

Figura 8. Local de avaliação da Alberta Infant Motor Scale (AIMS)

\subsection{Materiais de Consumo}

A estimulação do alcance foi realizada por meio de um objeto maleável e atrativo (Figura 6). Caso o lactente não tivesse interesse pelo objeto oferecido, um segundo objeto, do mesmo tipo, foi apresentado.

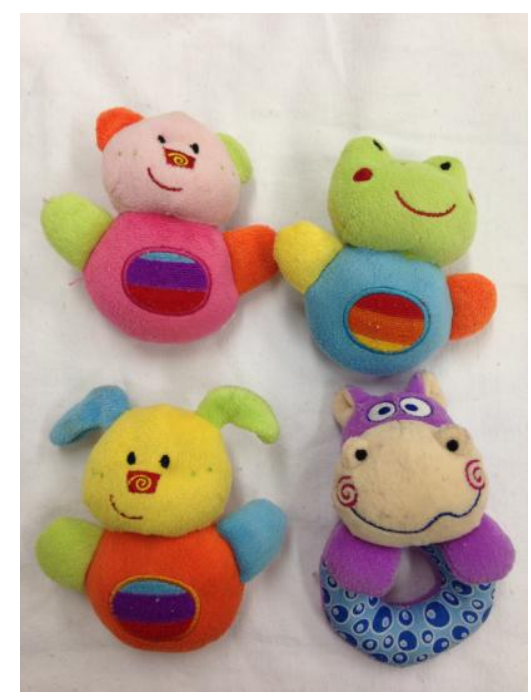

Figura 9. Brinquedos utilizados 
Para a limpeza da cadeira, do objeto e dos membros superiores do lactente foi utilizado álcool e toalha. Para a análise cinemática foram utilizados os marcadores padronizados pelo Sistema Qualysis fixados nos membros superiores dos lactentes com fita adesiva própria do kit do QTM, as quais eram hipoalérgicas. Além disso, utilizou-se um colchonete de EVA onde os lactentes eram posicionados para realização da avaliação da AIMS (Figura 5).

\subsection{Procedimentos Gerais}

O estudo foi desenvolvido de acordo com as Diretrizes e Normas Regulamentadoras das Pesquisas Envolvendo Seres Humanos (Resolução 466/2012, do Conselho Nacional de Saúde). Primeiramente foi elaborado e entregue um ofício contendo os esclarecimentos da pesquisa para a maternidade do Hospital Regional da Ceilândia, com o pedido de acesso aos prontuários das mães e dos RNs para que estes pudessem ser selecionados respeitando os critérios de inclusão do estudo. Após a autorização do acesso dos prontuários pelo hospital e a aprovação do Comitê de Ética e Pesquisa da UnB (protocolo número 064/12 (ANEXO 3), os dados de nascimento dos lactentes foram coletados por meio de um protocolo que continha dados dos prontuários médicos do recém-nascido $(\mathrm{RN})$ e das mães dos lactentes selecionados (Apêndice A). Este protocolo foi utilizado para assegurar as condições de saúde do lactente no momento da avaliação, assim como seu histórico pre e peri-natal. Com base nos dados encontrados nos prontuários, os pais foram contatados e informados da natureza do estudo e então convidados a participar.

Os pais que aceitaram o convite assinaram o Termo de Consentimento Livre e Esclarecido (ANEXO 1) e então foi agendada a data da avaliação do lactente que deveria coincidir com a data de aniversário de 6 meses, com uma tolerância de 7 dias antes ou após esta. Para os lactentes pré-termos as datas correspondiam a sua idade corrigida. Antes da avaliação, a examinadora se informou das condições gerais do lactente, tais como o estado comportamental e o horário da última amamentação.

O teste foi realizado entre as amamentações (após $1 \mathrm{~h}$ a $1 \mathrm{~h}$ e $30 \mathrm{~min}$ ) e não poderia coincidir com dias de vacinação. Os lactentes deveriam estar no estado de alerta inativo (estado 3), ou em estado de alerta ativo (estado 4), segundo a Escala Comportamental de Prechtl e Beintema (1964). O ambiente onde foi aplicado o teste encontrava-se silencioso, com luminosidade e temperatura adequadas para a 
realização da filmagem. Caso o lactente não estivesse colaborativo, apresentando choro ou inquietação, a avaliação era interrompida, o lactente acalmado e o teste reiniciado. Permanecendo o lactente inquieto, outra data era marcada por determinação da examinadora e acordada com o responsável pelo lactente, respeitando o máximo de 7 dias após a data de aniversario de 6 meses. Todos estes cuidados foram necessários para não houvesse influências no padrão de respostas dos lactentes.

As câmeras foram posicionadas de modo que os marcadores fossem visíveis ao longo de toda a trajetória do alcance. Foram utilizadas para a análise sete câmeras posicionadas em volta da cadeira infantil, latero-anteriormente e uma oitava câmera digital (webcam) foi posicionada na frente e à direita da criança para ser utilizada a fim de sanar possíveis dúvidas que pudessem surgir ao longo das análises (Figura 4). Esta última era sincronizada com as demais câmeras do sistema Qualysis.

\subsection{Sistema de Marcadores}

Os marcadores cinemáticos foram utilizados com o objetivo de tornar conhecidas a posição e a orientação dos segmentos corporais em um espaço tridimensional (ZHOU; HUOSHENG; HARRIS, 2005).

Foi adotado o sistema de marcas anatômicas, no qual os marcadores foram posicionados sobre as superfícies anatômicas dos centros articulares do ombro na borda externa do acrômio, no epicôndilo lateral do cotovelo (McDONALD; vanEMMERK; NEWELL, 1989;OUT et al., 1998; CARVALHO; TUDELLA; BARROS, 2005; ROCHA; SILVA; TUDELLA, 2006) e na região dorsal do carpo (OUT et al., 1998; CARVALHO; TUDELLA; BARROS, 2005; ROCHA; SILVA; TUDELLA, 2006). Para a análise dos dados apresentados no presente estudo, utilizou-se a reconstrução apenas dos marcadores do punho (Figura 7).

Os eletrodos de eletromiografia, visíveis na Figura 7, serviram para a análise de ativação muscular a qual não foi objetivo da presente dissertação. Os lactentes avaliados nesta pesquisa também eram participantes de outro projeto, cujos objetivos diferem-se do atual. 


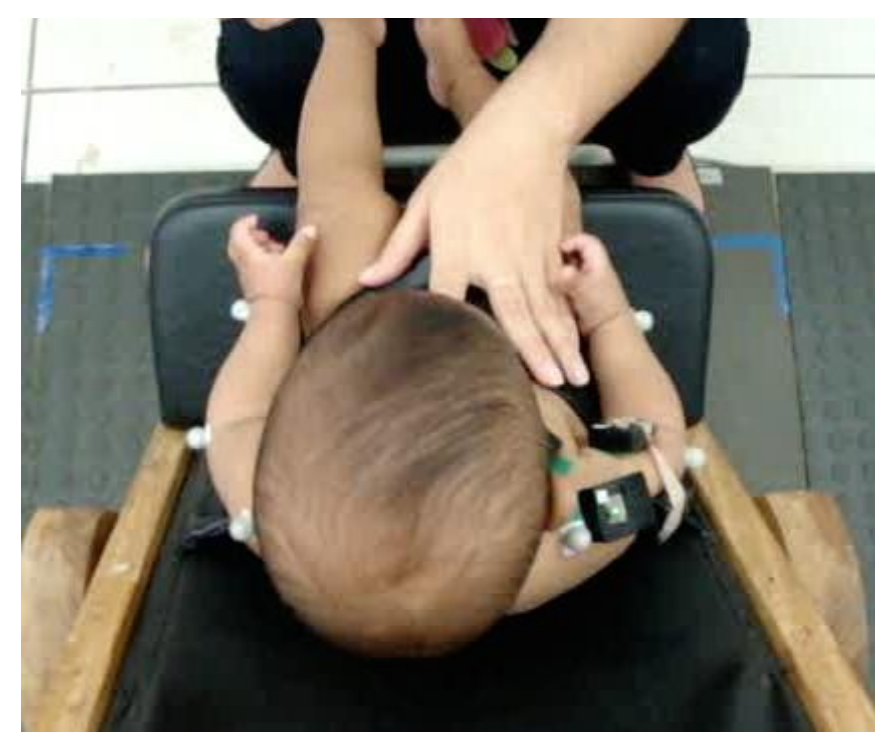

Figura 10. Posicionamento dos Marcadores

\subsection{Procedimento de teste}

Inicialmente o lactente foi despido pela mãe permanecendo somente com fraldas e a aplicação da AIMS foi realizada pelas examinadoras, tendo realizado previamente o índice de concordância inter e intra-examinadoras. A avaliação da AIMS foi filmada por uma câmera digital para posterior conferência, caso surgissem dúvidas no momento da pontuação.

Após a aplicação da AIMS, foi realizada a higienização da pele do lactente para posterior fixação dos marcadores. Em seguida, os lactentes foram posicionados na cadeira infantil em uma postura semi-reclinada a $50^{\circ}$ (Figura 8) (TOLEDO; TUDELLA, 2008; TOLEDO; SOARES; TUDELLA, 2011). A cadeira promoveu estabilidade da cabeça, tronco e quadril, porém permitiu liberdade de movimentos aos membros superiores e inferiores. Também foi utilizada uma faixa de tecido, de $15 \mathrm{~cm}$ de largura em volta do tronco do lactente, para melhor estabilidade de tronco (Figura 9). Um intervalo de 10 segundos foi permitido para que o lactente se adaptasse a situação. 


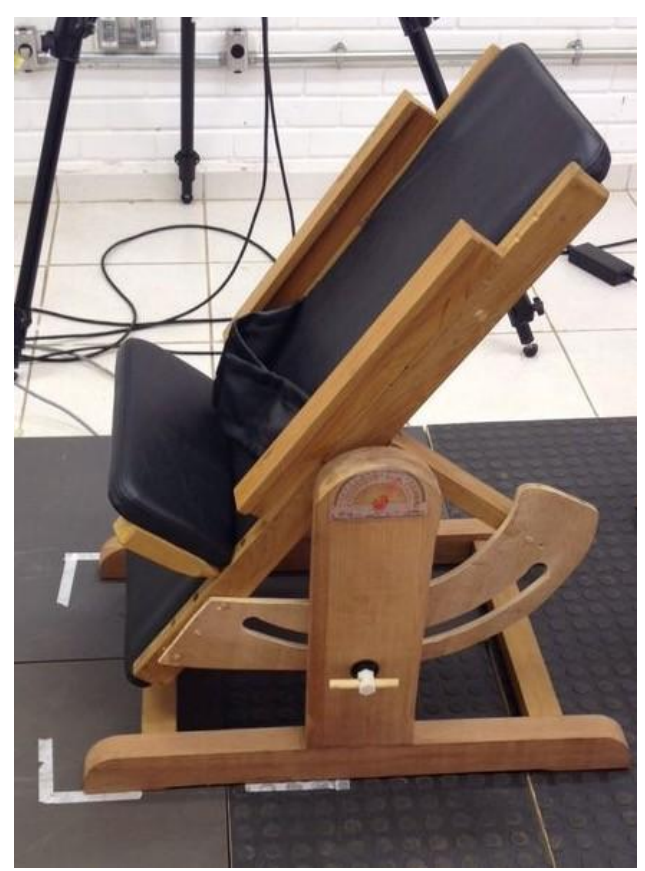

Figura 11. Cadeira Infantil semi-reclinada a 50

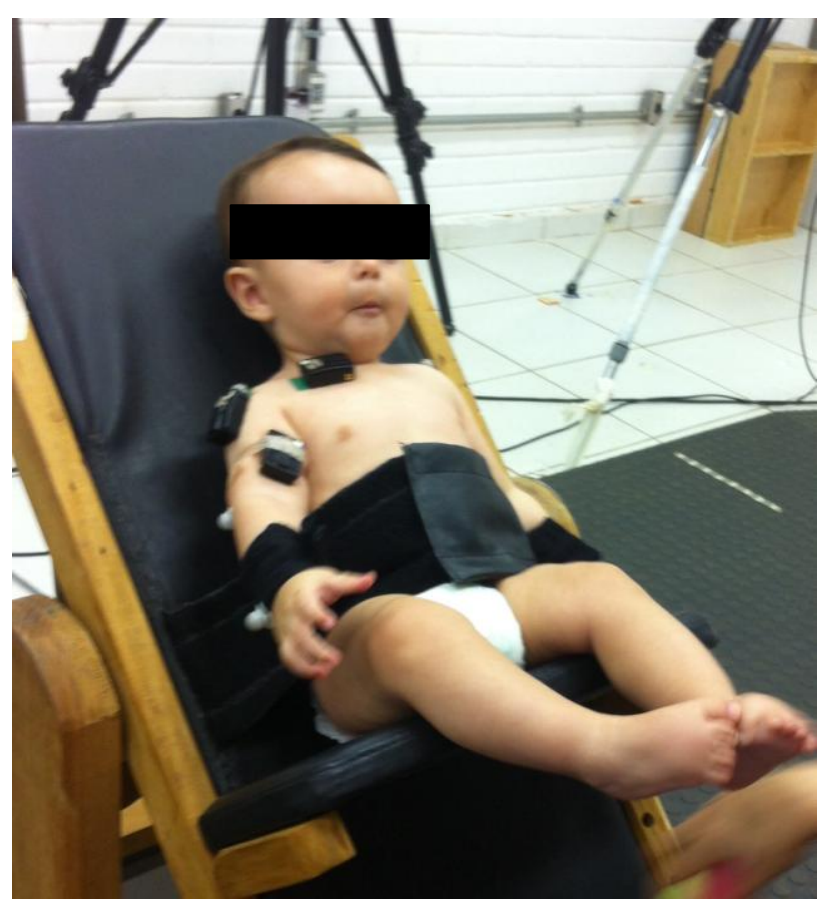

Figura 12.Faixa de tecido para estabilidade de tronco

Após o posicionamento da criança na cadeira, o objeto foi exibido pela examinadora, que estava posicionada à frente do lactente. $\mathrm{O}$ brinquedo foi apresentado durante 2 minutos que era o tempo total de duração do teste. O local de apresentação do objeto foi na linha média, na altura do ombro e na distância do comprimento dos braços do lactente (TOLEDO; TUDELLA, 2008;TOLEDO; 
SOARES; TUDELLA, 2011). A examinadora chamou a atenção do lactente para o objeto, movimentando-o momentaneamente, para que o lactente o percebesse e realizasse o alcance. Após o alcance, o objeto foi cuidadosamente retirado (ou apanhado) e reapresentado a fim de eliciar um novo alcance. O intervalo entre as reapresentações do objeto foi de aproximadamente 5 segundos. Assim, o número total de alcances dependia exclusivamente de cada lactente.

A análise do comportamento do alcance foi realizada posteriormente, por meio das variáveis espaço-temporais (cinemática do movimento).

\subsection{Sistema de Análise}

Definiu-se como alcance quando o lactente localizou o objeto no espaço, fixou o olhar sobre ele e realizou o movimento com um ou ambos os membros superiores em direção ao alvo, até tocá-lo. O início do alcance foi estabelecido como sendo o quadro da filmagem da webcam que mostrou o primeiro movimento de um ou ambos os membros superiores em direção ao objeto. E o final do alcance foi determinado como o quadro no qual qualquer parte da mão do lactente tocou o objeto. Primeiramente, foi estabelecido o final do alcance. A partir disso, voltava a filmagem para definir o início do alcance.

O alcance foi excluído quando o lactente apresentou choro ou irritação durante a realização do movimento, quando o lactente iniciou o movimento do braço com a mão próxima ao objeto (KONCZAK; DICHGANS, 1997; TOLEDO; TUDELLA, 2008) e quando o lactente ao invés de tocar o objeto tocou a mão da examinadora.

As variáveis cinemáticas foram analisadas por meio da reconstrução tridimensional do movimento pelo deslocamento das marcas afixadas nos centros articulares dos membros superiores, gerando um sistema de coordenadas $\mathrm{X}, \mathrm{Y}$ e Z (TOLEDO; SOARES; TUDELLA, 2012).

A pontuação da Escala AIMS utilizada referiu-se ao escore total (de 0 a 58 pontos) e ao percentil obtido a partir do gráfico elaborado pelos autores da escala (valores de 0 a 90). Para a presente pesquisa adotou-se como critério de atraso motor o comportamento motor considerado suspeito para a escala, ou seja, o percentil $25 \%$. A partir do percentil os lactentes, utilizou-se a classificação do percentil $25 \%$, o qual foram classificados como "Atrasados" aqueles que apresentaram valores de percentil menor ou igual a 25 e "Não Atrasados" para aqueles que possuiam percentil maior 
que 25 (PIPER et al, 1992; PIPER; DARRAH, 1994; SACCANI E VALENTINI, 2013).

\subsection{Variáveis analisadas}

\subsection{1: Variáveis cinemáticas}

As variaveis cinemáticas analisadas foram:

- Índice de retidão (IR): obtido pela razão entre a distância percorrida pela mão e a menor distância que poderia ser percorrida nesta trajetória. $O$ índice variava de 0 a 1 e quanto mais próximo de 1 for o índice, mais próximo de um segmento de reta terá sido a trajetória (THELEN; CORBETTA;SPENCER, 1996; CARVALHO; TUDELLA; SALVESBERGH, 2006; ROCHA; SILVA; TUDELLA, 2006).

- Velocidade média (VM): obtida pela razão entre a distância percorrida e o tempo gasto ao longo do movimento (MATHEW; COOK, 1990).

- Índice de ajuste $(\mathrm{IA})(\mathrm{mm} / \mathrm{s})$ : calculado pela razão entre o tempo após o pico de velocidade e a duração do alcance. Indica a proporção de tempo que foi necessário para desacelerar o movimento do braço para que a mão tocasse o objeto. Quanto maior o índice de ajuste, maior o tempo gasto para desacelerar o movimento do braço (TOLEDO; TUDELLA, 2008).

- Unidade de movimento (UM): definida como a velocidade máxima entre duas velocidades mínimas, sendo a diferença maior que $1 \mathrm{~cm} / \mathrm{s}$ (THELEN; CORBETTA; SPENCER, 1996). Para cada alcance realizado pelo lactente foi verificado a frequência de unidades de movimento gerando uma frequência média de unidades de movimentos (TODELO;SOARES; TUDELLA, 2012).

- Velocidade inicial $(\mathrm{mm} / \mathrm{s})(\mathrm{VI})$ : indica a velocidade da mão no momento do início do movimento de alcance.

- Velocidade de Pico (VP): foi definida como o valor máximo, em mm / s, identificado no perfil da velocidade da mão durante a trajetória do alcance (THELEN, 1996)

\subsubsection{Variáveis do comportamento motor:}

O comportamento motor foi analisado por meio dos percentis da AIMS. Se pelos escores totais individual de cada lactente (variação de 0-58 pontos). 


\subsection{Análise dos dados}

Os testes estatísticos foram realizados com auxílio do pacote de programa estatístico SPSS (versão 21.0). Incialmente realizou-se um teste para verificar a normalidade da amostra, o escolhido foi o Shapiro-Wilk que demonstrou que a amostra não apresenta normalidade e assim, optou-se pelo uso de testes nãoparamétricos.

Para a análise descritiva das variáveis também foi utilizado o programa SPSS (versão 21.0), verificou-se as medianas e os desvios padrões da variáveis e calculouse a percentagem de intercorrências neonatais para caracterização da amostra.

Com o intuito de verificar diferença entre os alcances realizados com a mão direita e esquerda, foi realizado inicialmente uma análise estatistica de diferença (Teste de Mann-Whitney) entre as mãos em cada grupo separadamente. Todos os grupos apresentaram diferenças entre as mãos. Ao analisar a diferença entre os grupos com cada mão separadamente, observou-se que as analises dos alcances realizados com a mão esquerda não apresentaram diferenças entre os grupos. Desta forma, optou-se por apresentar neste estudo os resultados referentes aos alcances realizados apenas com a mão direita em todos os grupos.

Para verificar a influência do peso ao nascer e da idade gestacional no alcance manual de forma independentes, foram realizadas analises comparando os grupos estratificados em peso ao nascer (peso adequado, baixo peso e muito baixo peso) e por faixas de idade gestacional (a termo, pré-termo tardio e muito prematuro).

A comparação entre os grupos em cada variável cinemática foi realizada por meio doteste não-paramétrico Kruskall-Wallys. Quando a variável apresentou diferença significativa entre os grupos, aplicou-se o teste de Mann-Whitney entre os diferentes grupos para identificar entre quais grupos encontravam-se as diferenças. Para este último teste adotou-se como significante o valor de p de 0,05 dividido por 3, considerando o número de grupos analisados (independente se analisado considerando o peso ao nascer ou a idade gestacional). Desta forma, o valor de $\mathrm{p}$ considerado significativo entre os grupos foi de $\mathrm{p}<0,017$.

A análise do comportamento motor também foi realizada por meio do teste Kruskall-Wallys e Mann-Whiteney. 
A partir da classificação motora dos lactentes entre "Atrasados" e "Não Atrasados" pela AIMS aplicou-se o teste de Risco Relativo que tem o intuito de verificar a ocorrência do atraso motor à presença dos fatores predisponentes que estratificaram os grupos (peso ao nascimento e idade gestacional). Para isto, foram aplicados quatro testes de Risco Relativo entre os grupos: Peso Adequado e Baixo Peso, Peso Adequado e Muito Baixo Peso, A termo e Prematuro Tardio, A termo e Muito Prematuro. O cálculo deste teste descreve a razão entre a incidência de indivíduos com determinado fator de risco e a incidência de indivíduos sem fator de risco. Com isso, se o resultado desta razão for acima de 1 implica um risco aumentado para atraso motor para os lactentes expostos a condição intrínseca do nascimento (baixo peso ao nascimento ou prematuridade), e caso seja menor que 1 não há risco à exposição. A partir deste teste também foi possível obter o ODDS Ratio que descreveu a probabilidade que o lactente exposto a um fator de risco possui de apresentar atraso motor. 
RESULTADOS 


\section{RESULTADOS}

Inicialmente foram coletados 392 alcances, sendo que destes 44 foram excluídos. Na Tabela 1 pode-se observar as causas das exclusões dos alcances separados em mão direita e esquerda.

Assim, após as exclusões a análise dos dados envolveram 348 movimentos de alcance no total da amostra. Na Tabela 2 encontra-se o número de alcances analisados em cada mão distribuídos nos grupos estratificados pelo peso ao nascimento e na Tabela 3 nos grupos estratificados pela idade gestacional.

Tabela 1. Alcances excluídos

\begin{tabular}{lccccc}
\hline \multicolumn{5}{c}{ Alcances Excluídos } \\
\hline $\begin{array}{l}\text { Mão } \\
\text { Direita }\end{array}$ & $\begin{array}{l}\text { Perda do } \\
\text { início do } \\
\text { alcance }\end{array}$ & $\begin{array}{c}\text { Mão } \\
\text { próxima }\end{array}$ & $\begin{array}{c}\text { Bate na mão } \\
\text { do examinador }\end{array}$ & $\begin{array}{c}\text { Erro de } \\
\text { filmagem }\end{array}$ & TOTAL \\
& 0 & 13 & 10 & 0 & 23 \\
$\begin{array}{l}\text { Mão } \\
\text { Esquerda }\end{array}$ & 3 & 3 & 8 & 4 & 18 \\
\hline
\end{tabular}

Tabela 2. Alcances analisados nos grupos estratificados pelo peso ao nascimento

\begin{tabular}{lccc}
\hline \multicolumn{4}{c}{ Alcances analisados } \\
\hline Grupo & Mao direita & Mão esquerda & TOTAL \\
Peso adequado & 80 & 60 & 140 \\
& 93 & 42 & 135 \\
Muito baixo peso & 45 & 28 & 73 \\
\hline TOTAL & 218 & 130 & $\mathbf{3 4 8}$ \\
\hline
\end{tabular}


Tabela 3. Alcances analisados nos grupos estratificados pela idade gestacional

\begin{tabular}{lccc}
\hline \multicolumn{4}{c}{ Alcances analisados } \\
\hline Grupo & Mao direita & Mão esquerda & TOTAL \\
A termo & 80 & 60 & 140 \\
& 110 & 56 & 166 \\
Muito Prematuro & 28 & 14 & 42 \\
\hline TOTAL & 218 & 130 & $\mathbf{3 4 8}$ \\
\hline
\end{tabular}

\subsection{Comparação entre os grupos divididos por peso ao nascer.}

Na Tabela 4 esta ilustrado a caracterização dos grupos estratificados pelo peso ao nascer segundo as intervenções neonatais descritas em porcentagem.

Tabela 4. Caracterização das intervenções neonatais dos grupos estratificados segundo o peso ao nascimento

\begin{tabular}{lll}
\hline \multicolumn{2}{c}{ Caracterização da amostra - Intervenções neonatais } \\
& Baixo Peso & Muito Baixo Peso \\
Peso ao nascer $(\mathrm{g})$ & $\mathrm{M}=1975( \pm 203)$ & M=1235( \pm 135$)$ \\
Ventilação Mecânica & $19 \%$ & $53 \%$ \\
Uso de Cpap & $19 \%$ & $60 \%$ \\
O2 Suplementar & $52 \%$ & $46 \%$ \\
Episódios de apnéia & $14 \%$ & $20 \%$ \\
\hline Infecção pós-natal & $42 \%$ & $66 \%$ \\
Fototerapia & $71 \%$ & $80 \%$ \\
\hline
\end{tabular}

\subsubsection{Comparações entre os Grupos}

A analise comparativa entre os grupos (divididos por peso ao nascer) mostrou diferença significativa entre os mesmos (IR p<0,000; VM p=0,013; VI p=0,006; VP $\mathrm{p}=0,012 ; \mathrm{UM} \mathrm{p}=0,001$; IA $\mathrm{p}=0,002$; AIMS $\mathrm{p}=0,013$ ). A seguir serão apresentados os resultados da analise comparativa entre cada dois grupos. 


\subsubsection{Análise comparativa entre os grupos Peso Adequado e Baixo Peso}

Com intuito de não repetir as figuras ao longo do texto, serão apresentados gráficos de cada variável contendo os três grupos e conforme a comparação entre os grupos serão feitas menções às figuras apresentadas anteriormente.

$\mathrm{Na}$ comparação entre os grupos Peso Adequado e Baixo Peso ao nascer, observou-se que o grupo Peso Adequado apresentou Índice de Retidão maior que o grupo Baixo Peso $(\mathrm{p}<0,000)$ (Figura 10). Nas variáveis Unidade de Movimento e Índice de Ajuste houve diferenças significativa entre os grupos, nas quais em ambas variáveis o grupo Peso Adequado apresentou menores valores $(\mathrm{p}<0,000$ e $\mathrm{p}=0,001$, respectivamente) que o grupo com peso adequado (Figuras 11 e 12).

As demais variáveis cinemáticas e o comportamento motor não apresentaram diferença entre estes dois grupos.

\section{índice de retidâo}

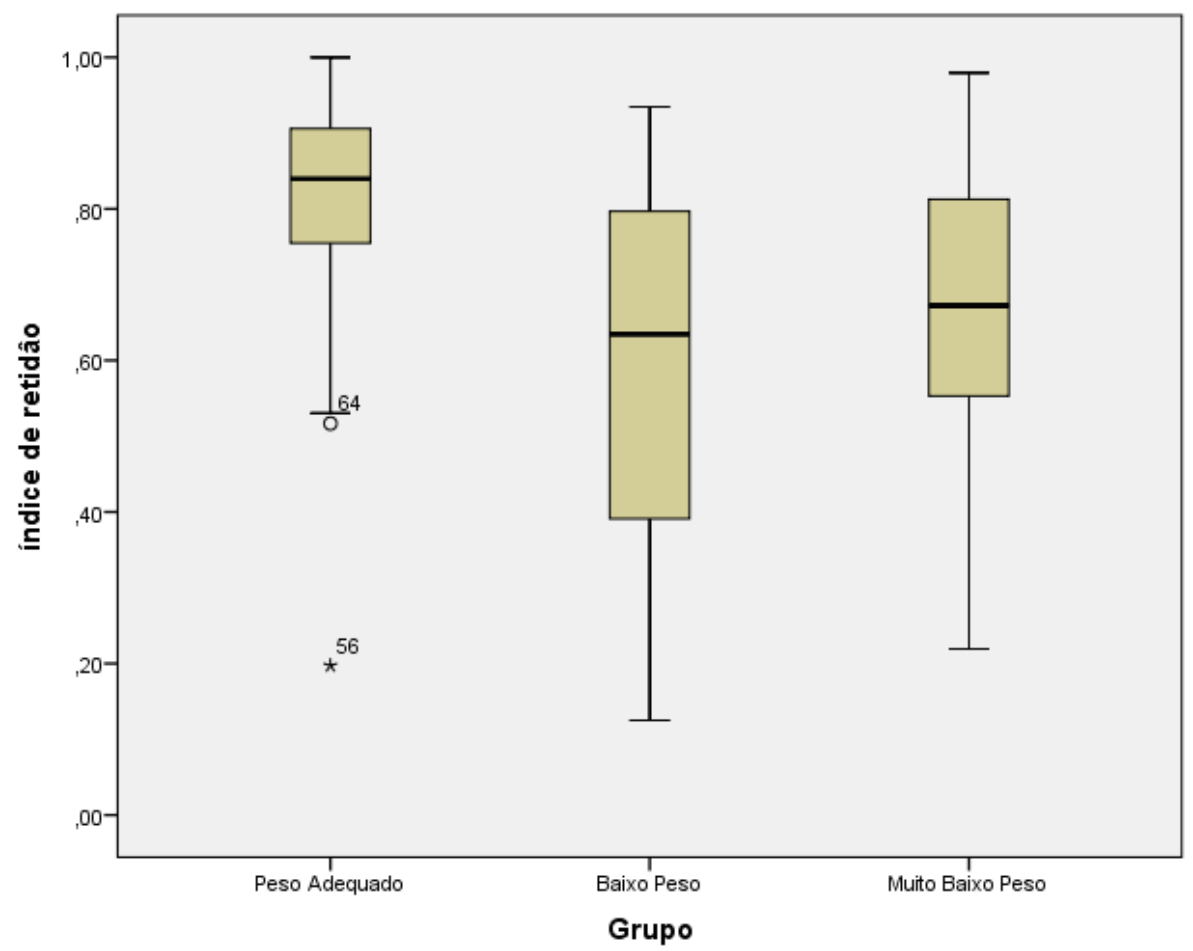

Figura 13. Índice de Retidão em cada grupo dividido por peso ao nascer 
Unidade de movimento

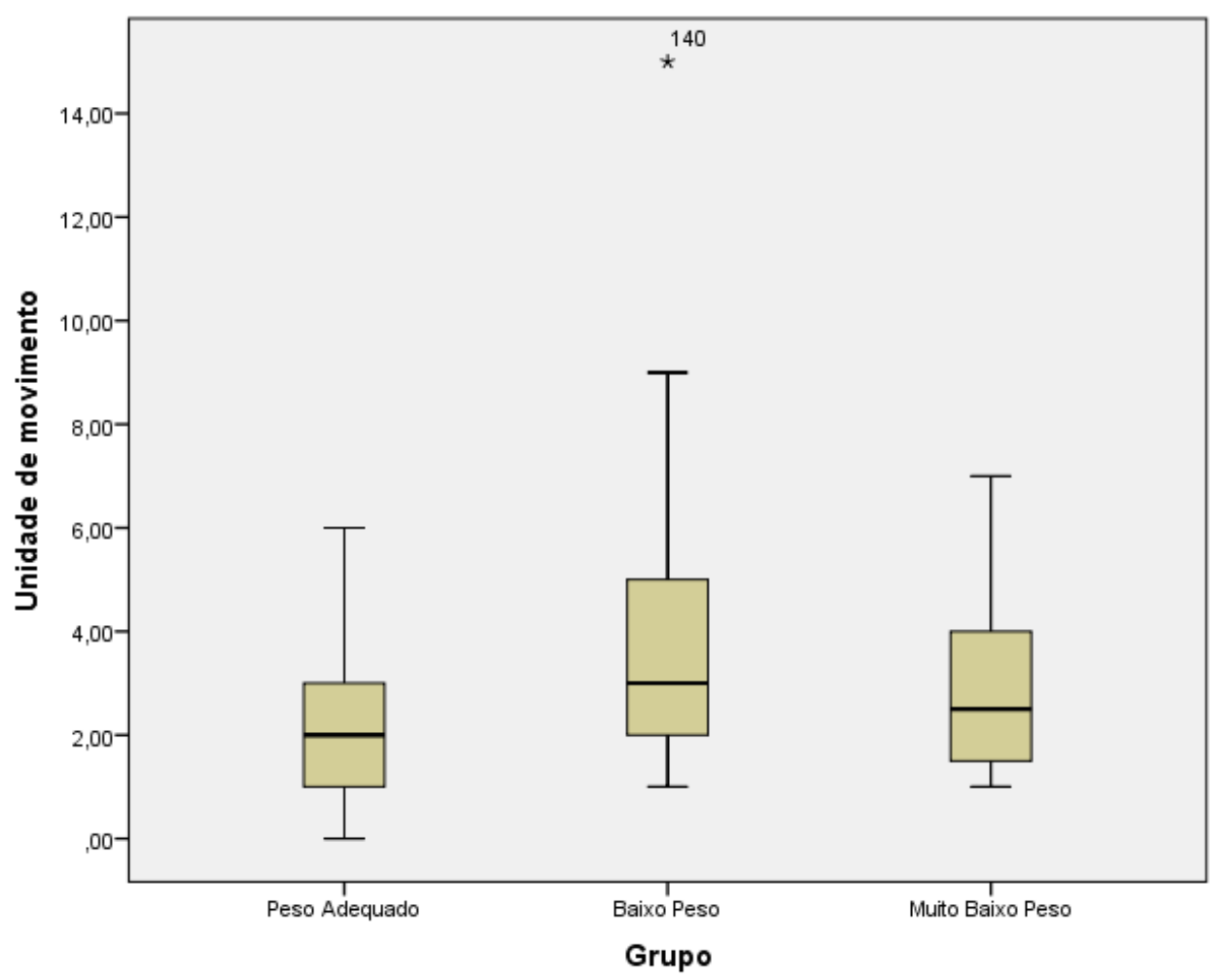

Figura 14. Unidade de Movimento em cada grupo dividido por peso ao nascer

Índice de ajuste

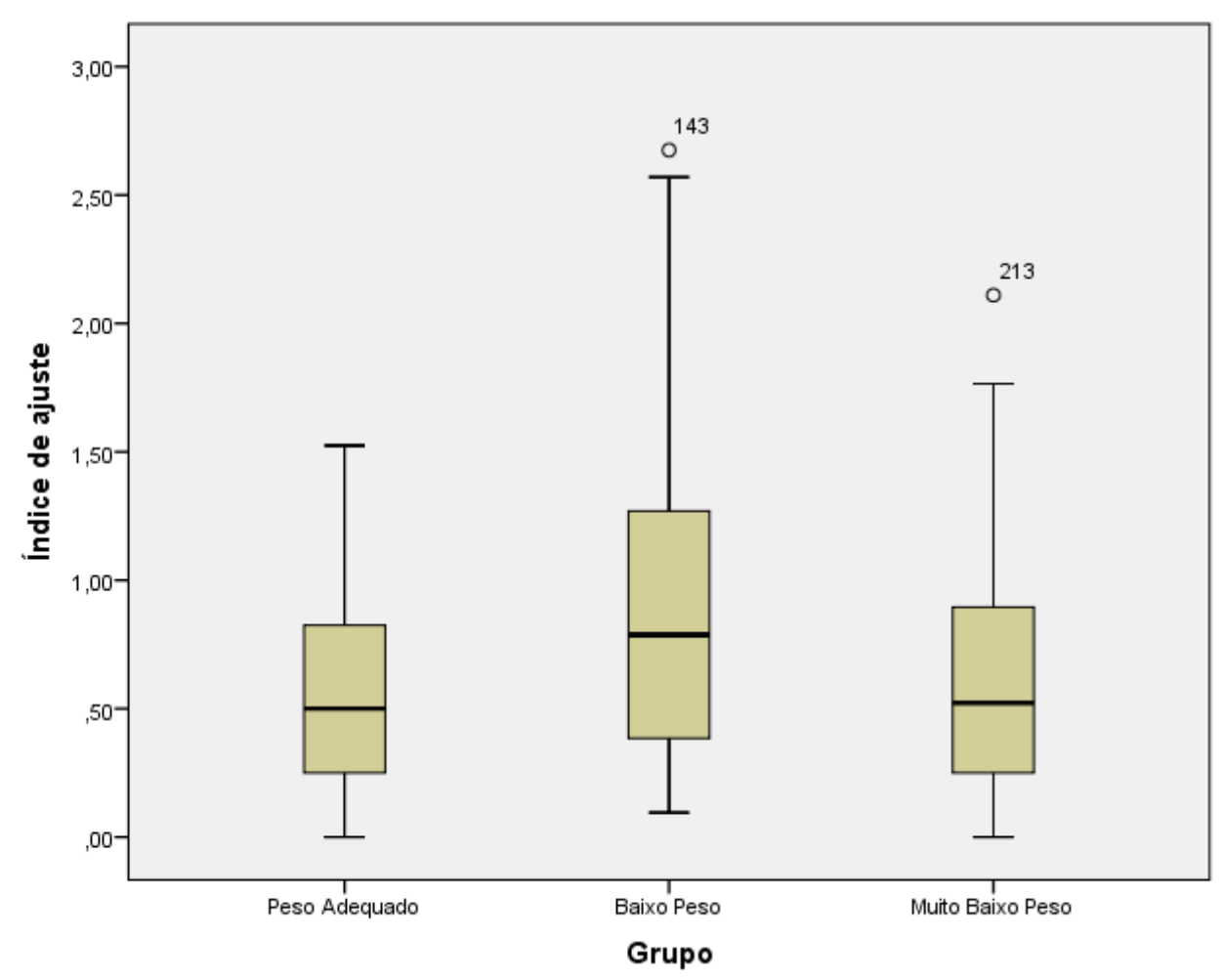

Figura 15. Índice de Ajuste em cada grupo dividido por peso ao nascer 


\subsubsection{Análise comparativa entre os grupos Peso Adequado e Muito Baixo Peso}

A análise entre os grupos Peso Adequado e Muito baixo Peso mostrou diferença nas variáveis Índice de Retidão (Figura 10), na qual o grupo Peso Adequado apresenta uma mediana maior que o grupo Muito baixo peso $(\mathrm{p}<0,000)$; Velocidades Iniciais e de Pico, nas quais o grupo Muito Baixo Peso apresentou medianas maiores que o grupo Peso Adequado ( $\mathrm{p}=0,001$ e 0,005 respectivamente) (Figuras 13 e 14, respectivamente).

As demais variáveis cinemáticas e o comportamento motor não apresentaram diferença entre estes dois grupos.

\section{Velocidade Inicial}

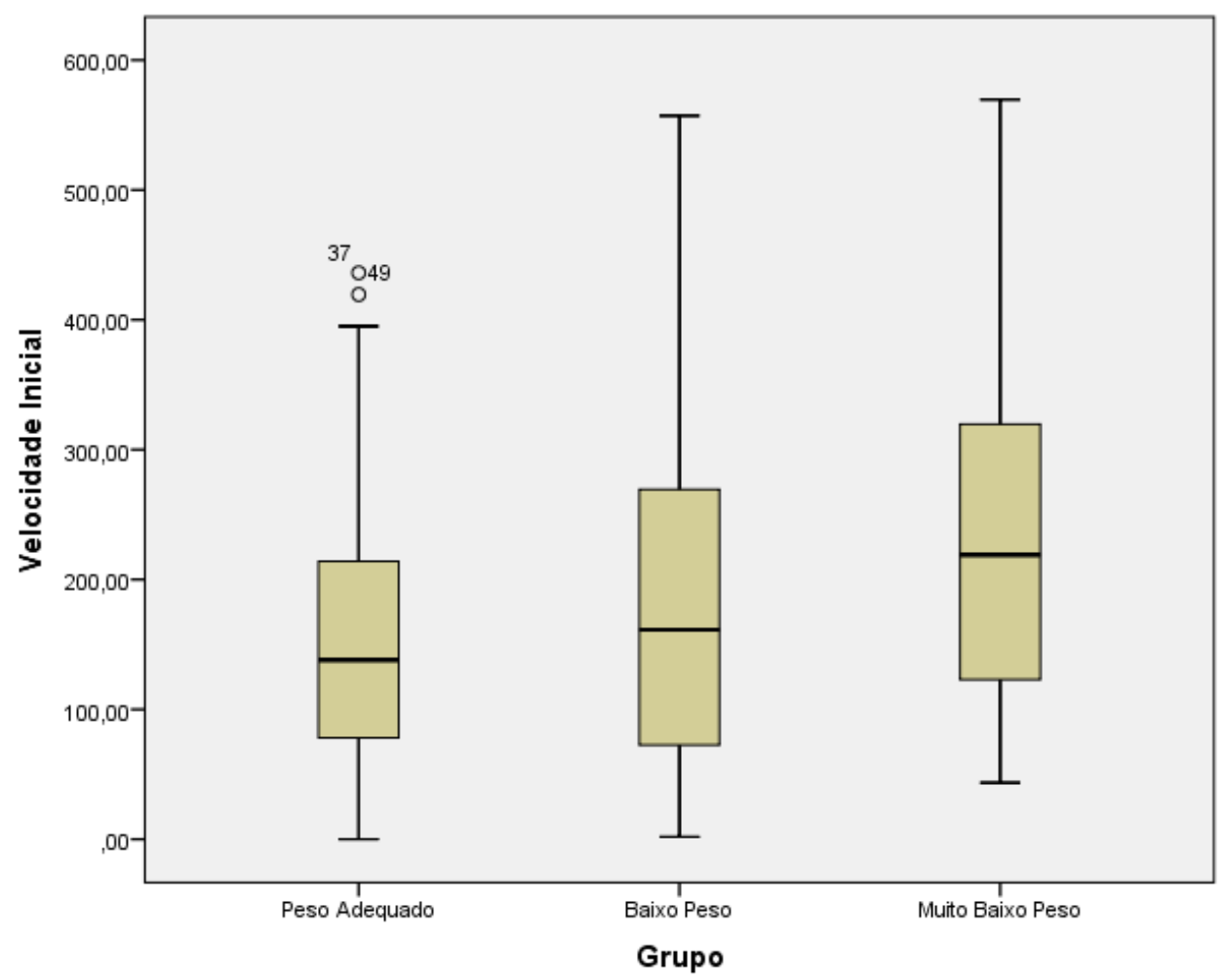

Figura 16. Velocidade Inicial em cada grupo dividido por peso ao nascer 


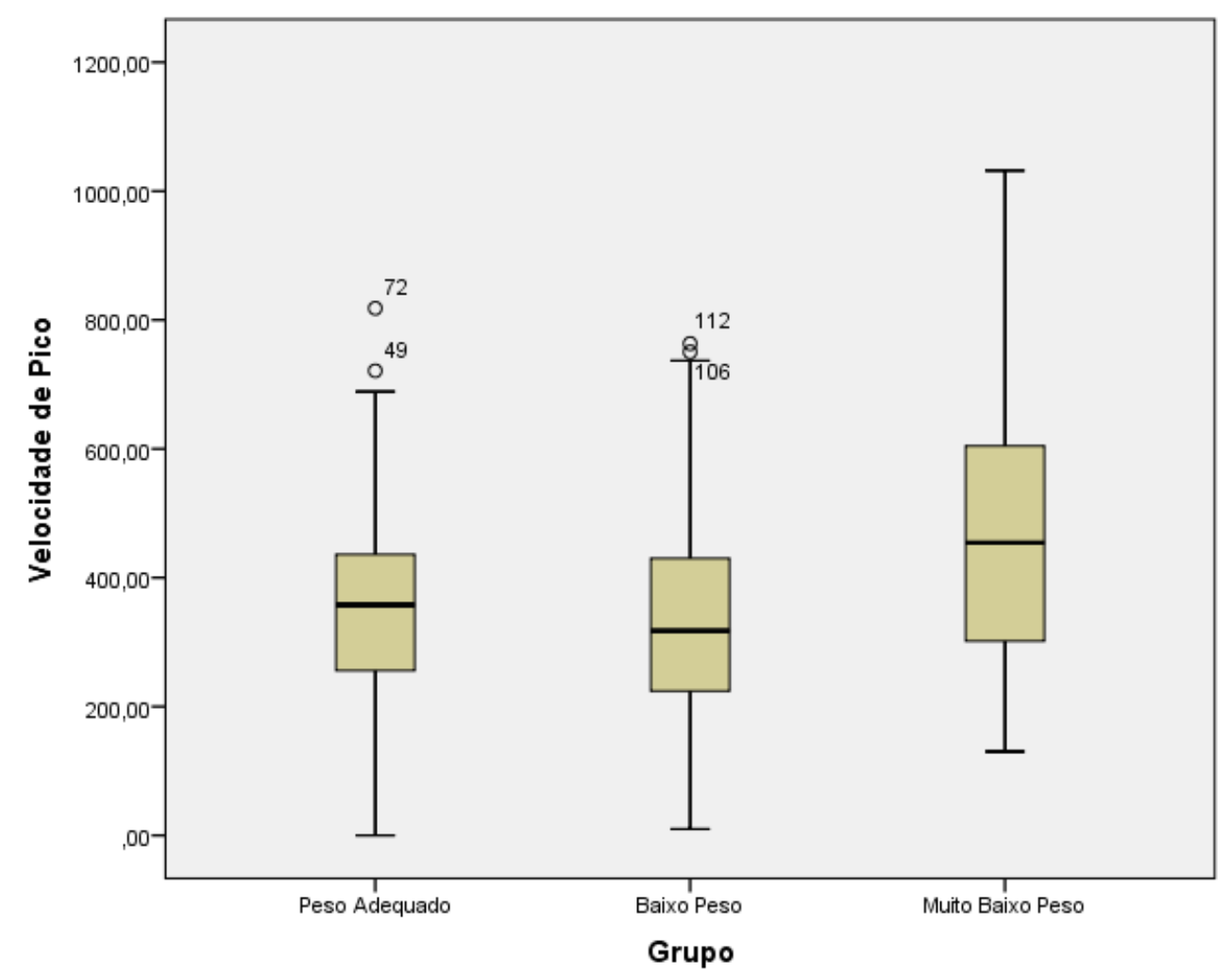

Figura 17. Velocidade de Pico em cada grupo dividido por peso ao nascer

\subsubsection{Análise comparativa entre os grupos Baixo Peso e Muito Baixo Peso}

$\mathrm{Na}$ comparação entre os grupos nascidos com peso abaixo do adequado, evidenciou-se que o grupo Muito Baixo Peso apresenta Velocidade Média (Figura 15) e de Pico (Figura 14) superior ao grupo Baixo Peso ( $\mathrm{p}=0,006$ e $\mathrm{p}=0,009$, respectivamente). Na variável Índice de Ajuste (Figura 12) os grupos não apresentaram diferenças estatisticamente significantes $(\mathrm{p}=0,020)$, porém o grupo Baixo Peso possui maiores valores que podem ser clinicamente importantes e que serão posteriormente discutidas.

Em relação ao comportamento motor global estes grupos apresentaram diferenças significantes, $\mathrm{p}=0,009$, demonstrado pelos percentis da AIMS maiores do grupo Baixo Peso (Figura 16).

As demais variáveis cinemáticas não apresentaram diferença entre estes dois grupos. 


\section{Velocidade Media}

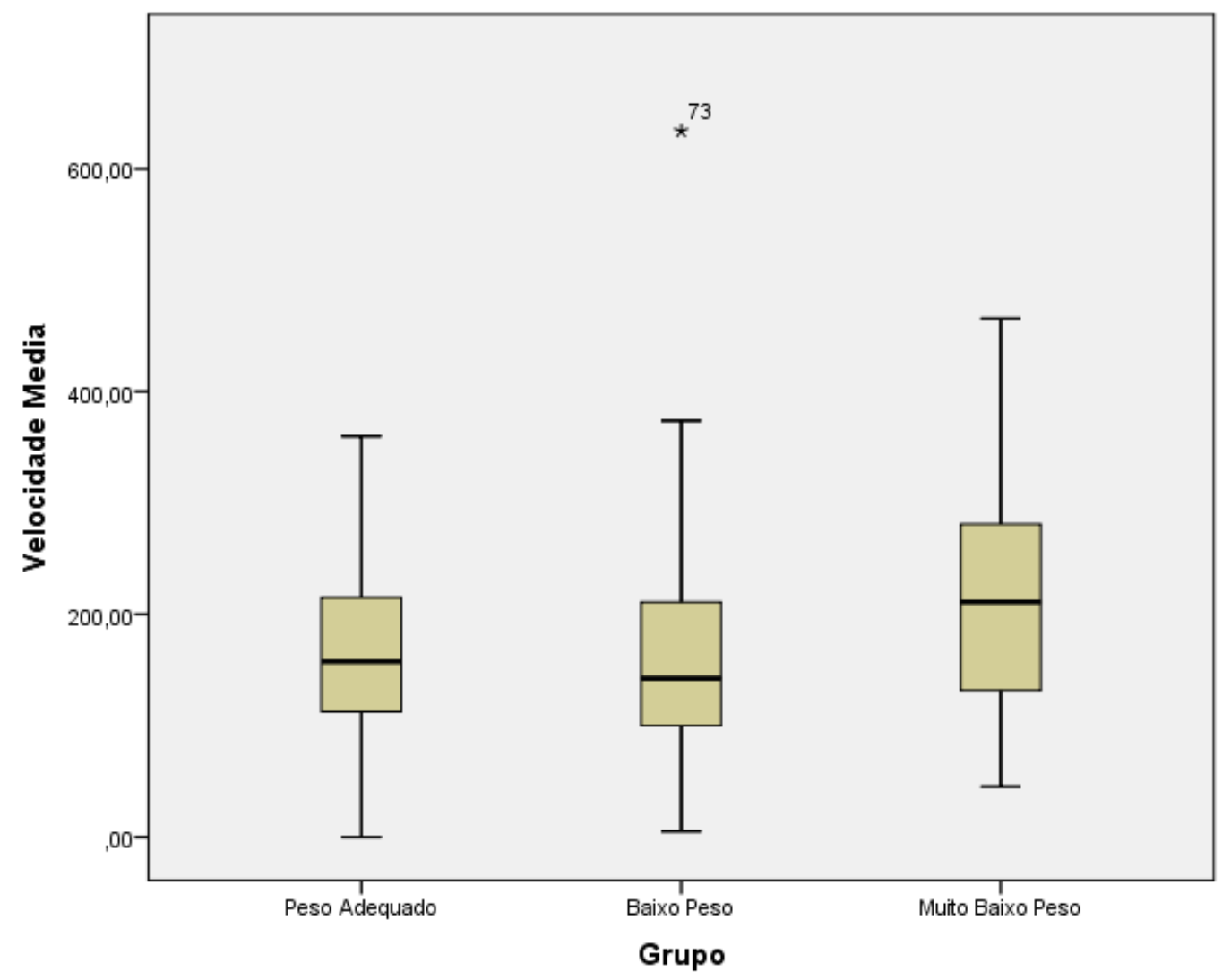

Figura 18. Velocidade Média em cada grupo dividido por peso ao nascer

\section{AIMS}

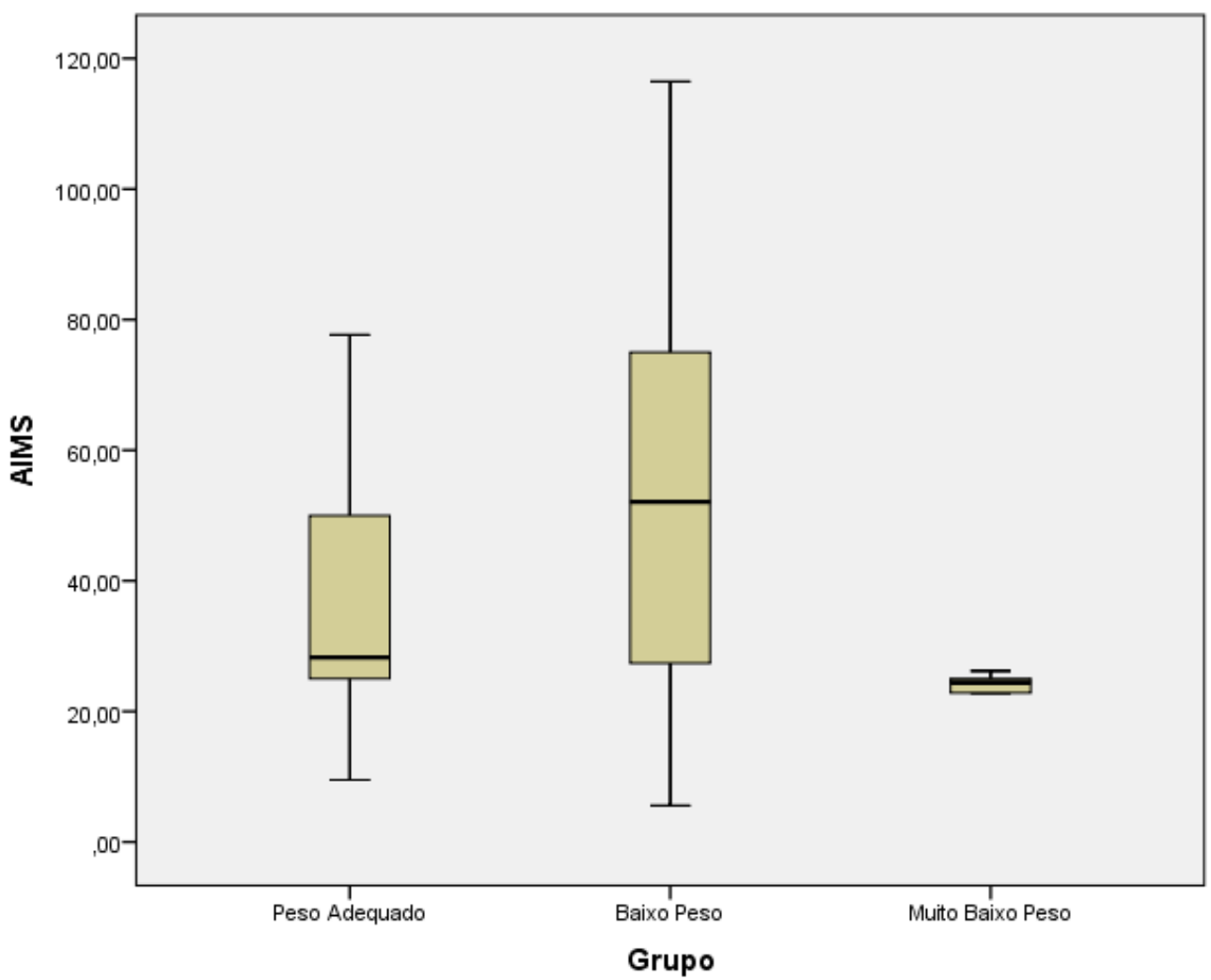

Figura 19. Comportamento Motor em cada grupo dividido por peso ao nascer 


\subsubsection{Análise do Risco Relativo}

Ao analisar o Risco Relativo dos lactentes com Baixo Peso e com Muito Baixo Peso de apresentarem atraso no desenvolvimento infantil, pode-se observar que o grupo Baixo Peso não evidenciou maiores chances de apresentar atraso motor quando comparados ao grupo com Peso Adequado $(\mathrm{RR}=0,800)$. Já os lactentes nascidos com Muito Baixo Peso possuem um risco aumentado em apresentar atraso no desenvolvimento motor $(\mathrm{RR}=2,262)$ e 3,73 vezes mais chance de ter atrasos quando comparados aos lactentes que nasceram com Peso Adequado (ODDS RATIO $=3,733)$. Estes valores podem ser analisados nas Tabelas 5 e 6 .

Tabela 5. Risco Relativo, grupo Baixo Peso ao nascer

\begin{tabular}{lc}
\hline \multicolumn{1}{c}{\begin{tabular}{c}
\multicolumn{1}{c}{$\begin{array}{c}\text { Risco Relativo } \\
\text { (Baixo Peso) }\end{array}$} \\
\hline
\end{tabular}} & Valores \\
\hline $\begin{array}{l}\text { Odds Ratio para Grupo (Muito Baixo } \\
\text { Peso/ Peso Adequado) }\end{array}$ & 0,753 \\
Para Coorte Atraso-Atrasado & 0,800 \\
Para coorte Atraso= Não Atrasado & 1,063 \\
\hline
\end{tabular}

Tabela 6. Risco Relativo, grupo Muito Baixo Peso ao nascer

\begin{tabular}{|c|c|}
\hline \multicolumn{2}{|l|}{$\begin{array}{c}\text { Risco Relativo } \\
\text { (Muito Baixo Peso) }\end{array}$} \\
\hline & Valores \\
\hline $\begin{array}{l}\text { Odds Ratio para Grupo (Muito Baixo } \\
\text { Peso/ Peso Adequado) }\end{array}$ & 3,733 \\
\hline Para Coorte Atraso-Atrasado & 2,262 \\
\hline Para coorte Atraso= Não Atrasado & 0,606 \\
\hline
\end{tabular}

* $95 \%$ de intervalo de confiança

\subsection{Comparação entre os grupos divididos por idade gestacional.}

Ao distribuir os lactentes em grupos segundo a idade gestacional, obteve-se um total de 21 lactentes A termo, 25 de Prematuro Tardio e 11 lactentes Muito 
Prematuro. Analisamos os mesmos 218 alcances (mão direita), porém agora distribuídos em 80 alcances do grupo A termo, 110 dos Prematuros Tardios e 28 do grupo Muito Prematuro.

A Tabela 7 ilustra as intervenções neonatais que cada um dos grupos foi subemetida em valores de porcentagem.

Tabela 7. Caracterização das intervenções neonatais dos grupo estratificados pela idade gestacional

\begin{tabular}{lll}
\hline \multicolumn{2}{c}{ Caracterização da amostra - Intervenções neonatais } \\
\hline Idade Gestacional (semanas) & $\begin{array}{l}\text { Prematuro Tardio } \\
\text { dias }( \pm 1,60)\end{array}$ & $\begin{array}{l}\text { Muito Prematuro } \\
\text { M=29 semanas }( \pm 1,69) \text { e } 1\end{array}$ \\
Ventilação Mecânica & $16 \%$ & $\begin{array}{l}\text { dia }( \pm 1,58) \\
\text { Uso de Cpap }\end{array}$ \\
O2 Suplementar & $24 \%$ & $81 \%$ \\
Episódios de apnéia & $56 \%$ & $63 \%$ \\
\hline Infecção pós-natal & $12 \%$ & $63 \%$ \\
Fototerapia & $40 \%$ & $27 \%$ \\
\hline
\end{tabular}

\subsubsection{Comparações entre os Grupos ditribuidos pela idade gestacional}

A analise comparativa entre os grupos (divididos por idade gestacional) mostrou diferença significativa entre os mesmos (IR $\mathrm{p}<0,000$; VI $\mathrm{p}=0,037$; UM $\mathrm{p}=0,01$; IA $\mathrm{p}<0,000$ ). A seguir serão apresentados os resultados da analise comparativa entre cada dois grupos.

\subsubsection{Análise comparativa entre os grupos A termo e Prematuro Tardio}

Na comparação entre os grupos a termo e prematuro Tardio foi encontrada diferença significante na variável Índice de Retidão, na qual o A termo apresentou valores maiores que o grupo Prematuro Tardio $(\mathrm{p}=0,001)$ (Figura 17). Com relação as variáveis Unidade de Movimento (Figura 18) e Índice de Ajuste (Figura 19) o grupo Prematuro Tardio evidenciou maiores valores em relação ao grupo A termo $(\mathrm{p}<0,000$ e $\mathrm{p}=0,001$, respectivamente). 


\section{Índice de Retidão}

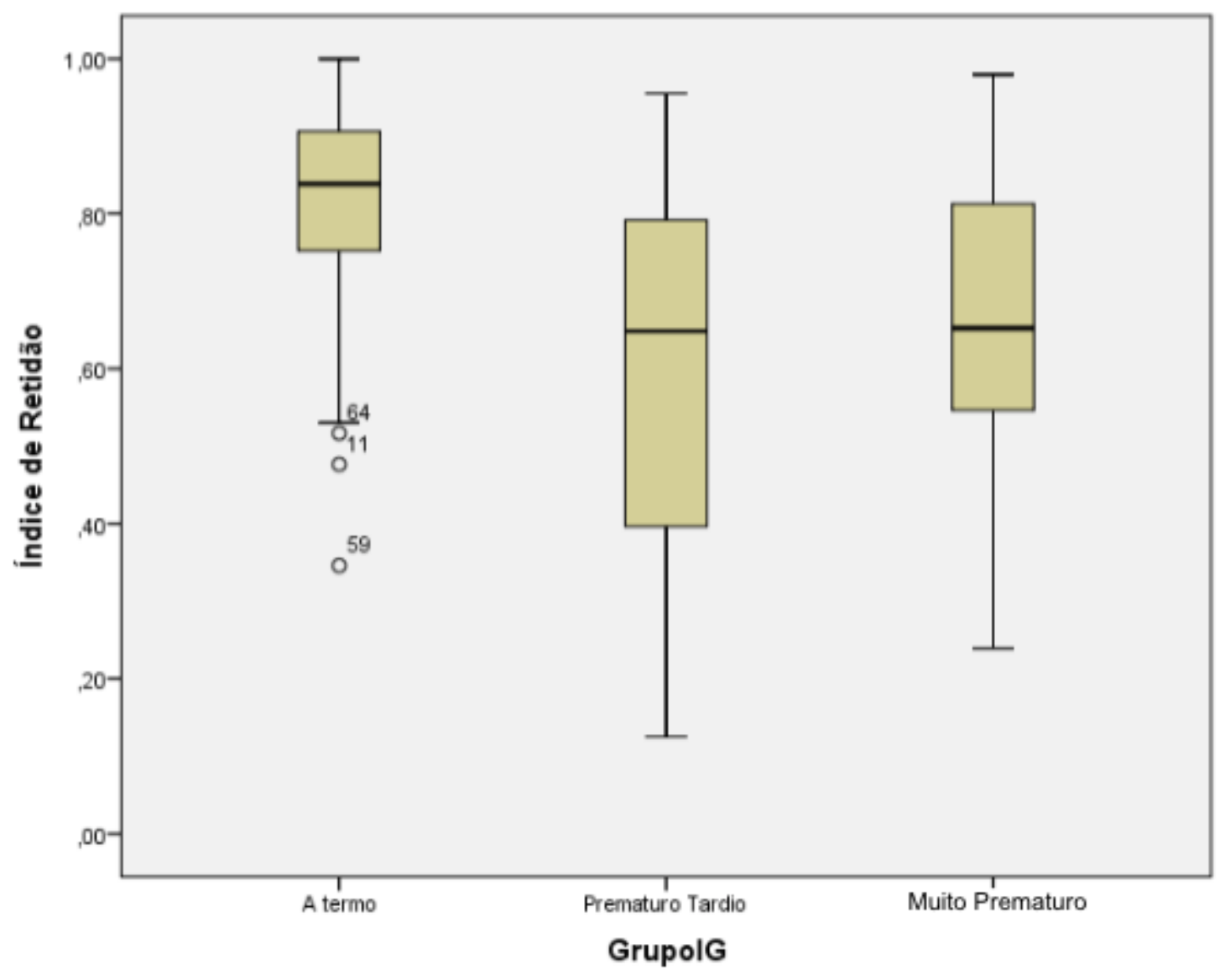

Figura 20. Índice de Retidão em cada grupo dividido por idade gestacional

As demais variáveis cinemáticas e o comportamento motor não apresentaram diferença entre estes dois grupos. 


\section{Unidade de Movimento}

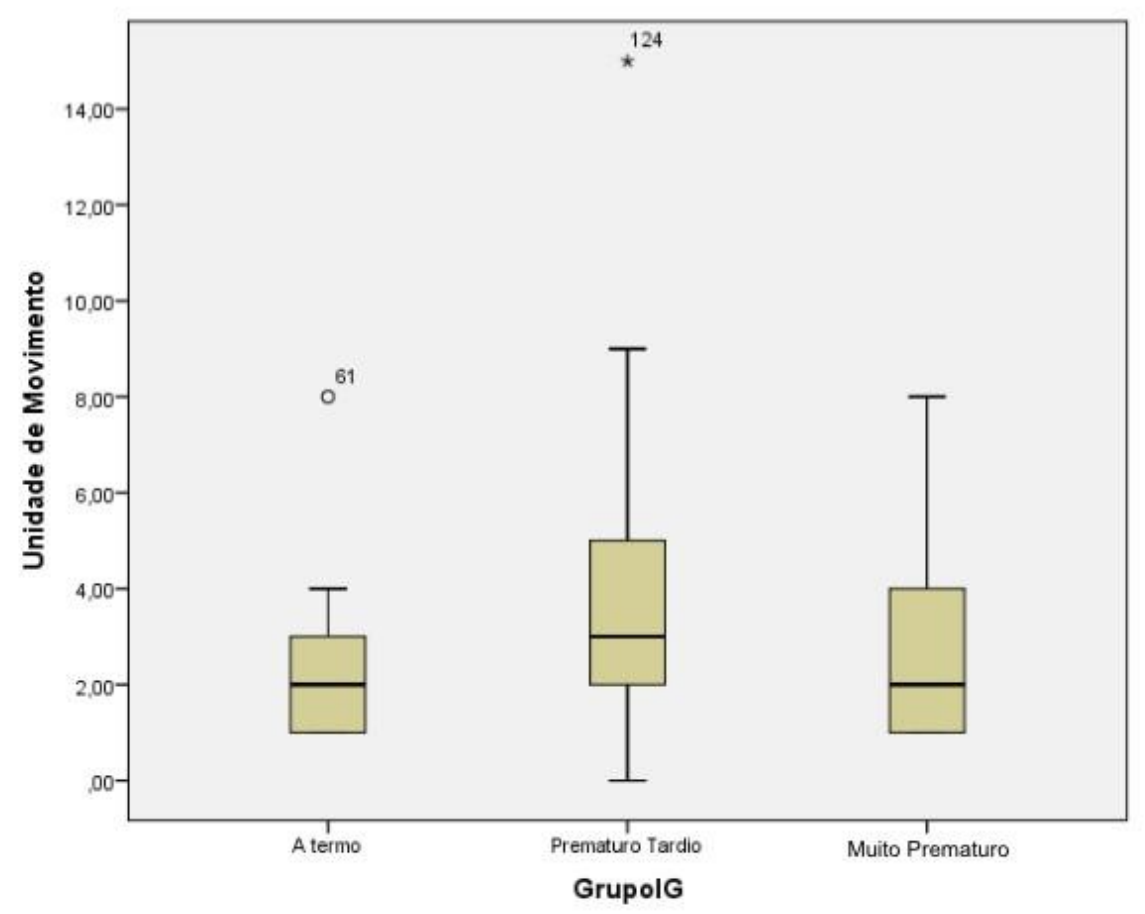

Figura 21. Unidade de Movimento em cada grupo dividido por idade gestacional Índice ajuste

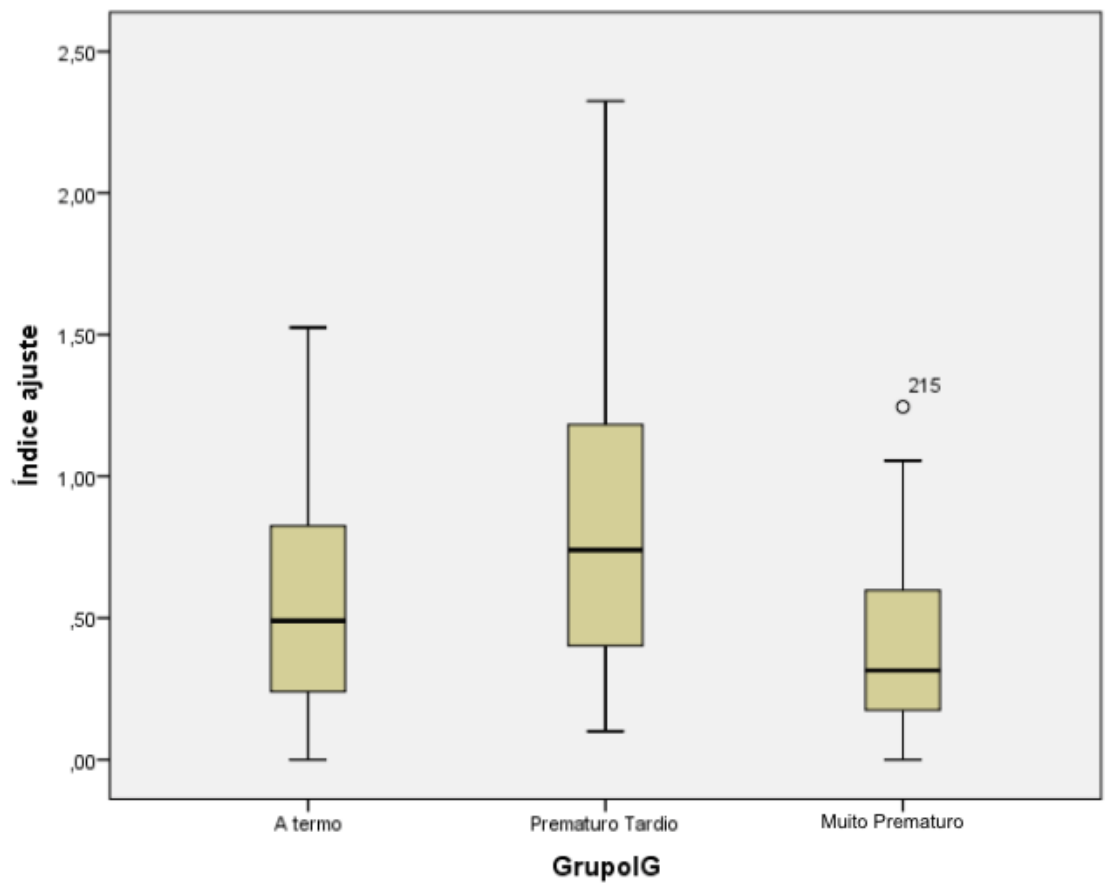

Figura 22. Índice de Ajuste em cada grupo dividido por idade gestacional 


\subsubsection{Análise comparativa entre os grupos A termo e Muito Prematuro}

A variável Índice de Retidão (Figura 17) apresentou-se maior no grupo A termo em relação ao grupo Muito Prematuro $(p<0,000)$, enquanto a Velocidade Inicial apresentou-se menor no grupo A termo ( $p=0,017)$ (Figura 20).

As demais variáveis cinemáticas e o comportamento motor não apresentaram diferença entre estes dois grupos.

\section{Velocidade Inicial}

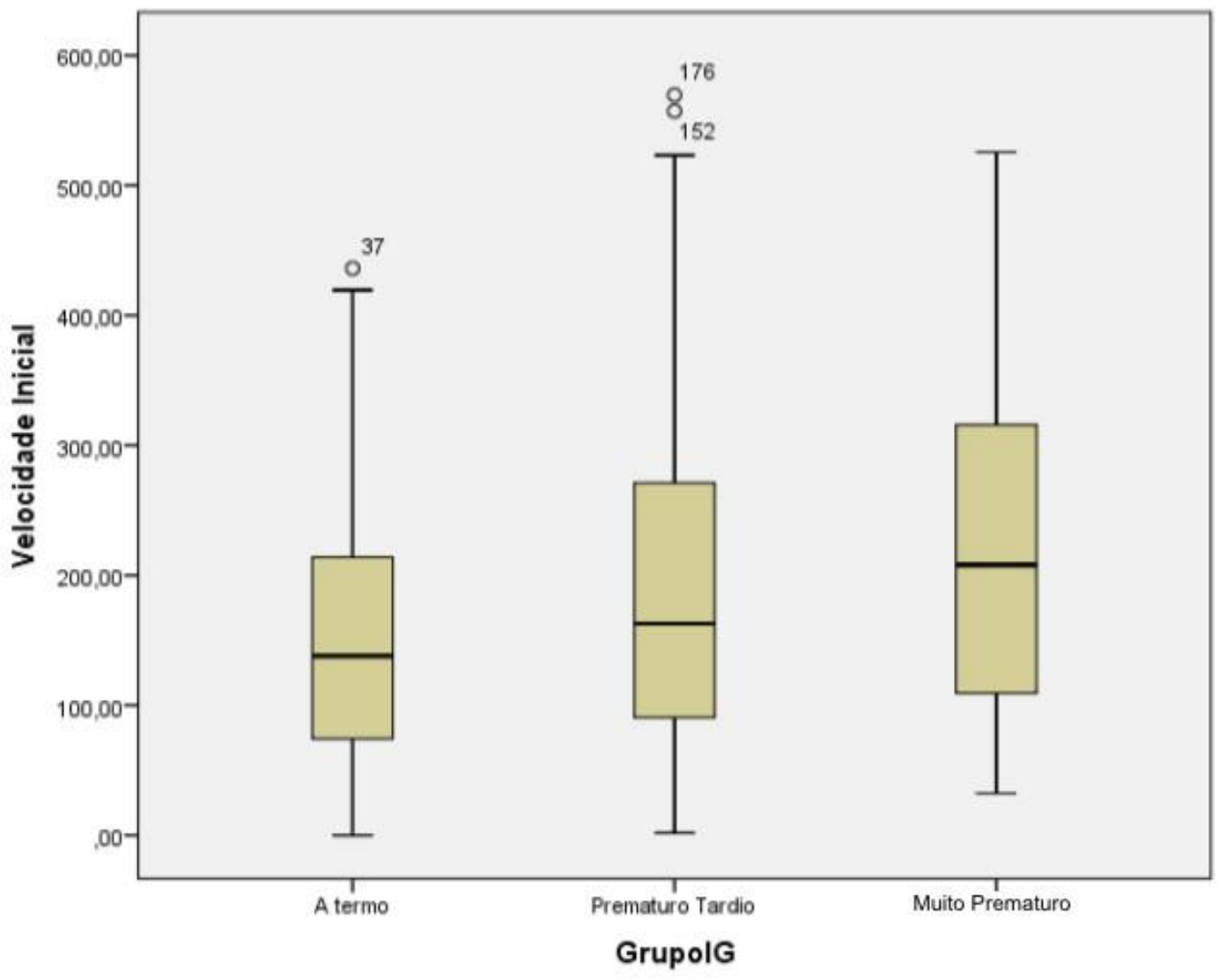

Figura 23. Velocidade Inicial em cada grupo dividido por idade gestacional 


\subsubsection{Análise comparativa entre os Grupos Prematuro Tardio e Muito Prematuro}

$\mathrm{Na}$ análise entre os prematuros apenas o Índice de Ajuste (Figura 19) se mostrou diferente significativamente, com o grupo Prematuro Tardio apresentando valores maiores nesta variável que o grupo Muito Prematuro $(\mathrm{p}<0,000)$.

As demais variaveis cinemáticas e o comportamento motor não apresentaram diferença entre estes dois grupos.

\subsubsection{Análise do Risco Relativo}

Ao analisar o risco relativo dos lactentes prematuros (Tardio e Muito Prematuro) apresentarem atrasos no desenvolvimento motor, segundo a escala AIMS, observou-se que o grupo Prematuro Tardio não apresenta risco em ter atrasos motores quando comparado a lactentes A termo ( $R R=0,865)$; contudo os Muito Prematuros evidenciam um risco elevado em desenvolver atraso motor $(R R=2,00)$ e 2,8 vezes mais chance disto acontecer quando comparado ao grupo A termo (ODDS RATIO = 2,800). Nas tabelas 8 e 9 estão descritos os valores encontrados do Risco Relativo dos grupos.

Tabela 8. Risco Relativo, grupo Prematuro Tardio

\begin{tabular}{lc}
\hline \multicolumn{1}{c}{\begin{tabular}{c}
\multicolumn{1}{c}{ Risco Relativo } \\
(Prematuro Tardio/ A termo)
\end{tabular}} \\
\hline \multicolumn{1}{c}{$\begin{array}{l}\text { Odds Ratio para Grupo (Prematuro } \\
\text { Tardio/ A termo) }\end{array}$} & 0,563 \\
Para Coorte Atraso-Atrasado & 0,865 \\
Para coorte Atraso= Não Atrasado & 1,538 \\
\hline
\end{tabular}

* 95\% de intervalo de confiança 
Tabela 9. Risco Relativo, grupo Muito Prematuro

\section{Risco Relativo}

(Muito Prematuro/ A termo)

\begin{tabular}{lc}
\hline & Valores \\
Odds Ratio para Grupo (Muito & 2,800 \\
Prematuro/ A termo) & 2,00 \\
Para Coorte Atraso-Atrasado & 0,714 \\
Para coorte Atraso= Não Atrasado & \\
\hline
\end{tabular}

* 95\% de intervalo de confiança 


\section{DISCUSSÃO}




\section{DISCUSSÃO}

Este estudo teve como objetivo geral analisar a influência do peso ao nascer e da prematuridade no alcance manual de lactentes aos 6 meses de idade corrigida. Especificamente, eram objetivos comparar as variáveis cinemáticas do alcance e o comportamento motor grosso entre os diferentes grupos estratificados pelo peso ao nascimento e pela idade gestacional, além de verificar se o peso ao nascimento ou a idade gestacional são fatores de risco relativo para atraso motor.

Em ambas análises pela estratificação dos grupos (peso ao nascer e idade gestacional), foram encontradas diferenças significativas nas variáveis cinemáticas Índice de Retidão, Unidade de Movimento e Índice de Ajuste tanto nos grupos Baixo Peso e Peso Adequado quanto entre os Prematuros Tardios e os A termos.De uma forma geral, os resultados mostraram que os lactentes com baixo peso ao nascer e os prematuros tardios apresentaram uma maior trajetória para tocar o objeto, com um movimento mais tortuoso, com mais acelerações e desacelerações e um maior tempo para tocar o objeto após o pico da velocidade que osnascidos a termo e com peso adequado. Segundo Carvalho \& Tudella (2004) e Grego, Soares \& Tudella (2013) no período de emergência do alcance o movimento do membro superior ocorre de forma tortuosa, curvilínea, com várias unidades de movimento e com menos precisão. Características semelhantes as encontradas nos grupos Baixo Peso e Prematuro Tardiodo presente estudo, sugerindo que aos 6 meses de idade corrigida o alcance desses lactentes corresponde a ummovimento maisimaturo dentro do desenvolvimento típico, correspondente aos 4 meses de um lactente nascido sem restrições intrínsecas. (CARVALHO E TUDELLA, 2004; GRECO, SOARES E TUDELLA, 2013)

Especificamente com relação a variável Unidade de Movimento, um possível fator que pode ter influenciado o seu aumento no alcance dos gruposprematuro de Baixo Pesoe Prematuro Tardio é o déficit de contração muscular que estes lactentes podem apresentar por possuírem menor quantidade de massa magra. O estudo de AHMAD et. al. (2010) comparou as medidas de composição corporal (peso corporal, comprimento, circunferência da cabeça, área transversa de gordura, massa corporal magra regional, composição óssea) de um grupo de lactentes prematuros, com idade gestacional média de 33 semanas e peso ao nascer médio de $2296 \mathrm{~g}$, que foram 
avaliados entre 9 e 89 dias de vida de idade corrigida e concluíram que esse grupo de lactentes possuem significativamente menores valores de massa corporal magra e área muscular, indicando que mesmo com os avanços das técnicas de UTI neonatal as intervenções são incapazes de proporcionar as condições ideais equivalentes aquelas encontradas no ambiente intra-útero. Portanto, esta alteração na quantidade de massa muscular evidente em prematuros Tardios e lactentes que nasceram com Baixo Peso pode ter como consequências contrações musculares pouco efetivas ou descoordenadas refletindo um movimento com mais acelerações e desacelerações a fim de compensar este déficit de contração muscular pela menor quantidade de fibras musculares.

Ao analisarmos a variável Índice de Ajuste, que também apresentou-se mais elevada nos grupos Baixo Peso e Prematuro Tardioque nos lactentes com Peso adequado e nos A termos, caracterizando um maior tempo gasto após o Pico de Velocidade até tocar o objeto, demonstrando que esses lactentes de Baixo peso e prematuros Tardios necessitam de mais tempo para coordenar o movimento da mão com as informações visuais e proprioceptivas para alcançar adequadamente o objeto. Tal resultado representa que, possivelmente, estes lactentes não amadureceram ou experimentaram adequadamente as fases iniciais do desenvolvimento da coordenação viso-motora que são necessárias para o surgimento do alcance. De acordo com Carvalho \& Tudella (2004), Arias et. al. (2010) e Araújo et. al. (2011), para adquirirem a coordenação olho-mão os bebês necessitam passar por quatro etapas principais: a primeira, o lactente olha a mão com interesse mas não é capaz de modificar os movimentos dos membros superiores para que elas permaneçam no campo visual; em seguida, na segunda etapa os lactentes conseguem manter mais temposuas mãos em seu campo visual a partir de uma maior ativação de dedos e membros superiores; a terceira etapa caracteriza-se por alguns movimentos de alcance desde que sua mão e objeto sejam vistos simultaneamente no mesmo campo visual; e por fim a quarta fase ocorre com mais ou menos 4 meses e o lactente inicia o alcance funcional com maior controle entre a coordenação do membro superior e as informações visuais do objeto (CARVALHO E TUDELLA, 2004, ARIAS et. al., 2010, ARAÚJO et. al., 2011). Ao considerar que os lactentes prematuros Tardios e com baixo pesodo presente estudo tiverem de prolongar o tempo de desaceleração da mão para tocar o objeto com sucesso, parece que alguma destas etapas citadas não 
foram adequadamente experimentadas causando uma alteração na coordenação visuomanual e fazendo-os encontrarem esta estratégia de prolongar o tempo de desaceleração da mão para conseguir tocar o objeto de interesse completando o movimento de alcance.

Além disso, outros estudos que avaliaram crianças prematuras e que nasceram com baixo peso em diversas idades, inclusive na pré-escolar, que é a fase que melhor reflete estes aspectos, também concluíram que esta população possui déficits de coordenação visuo-motora, reforçando esta teoria. (CAÇOLA E BOBBIO, 2010). Acrescenta-se ainda, a partir destes resultados, a possibilidade de se criar a hipótese de que estas alterações no alcance manual possam ser os primeiros sinais de problemas no desenvolvimento da coordenação olho-mão de lactentes prematuros Tardiosou que nasceram com baixo peso.

Resultado semelhante na variável Índice de Ajuste foi encontrado no estudo de Toledo \& Tudella (2008), o qual analisaram variáveis cinemáticas de lactentes prematuros de baixo risco, ou seja, nascidos entre 32 e 36 semanas e com peso ao nascer maior que 2500g. Os autores atribuiram este resultado ao fato destes prematuros terem adotado como estratégia para realização do alcance o aumento do tempo de desaceleração da mão para suprir as restrições intrínsecas de percepção, coordenação olho-mão e de integração viso-motora que são comunsnesses prematuros. Porém, no presente estudo este resultado não foi encontrado somente no grupo prematuro Tardio, mas também apresentou-se no grupo de prematuros nascidos com baixo peso, evidenciando que as restrições citadas e esta estratégia de desaceleração também foram encontradas nestes lactentes.

$\mathrm{Na}$ comparação entre os grupos Peso Adequado e Muito Baixo Peso foi verificado que o grupo Muito Baixo peso apresentaram menor Índice de Retidão e maior Velocidade Inicial e de Pico que os lactentes com peso adequado. Estes resultados indicam que mesmo apresentando valores de velocidade inicial mais altos o grupo Muito Baixo Peso apresentam Índice Retidão menor, o que caracteriza um movimento rápido porém menos fluente e preciso.

Apesar da variável Velocidade Média não ter resultado em diferença significativa entre os grupos, podemos entender que o grupo Muito Baixo Peso apresenta um movimento mais rápido de alcance, pois quando percebemos que sua 
trajetória foi mais tortuosa (aumento do Índice de Retidão) consequentemente seu deslocamento foi maior, considerando que o cálculo da velocidade média é o delta da trajetória sobre o delta do tempo, havendo uma trajetória maior espera-se, através do cálculo, uma Velocidade Média consequentemente maior por serem valores diretamente proporcionais. E ainda, ao analisarmos de forma geral os valores de mediana da velocidade média dos grupos, é possível observar que o grupo Muito Baixo Peso é o que apresenta maiores valores. Portanto, mesmo não resultando em diferenças significativas pode-se considerar que a velocidade média do grupo Muito Baixo Peso foi maior.

A velocidade inicial apresentou-se elevada nesta população de Muito Baixo Peso quando comparado com grupo Peso Adequado, fato que também ocorreu no grupo Muito Prematuro em relação ao grupo A termo. Este resultado pode ter sido consequente a baixa massa magra também característica dos lactentes prematuros de Muito Baixo Peso. Em uma revisão sistemática da literatura que avaliou a composição corporal de lactentes prematuros de 8 estudos (733 crianças), com idade gestacional média de 30 semanas e peso ao nascer médio de 1,18 quilos, evidenciou que os esses pré-termos apresentam déficit significativo de massa magra em sua composição corporal (JOHNSON et. al., 2012). Outros estudos têm demonstrado que lactentes que nasceram com menos de $1500 \mathrm{~g}$ apresentam crescimento linear e ganho de massa magra diminuídos ao longo do tempo e de forma mais evidente que os nascidos com baixo peso (GABRIEL et. al., 2009; JOHSON et. al., 2012; PFISTER E RAMEL, 2014). E, ainda, comprovou-se que prematuros que tiveram mais doenças ou complicações ao longo da internação hospitalar apresentaram menor massa magra aos 4 meses de idade (RAMEL et. al., 2011). Ao analisarmos as intervenções sofridas pelos grupos Muito Prematuroe Muito Baixo Peso podemos observar que a maioria de ambos os grupos os lactentes foram submetidos a ventilação mecânica (GMP 81\%; GMBP 53\%), apresentaram infecção neonatal (GMP 81\%; GMBP 66\%) e necessitaram de fototerapia (GMP 100\%; GMBP 80\%), tornando-se mais um fator influenciador de menor massa magra.

Segundo Gabriel et. al. (2009) afirmam que devido a massa muscular muito diminuída esta população de lactentes nascidos com muito baixo peso podem realizar padrões de contração muscular atipicas e de vários grupos musculares ao mesmo tempo, gerando como consequência uma contração muscular dessincronizada e 
exacerbada. O que se evidenciou nos presentes resultados, onde estes lactentes realizaram um movimento inicial mais rápido porém impreciso por ter apresentado associado um Índice de retidão baixo.

Além da menor massa muscular presente nesta população, outro fator dificultador de um movimento harmônico são as evidências de que estes lactentes Muito Prematuros e de Muito Baixo Peso apresentam uma hipertonia transitória da musculatura de cintura escapular. Segundo Georgieff \& Bernbaum (1986), prematuros que nasceram com peso menor que $1750 \mathrm{~g}$ apresentaram retração escapular, na qual avaliaram como uma hipertonia muscular, durante o primeiro ano de vida. Esta condição da musculatura escapular dificulta o início do movimento pois a retração escapular impossibilita iniciar um movimento de abdução escapular e propulsão do ombro para a realização do alcance. Possivelmente, esta hipertonia escapular somadaa uma baixa quantidade de massa magra induziuesses lactentes a utilizarem o aumento da velocidade inicial como estratégia para conseguirem vencer a retração da escápula e realizar o movimento, gerando uma impulsão do braço.

Seguindo uma trajetória com um movimento inercial rápido e incoordenado por estas contrações musculares deficitárias, provavelmente não houve um controle muscular adequado para harmonizar o movimento e controlar as velocidades, consequentemente atingiram uma velocidade de pico também elevada, o que ocorreu com os lactentes do grupo Muito Baixo Peso (GABRIEL et. al., 2009).

Associado a esta contração desorganizada a nível muscular, há também uma característica estrutural a nível cerebral dos lactentes nascidos com Muito Baixo Peso e dos Muito Prematuros que é o subdesenvolvimento do cerebelo. Segundo estudos, o desenvolvimento cerebelar passa por um pico de desenvolvimento entre o segundo e o terceiro trimestre de gestação, onde há aumento de quase 5 vezes em relaçãoas demais partes do cérebro: a partir da $28^{\mathrm{a}}$ semana há um aumento de 3,5 vezes de volume, a área de superfície do córtex cerebelar aumenta em quase 30 vezes partir da $24^{\mathrm{a}}$ semana e a partir da $30^{a}$ semana a diferenciação das células cerebelares esta em pico (VOLPE, 2009). O nascimento muito prematuroacarreta no subdesenvolvimento do cerebelo com diminuição do volume e alterações na substância branca cerebelar em idade corrigida. Além da prematuridade, há evidências que o peso neonatal tem correlação direta com o volume cerebelar e, ainda, que uso de corticoides e a intubação precoce também são fatores adicionais que influenciam a diminuição da 
proliferação da células da camada externa do cerebelo (EVENSEN et.al., 2003; VOLPE, 2009; ZWICKER et. al., 2013). Quanto menor a idade gestacional e o peso ao nascimento há tendência de uma maior diversidade de intervenções intrahospitalares e tempo de internação, aumentando os riscos de serem submetidos aos diferentes procedimentos neonatais (TRONCHIN E TSUNECHIRO, 2007), inclusive as intervenções acima citadas.

Analisando o grupo de Muito Prematuros observa-se que a idade gestacional média é de 29 semanas e 1 dia, ou seja, nasceram no momento que o cerebelo estava em pleno desenvolvimento e proliferação, e também constata-se que $81 \%$ foram submetidos a ventilação mecânica no período neonatal. Não muito dferente é o grupo de lactentes nascidos com muito baixo peso, o qual 53\% necessitaram de ventilação mecânica durante a internação hospitalar. Portanto, é evidente que os lactentes de ambos os grupos possuem fatores condicionantes de um subdesenvolvimento cerebelar. Este fato sugeri que esses lactentes podem apresentar distúrbios de cerebelo que caracteriza-se pela má capacidade de planejamento motor e aprendizagem, baixo controle de tônus muscular e de aprimoramento das atividades motoras automáticas, comuns nas atividades funcionais (EVENSEN et.al., 2003; SHAH et. al., 2006; VOLPE, 2009; ZWICKER et. al., 2013).

Analisando somente as variáveis do grupo nascido com Muito Baixo Peso o subdesenvolvimento cerebelar esclarece as características do alcance encontradas, onde os lactentes realizam um movimento rápido (velocidade inicial e de pico alta, maior mediana de velocidade média) mas sem um índice de retidão alto, ou seja, movimento tortuoso. Considerando as funções do cerebelo e se há alteração do mesmo, é possível inferir que o planejamento do movimento esta deficitário, com baixo controle ou alteração de tônus muscular, de destreza manual e deficiência em automatizar tarefas motoras aprendidas, pois todas estas são funções do cerebelo (EVENSEN et.al., 2003; SHAH et. al., 2006; VOLPE, 2009; ZWICKER et. al., 2013).

Portanto, sugere-se que o alcance dos lactentes de Muito Baixo Peso caracteriza-se por apresentar maiores valores de velocidade inicial a fim de vencer as limitações intrínsecas, como a diminuição de massa magra e hipertonia de cintura escapular, e ao longo da trajetória apresenta um movimento com baixo controle e com poucos ajustes pois apresenta uma velocidade de Pico elevada e com inadequado 
planejamento motor verificado pelo índice de retidão baixo (movimento tortuoso), ambos consequente do subdesenvolvimento cerebelar pós-natal.

Já ao analisarmos as características do alcance do grupo de Muito Prematuros a alteração cerebelar é sugestiva na variável Índice de Retidão que apresentou valor baixo, pois o movimento não é adequadamente ajustado ao longo da trajetória, evidenciando um planejamento e aprendizado motor deficitários. $\mathrm{O}$ alcance acontece inicialmente de maneira rápida mas com poucos ajustes ao longo da trajetória (pouca ação de cerebelo), pois não é um movimento retilíneo e não há controle das velocidades, caracterizando também um planejamento motor da tarefa inadequado.

Ao compararos lactentes do grupo Baixo Peso com o grupo Muito Baixo Peso pode-se observar diferenças nas velocidades médias e de pico, nas quais os lactentes com baixo peso apresentaram valores mais baixos. Estes resultados se assemelham com os achados dos Peso Adequado com os Muito Baixo Peso, reforçando as características cinemáticas do alcance dos lactentes desse último, os quais apresentam um movimento mais rápido que não significa que seja mais flúido e preciso.

A velocidade média e de pico dos Muito Baixo Peso foi significativamente maior, sugerindo que esses lactentes com baixo peso apresentam maior controle do movimento de alcance através das velocidades. Associado a isto, na variável Índice de Ajuste entre os grupos apresentou valor de $\mathrm{p}=0,020$ o que não é significativo, mas é clinicamente importante para entendermos as diferenças de comportamento motor entre os lactentes nascidos com baixo peso. Considerando esta variável na comparação pode-se perceber que diferente dos lactentes com muito baixo peso que não controlam a velocidade do braço ao longo da trajetória, o grupo baixo peso parece utilizar a desaceleração da mão como estratégia de controle do movimento e sucesso do alcance. Esta ausência de controle da velocidade e de estratégia de desaceleração do braço sugerem que o planejamento e o ajuste ao longo do movimento que são tarefas exercidas principalmente pelo cerebelo, o que tende a reforçar os déficits cerebelares presentes nos lactentes de Muito Baixo Peso quando comparadas com o Baixo Peso (SHAH et. al., 2006; VOLPE, 2009; ZWICKER et. al., 2013).

Ainda analisando o Índice de Ajuste, que foi a única variável na comparação entre os prematuros que apresentou diferença significativa, na qual os muito prematuros apresentaram menores valores que as prematuros tardios, resultado semelhante ao encontrado entre os baixo peso. Uma possível explicação para ambos 
os grupo (muito baixo peso e Muito Prematuro) não terem utilizados a mesma estratégia de desaceleração utilizada pelo baixo peso é devido déficit sensorial ainda mais exacerbados nesses lactentes. Segundo Cabral et. al. (2015), que avaliaram prematuros com idade gestacional média de 31,3 semanas e com peso médio ao nascer $1506 \mathrm{~g}$ constataram que quanto maior a sobrecarga de estímulos sensoriais nas internações neonatais maiores as chances de alterar as respostas das crianças aos estímulos sensoriais. Como analisado anteriormente, os lactentes muito prematuros e os nascidos com muito baixo peso da presente amostra foram submetidos em mais intervenções que os grupos prematuro tardio e baixo peso, culminando em maior sobrecarga sensorial.

Além disso, Segundo Caçola \& Bobbio (2010) os prematuros de Muito Baixo Peso aumentam a velocidade do movimento no intuito de compensar a falta de integração das informações proprioceptivas e de visão, o que caracteriza adequadamente os resultados encontrados: uma velocidade média e de pico aumentada associada a um alto do Índice de Ajuste.

Wang et. al. (2014) examinaram a função manual dos prematuros com idade gestacional média de 29,3 semanas e com peso ao nascimento médio de 1134,9 gramas entre 6 e 24 meses de idade e constataram que estes lactentes apresentam função manual prejudicada a partir dos 6 meses que piora até os 12 meses de idade corrigida. Além destes autores, outros estudos também encontraram uma piora da função manual de lactentes nascidos prematuros com menos de $1500 \mathrm{~g}$ e as explicações são diversas, além das questões cerebelares, da baixa área de massa magra e do déficits sensoriais mais evidentes nesta população, também apresentam baixo perimetro cefálico que atribui-se a uma diminuição de massa cerebral e alta incidência de dispraxia (GABRIEL et. al., 2009; AHMAD et. al., 2010; CAÇOLA E BOBBIO, 2010; RAMEL et. al., 2011; PFISTER E RAMEL, 2014). A partir dos resultados desses estudos, é possível constatar que as características cinemáticas do movimento de alcance dos muito prematuros e dos nascidos com muito baixo peso são ineficazes para uma função manual adequada. Considerando que o presente estudo foi realizado aos 6 meses de idade corrigida, estas características apresentadas pelos lactentes prematuros e de muito baixo peso podem ser as primeiras alterações cinemáticas do alcance que configuram a piora da função manual, podendo servir de base para parâmetros de avaliação e intervenção precoce nesta população. 
A piora motora dos pramaturos com Muito Baixo Peso em relação aos Baixo Peso não se limita apenas as funções manuais. Segundo Kieviet et. al. (2009) e Watkins et. al. (2014) maior peso ao nascer e maior idade gestacional estão relacionado a melhora psicomotora durante o desenvolvimento. Estes dados corroboram com nossos achados da AIMS, no qual os lactentes com Muito Baixo Peso apresentaram piores escores sugerindo que o peso ao nascer é determinante para um desempenho motor inferior. Van Haastert et. al. (2006) utilizaram em seu estudo a AIMS em 800 prematuros com idade gestacional média de 29 semanas e peso ao nascimento médio de $1194 \mathrm{~g}$, a fim de analisar o desenvolvimento motor bruto ao longo dos 18 meses e constataram que os fatores como insuficiente crescimento pósnatal, baixa maturação cerebral (principalmente de cerebelo) e menor tamanho muscular são os fatores influenciadores para uma baixa pontuação na AIMS, os quais possivelmente estão todos presentes nos lactentes prematuros de Muito Baixo Peso do presente estudo.

Considerando aspectos cerebrais, estudos também sugerem que lactentes de muito baixo peso apresentam menores valores de perímetro cefálico no qual relacionam a uma menor massa cefálica e atribuem este fato a um risco aumentado de déficit no neurodesenvolvimento com uma vunerabilidade significativa em córtex sensorio-motor (LAFEBER et. al., 2013; PFISTER E RAMEL, 2014). Este fato foi correlacionado a aquisições de várias habilidades motoras de forma tardia pela população de Muito Baixo Peso (GABRIEL et. al., 2009).

Porém não podemos atribuir o pior desempenho motor somente ao fator do peso ao nascimento, pois apesar de não ter se revelado diferenças significativas no percentil da AIMS, a idade gestacional comprovou-se através do Risco Relativo positivo, ser um característica intrínseca determinante para a ocorrência de 2,8 vezes (ODDS RATIO) mais chance de aparecimento de atrasos motores nos Muito prematuros. Um estudo de Jeng, Yau \& Teng (1998) avaliaram os fatores de risco neonatais para comprometimentos neuromotores de lactentes com peso médio ao nascer de 1109 gramas e idade gestacional média de 29,8 semanas e constataram que os valores de ODDS RATIO altos estavam presentes em lactentes que fizeram uso de oxigenioterapia e ventilação mecânica. Ambas intervenções presentes na maioria das internaçõesdos muito prematuros $81 \%$ necessitaram de ventilação mecânica $63 \%$ em 
algum momento da internação precisaram de oxigênio suplementar, portanto, esses fatores corroboraram com os achados do estudo citado.

Este pior desempenho motor apresentado pela população nascida com Muito Baixo Peso e prematura não se limita apenas a primeira fase do desenvolvimento motor, já comprovou-se que 1 a cada 4 crianças nascidas com menos de $1500 \mathrm{~g}$ apresentam problemas motores aos 14 anos (EVENSEN et. al., 2003); possuem 6-8 vezes mais chance de apresentar dispraxia interfirindo nas suas tarefas motoras diárias (ZWICKER et. al., 2013); e mesmo que mantenham um desempenho motor estável depois dos primeiros anos, na idade pré-escolar podem voltar a apresentar pior desempenho motor (KIEVIET, 2009).

Há diversas evidências que os prematuros nascidos com Baixo Peso também apresentam maiores chances de atrasos no desenvolvimento motor em relação aos nascidos com mais de 2500g (CAÇOLA E BOBBIO, 2010), fato que não ocorreu no presente estudo pois o Risco Relativo $(<1)$ de apresentar atraso motores a partir da AIMS não foi observado entre os nascidos com Peso Adequado e com Baixo Peso e nem diferenças entre os percentis da escala. Atribui-se a este resultado o fato de todos os lactentes prematuros deste estudo serem participantes de um projeto de fallow-up de desenvolvimento motor do qual foram recrutados, lá os responsáveis pelos lactentes são orientados a estimulá-los conforme seu desenvolvimento motor do momento da consulta a partir da avaliação da AIMS, isto a partir da primeira consultaapós internação hospitalar até a marcha independente. Considerando que a interação dinâmica entre o corpo e o ambiente são determinantes para realização de tarefas motoras, as restrições ambientais (que podem ser favoráveis ou desfavoráveis) podem causar diferenças no desempenho motor e na taxa de aquisição motora dos lactentes (CABRAL et. al., 2015). Portanto, é possível sugerir que as orientações aos pais neste projeto de acompanhamento de prematurostem surtido efeito positivo nos lactentes nascidos com Baixo Peso aos 6 meses de idade corrigida pois não apresentaram aumento de risco de atraso motor.

Em contrapartida, os lactentes nascidos com menos de $1500 \mathrm{~g}$ que também são acompanhados neste mesmo projeto de fallow-up apresentaram 3,73 (ODDS RATIO) vezes mais chances de apresentarem atrasos motores em relação aos nascidos com mais de $2500 \mathrm{~g}$ a termo. Primeiramente, este fato nos esclarece que este efeito positivo de orientações aos pais do desenvolvimento motor não pode ser percebido nessa 
população, sugerindo que apenas as orientações de estímulos aos pais não são sucifientes para compensar as restrições intrínsecas presentes nestes lactentes. Ainda assim, não podemos desconsiderar que estes lactentes possuem maiores chances de apresentarem internação prolongada devido a maior dificuldade de ganho de peso após o nascimento e maior incidência de complicações pós-natais, o que pode ter influenciado noinício tardio no programa de fallow-up, com isso tiveram menor número de consultas até os 6 meses de idade corrigida e menos tempo de estimulação pelos pais sob orientação profisional para compensar possíveis atrasos. De qualquer maneira, é notório a partir destes dados que lactentes nascidos com muito baixo peso devem ter atenção especial em programas de fallow-up e ainda deve-se considerar o encaminhamento imediato a programas de intervenção precoce após alta hospitalar para auxiliar nas aquisições destas primeiras habilidades, como o alcance manual. 


\section{CONCLUSÃO}




\section{CONCLUSÃO}

A partir dos resultados do presente estudo é possível concluir que os lactentes nascidos com baixo peso apresentam um alcance com mais acelerações e desacelerações, mais tortuoso e com mais tempo de desaceleração da mão que os lactentes que nasceram com peso adequado, caracterizando um alcance mais imaturo e possivelmente decorrente de déficits sensorias. Já os lactentes nascidos com muito baixo peso apresentam um alcance com velocidade inicial e de pico altos e um movimento tortuoso, possivelmente consequente da baixa massa magra, subdesenvolvimento cerebelar e hipertonia de cintura escapular, típicos nestes lactentes.

Os prematuros tardios apresentam um alcance similar ao lactente de baixo peso do presente estudo, sugerindo semelhanças nas restrições intrísecas dos grupos. E o movimento de alcance dos muito prematuros é pouco fluente e possui velocidade inicial alta, também devido a baixa massa magra e a uma ação de cerebelo deficitária nos ajustes motores necessários.

Os grupos Muito Baixo Peso e Muito Prematuros tiveram um risco relativo alto de apresentarem atrasos motores, determinados pelas restrições intrínsecas desses lactentes e pelas intervenções neonatais sofridas devido ao uso de oxigênio suplementar e da ventilação mecânica. 


\section{IMPLICAÇÕES CLÍNICAS}




\section{IMPLICAÇÕES CLÍNICAS}

A partir dos resultados e analises do presente estudo verifica-se a necessidade de uma estimulação visual associada a treino de alcance para os lactentes prematuros tardios e nascidos com baixo peso, isto para tentar diminuir os déficits visuais e proprioceptivos que podem estar presentes nesta população. Mesmo que esses lactentes tenham encontrado estratégias em alterar o movimento de alcance para superar essas restrições intrínsecas, com a estimulação precoce pode tornar o movimento de alcance deles mais preciso e fluido. Para a estimulação visual e de alcance pode ser utilizado objetos com cores de contraste, como preto e branco, e iniciar durante as fases de aquisição do alcance entre 2 e 4 meses. Esta estimulação pode ser realizada pelos próprios pais sob orientação profissional ou por executada por fisioterapeutas ou terapeutas ocupacionais.

Quanto aos lactentes muito prematuros e os nascidos com muito baixo peso, observou-se alterações do movimento cinemático do alcance, sem estratégias apropriadas para vencer as restrições intrínsecas, ou seja, aos 6 meses de idade corrigida esses lactentes já encorporaram estas alterações de movimento para a habilidade do alcance. E por isto, sugere-se a intervenção precoce nesses lactentes, também antes da aquisição do alcance (por volta dos 2 meses de idade) realizando treinos específicos de alcance manual, como os utilizados no estudo de Greco, Soares e Tudella (2013). Além disso, é também necessário agregar a estes treinos estimulações sensoriais mais diversas possíveis (visual, tátil, auditiva), já que também apresentam déficits sensoriais significativos.

Associando o movimento de alcance com o comportamento motor geral avaliado pela AIMS, pode-se sugerir que os lactentes nascidos com muito baixo peso e muito prematuros necessitam de intervenção precoce e imediata, tanto para a aprendizagem da habilidade de alcance manual quanto para estimulação adequada de habilidades motoras grossas. E os lactentes nascidos com baixo peso e prematuros tardios podem se desenvolver adequadamente com um suporte profissional de orientação aos pais e monitoramento do desenvolvimento. 
LIMITAÇÕES DO ESTUDO 


\section{LIMITAÇÕES DO ESTUDO}

Ressalta-se como limitação do presente estudo a impossibilidade de se ter uma amostra com restrições intrínsecas isoladas, por exemplo lactentes prematuros nascidos com peso adequado ou lactentes nascidos com baixo peso mas a termo. Pois há uma dificuldade em se ter lactentes muito prematuros sem terem nascidos com baixo peso, ao mesmo tempo que é dificil haver lactentes nascidos com muito baixo peso mas com mais de 37 semanas, em geral essas características inevitavelmente veem associadas. O que tornou inviável ter grupos somente com uma das restrições intrínsecas estudadas. 


\section{REFERÊNCIAS BIBLIOGRÁFICAS}




\section{REFERÊNCIAS BIBLIOGRÁFICAS}

AHMAD, I.; NEMET, D.; ELIAKIM, A.; KOEPPEL, R;GROCHOW, D.; COUSSENS, M.; GALLITTO, S.;JULIA RICH, J.; PONTELLO, A.;SZU-YUN LEU, S.; COOPER, D. M.; WAFFARN, F. Body Composition and Its Components in Preterm and Term Newborns: A Cross-Sectional, Multimodal Investigation. American Journal of humanbiology, Vol 22, p. 69-75, 2010.

ARAÚJO, D. M.; SANDE, L. A. P. S; FERNANDES, L. F. R. M.; PEREIRA, K. Comportamento de lactentes em decúbito lateral e a influência da adição de peso no punho. Con Scientia e Saúde, Vol 10, p. 151- 159, 2011.

ARIAS, A. V.; GONÇALVES, V. M. G.; CAMPOS, D.; SANTOS, D. C. C.; GOTO, M. M. F.; CAMPOS-ZANELLI, T. M. Desenvolvimento das habilidades motoras finas no primeiro ano de vida. Revista de Neurociência, Vol. 18, n. 4, p. 544-554. In press. 2010 .

BARON, I. S.; REY-CASSERLY, C. Extremely Preterm Birth Outcome: A Review of Four Decades of Cognitive Research. Neuropsychol Rev., Vol. 20, p. 430-452, 2010.

BERNSTEIN, N. A. Co-ordination and regulation of movements. New York, Pergamon Press, 1967.

CABRAL, T. I.; SILVA, L. G. P. ; TUDELlA, E. MARTINEZ, C. M. S. Motor development and sensory processing: A comparative study between preterm and term infants. Research in Developmental Disabilities, Vol. 36, p. 102-107, 2015.

CAÇOLA, P.; BOBBIO, T. G. Baixo peso ao nascer e alterações no desenvolvimento motor: a realidadeatual. RevistaPaulista de Pediatria, Vol.28, p.70-6, 2010.

CADORET, G., BEUTER, A. Early development of reaching in Down syndrome infants. Early Human Development, Vol.36, p.157-173, 1994.

CAMPBELL, S. K.; KOLOBE, T. H. A.; WRIGHT, B. D.; LINACRE, J. M. Validity of the Test of Infant Motor Performance for prediction of 6-, 9- and 12-month scores on the Alberta Infant Motor Scale. Developmental Medicine \& Child Neurology, Vol. 
44; p. 263-272, 2002.

CAMPOS, A. C., ROCHA, N. A. C. F., SAVELSBERGH, G. J. P. Reaching and grasping movements in infants at risk: A review. Research in Developmental Disabilities , Vol. 30, p. 819-826, 2009.

CAMPOS, A. C.; FRANCISCO, R. K. GEERT J.P. Savelsbergh, Nelci Adriana Cicuto Ferreira Rocha. How do object size and rigidity affect reaching and grasping in infants with Down syndrome? Research in Developmental Disabilities. Vol., 32 , p. 246-252, 2011.

CARVALHO, R. P. A; TUDELLA, E. Influência da postura corporal no movimento de alcance manual em lactentes de 4 meses de vida. 132 páginas. Dissertação (Mestrado) - Universidade Federal de São Carlos. São Carlos, 2004.

CARVAlHO, R.. P.; TUDELlA, E.; BARROS, R..M.L. Utilização do sistema Dvideow na análise cinemática do alcance manual de lactentes. Revista Brasileira de Fisioterapia; Vol. 9, p. 1-7, 2005.

CARVALHO, R.P.; TUDELlA, E.; SAVELSBERGH, G.J.P. Spatio-temporal parameters in infant s reaching movements are influenced by body orientation. Infant Behavior \& Development, Vol.10, 2007.

CHARITOU, S.; ASONITOU, K.; KOUTSOUKI, D. Prediction of infant's motor development. Procedia Social and Behavioral Sciences, Vol. 9, 2010.

CPOBERTTA, D. Why do infants regress to two-handed reaching at the end of the first year? Infant Behavior and Development, Vol. 21, 1998.

CORBETTA, D., WILLIAMS, J., SNAPP-CHILDS, W. Plasticity in the development of handedness: evidence from normal development and early assimetric brain injury. Developmental Psychobiolgy, Vol. 48, p. 460-471, 2006.

DARRAH, J. PIPER; M.; WATT, Man-Joe. Assessment of gross motor skills of atrisk infants: predictive validity of the Alberta Infant Motor Scale. Developemental medicine \&ChildNeurology, Vol. 40, p. 485-491, 1998. 
EVENSEN, K. A. I.; VILK, T.; HELBOSTAD, J.; INDREDAVIK, M. S.; KULSENG, S.; BRUBAKK, A. M. Motor skills in adolescents with low birth weight. Arch Dis Child Fetal Neonatal, Vol. 89, p. 451-455, 2004.

FALLANG, B.; SAUGSTAD, O. D.; GRØGAARD, J.; HADDERS-ALGRA, M. Kinematic Quality of Reaching Movements in Preterm Infants. Pediatric Research, Vol. 53, n. 5, 2003.

FRÔNIO, J. S.; SILVA, L. M. A.; GONÇALVES, R. J.; CHAGAS, P. S. C.; RIBEIRO, L. C. Influência da posição do objeto na frequência de alcances manuais em lactentes com desenvolvimento típico. Fisioterapia e Pesquisa, Vol. 18, n.2, p. 139-44, 2011.

GABRIEL, M. M. A.; ALONSO, C. R. P.; BÉRTOLO, J. C.; CARBONERO, S. C.; MAESTRO, M. L.; PUMAREGA, M. M.; DÍAZ, C. A.; PABlOS, D. L. Age of sitting unsupported and independent walking in very low birth weight preterm infants with normal motor development at 2 years. Acta Pediatrica, Vo. 98, p. 1815-1821, 2009.

GEORGIEFF, M. K.; BERNBAUM, J. C. Abnormal shoulder girdle muscle tone in preterm infants during their first 18 months. Pediatrics, Vol. 77, p. 664-669, 1986.

GIBSON, E. J. The concept of affordances un development: the renascence of functionalism. In: Collins - The concept of development Minnesota Symposlum on Child Psychology. Hillsdate, Ertbaum, p.55-81, 1982.

GOLDENBERG, R. L.; CULHANE, J. F. Low birth weight in the United States. The American Jornal of Clinical Nutrition, Vol. 85, p. 584S-90S, 2007.

GRAAF-PETERS, V. B., BAKKER, H., VAN EYKERN, L. A., OTTEN, B., HADDERS-ALGRA, M. Postural adjustments and reaching in 4- and 6-month-old infants: an EMG and kinematical study. Experimental Brain Research.Vol.181, p. 647-656, 2007.

GRECO, A. L. R.; SOARES, D. A.; TUDELLA, E. Comparar o efeito de um treino de alcance de curta duração nos ajustes proximais e parâmetros cinemáticos do 
alcance e preensão de lactentes com alterações neurossensoriais. Movimenta, Vol. 6, n. 3, 2013.

GROOT, L. Posture and motility in preterm infants.Developmental Medicine \& Child Neurology, Vol. 42, p. 65-68, 2000.

GUIMARÃES, E. L.; CUNHA, A. B.; SOARES, D. A.; TUDELlA, E. Reaching Behavior in Preterm Infants During the First Year of Life: A Systematic Review. Motor Control. Vol. 17, p. 340-354, 2013.

HADDERS-ALGRA, M., STREMMELAAR, E.F., Towen, B.C.L. Development of postural adjustments during reaching in infants with CP. Developmental Medicine and Child Neurology, Vol.41, p. 766-776, 1999.

HADDERS-AGRA, M. The neuronal group selection theory: a tramework to explanvanation in normal motor development. Development Med. Child. Neurol. Vol. 42, p. 566-573, 2000.

HEATHCOCK, J. C.; LOBO, M.; GALLOWAY, J. C. Movement Training Advances the Emergence of Reaching in Infants Born at Less Than 33 Weeks of Gestational Age: A Randomized Clinical Trial. Physical Therapy, Vol. 88,n. 3, 2008.

KIEVIET, J. F.; PIEK, M. P.; AARNOUDSE-MOENS, C. S.; OOSTERLAAN, J. Motor Development in Very Preterm and Very Low-Birth-Weight Children From Birth to Adolescence. JAMA, Vol. 302, p. 2235-2242, 2009.

KONCZAK, J., DICHGANS, J. The development toward stereotypic arm kinematics during reaching in the first 3 years of life. Experimental Brain Research, Vol. 117, p. 346-354. 1997.

JENG, S.; YAU, K. T; TENG, R. Neurobehavioral developmental at term in very low birth weight infants and normal term infants in Taiwan. Early Human Development, Vol. 51, p. 235-245, 1998.

JOHNSON, M. J.; WOOTTON, S. A.; LEAF, A. A.; JACKSON, A. A. Preterm Birth 
and Body Composition at Term Equivalent Age: A Systematic Review and Metaanalysis. PEDIATRICS, Vol. 130, n. 3, 2012.

KAMM, K.; THELEN, E.; JENSEN, J.A dynamical systems approach to motor behavior connections. Child Develop. Vol. 64, p.953-959, 1993.

LAFEBER, H. N.; LAGEMAAT, M.; ROTTEVEEL, J.; WEISSENBRUCH, M. Timing of nutritional interventions in very-low-weight infants: optimical neurodevelopment compared with the onset od the metabolic syndrome. The American Journal of Clinical Nutrition, Vol.98, 2013.

LAGASSE, L.L., VAN VORST, R.F., BRUNNER, S.M., LESTER, B.M. Effects of in utero exposure to cocaine and/or opiates on infant's reaching behavior. Annals of New York Academy of Sciences, Vol. 846, p.405-407, 1998.

LOCKMAN, J. J.; THELEN, E.A dynamical systems approach to motor development. Phycal Therapy. Vol. 70, n. 12, p. 763-775, 1990.

LOCKMAN, J. J.; THELEN, E. Developmental bodynamics brain, body, behavior connections. Child Development. Vol. 64, p. 953-959, 1993.

MATHEW, A., COOK, M. The control of reaching movements by young infants. Child Development. Vol. 61, p. 1238-1257, 1990.

McGRAW, M. B.The neuromuscular maturation of the human infant. New York, Halther, 1995.

McDONALD, P.V.; vanEMMERICK, R.E.A.; NEWELL,K.M. The effects of practice on limb kinematics in a throwing task.Journal of Motor Behavior, Vol. 21, n. 3, p.245-264, 1989.

NEWELL, K. M. Constrants on the development of coordination. In: Wade, M. G. e Whiting, H. T. A. (ed.) - Motor development in children: aspects od coordination and control. Boston, Martin Nighoff, p. 341-356, 1986.

NEWTON, R. A. Controle Motor. In. Umphred, A. D. - FisioterapiaNeurológica, São Paulo, Manole, p. 43-51, 1994. 
ORGANIZAÇÃO MUNDIAL DE SAÚDE . Nota descriptiva N`363 de novembro de 2013. Disponível em: < http://www.who.int/mediacentre/factsheets/fs363/es/>. Acesso em: 13 de maio de 2015.

ORGANIZAÇÃO MUNDIAL DE SAÚDE. Assembléia Mundial de Saúde. Resoluções WHA20.19 e WHA43.24, de acordo com o Artigo 23 da Constituição da Organização Mundial da Saúde. Disponível em: <http://www.datasus.gov.br/cid10/V2008/WebHelp/definicoes.htm > Acesso em: 13 de maio de 2015.

OUT,L; et al. The effect of posture on early reaching movement. Journal of Motor Behavior.Vol. 30, p.260-272, 1998.

PFISTER, K. M.; RAMEL, S. E. Linear Growth and Neurodevelopmental Outcomes. Clin Perinatology, Vol. 41, p. 309-321, 2014.

PLANTINGA, Y., PERDOCK, J., DE GROOT, L. (1997). Hand function in low-risk preterm infants: Its relation to muscle power regulation. Developmental Medicine and Child Neurology, 39(1), 6-11.

PIPER, M.C.; PINNELL, L.E.; DARRAH, J.; MAGUIRE, T.; BYRNE, P.J. Construction and validation of the Alberta Infant Motor Scale (AIMS). Journal Article, Research Support, Vol. 83, p. 46-50, 1992.

PIPER, M.C; DARRAH, J. Motor Assessment of the Developing Infant. Elsevier Health, Philadelphia WB: SaundersCompany;1994.

PRECHTL, H. F. R., \& BEINTEMA, D. J.The neurological examination of the fullterm newborn infant.Clinics in development medicine. London: Lavenham Press, 1964.

RAMEL, S. E.; GRAY, H. L.; ODE, K. L.; YOUNGE, N.; GEORGIEFF, M. K.; DEMERATH, E. W. Body Composition Changes in Preterm Infants Following Hospital Discharge: Comparison With Term Infants. Journal of Pediatric Gastroenterology and Nutrition, Vol. 53, n. 3, 2011.

REED, E. S. An outline of a theory of action systems. Jornal Motor Behavior.Vol. 14, 
n. 2, p.95-134, 1982.

RESTIFFE, A. P.; GHERPELLI, L. D. Comparison of Chronological and Corrected Ages in the Gross Motor Assessment of Low-risk Preterm Infants during the first year of life. Arquivo de Neuropsiquiatria, Vol. 64, p.418-425, 2006.

ROCHA, N. A. C. F.; TUDELLA, E. Teorias que embasam a aquisição das habilidades motoras do bebê. Desenvolvimento. Vol. 11, n. 66, p.5-11, 2003.

ROCHA, N. A. C. F.; SILVA; F. P. S.; TUDELLA, E. Influência do tamanho e da rigidez dos objetos nos ajustes proximais e distais do alcance de lactentes. Revista Brasileira Fisioterapia. Vol. 10, n. 3, p. 263-269, 2006.

ROCHAT, P.; SENDERS, S. J. Active touch in infancy: action systems in development. In: Weis, M.J. S. e Zelazo, P. R. (ed.). Newborn attention: biological and the influence of experience. New Jersey, Ablex Publishers, p. 412-442, 1991.

SACCANI, R.; VALENTINI, N. C. Reference curves for the Brazilian Alberta Infant Motor Scale: percentiles for clinical description and follow-up over time. Jornal de Pediatria, Vol. 88, p.40-47, 2012.

SACCANI, R.; VALENTINI, N. C. Cross-cultural analysis of the motor development of Brazilian, Greek and Canadian infants assessed with the Alberta Infant Motor Scale. Revista Paulista de Pediatria. Vol. 31, p. 350-358.

SACCO, S.; MOUTARD, M.L.; FAGARD, J. Agenesis of the corpus callosum and the establishment of handedness. Developmental Psychobiology, Vol. 48, p. 472-481, 2006.

SAMPIERI, R. H.; COLLADO, C. F.; LUCIO, M. P. B. Metodologia de Pesquisa. $5^{\circ}$ Edição. São Paulo: Penso Editora, 2013. 624 páginas.

SANTOS, D. C. C.;CAMPOS, D.; GONÇALVES, V. M. G.;MELlO, B. B. A.; CAMPOS, T. M.; GAGLIARDO, H. G. R. G. Influência do baixo peso ao nascer sobre o desempenho motor de lactentes a termo no primeiro semestre de vida. Revista Brasileira de fisioterapia, Vol. 8, No. 3, p. 261-266, 2004. 
SCHUETZE, P., CROFF, S.L., DAS EINDEN, R. The development of motor assimetries in one-month-old infants who were prenatally exposed to cocaine.Laterality, Vol. 8, p.79- 93, 2003.

SHAH, D. K.; ANDERSON, P. J.; CARLIN, J. B.; PAVLOVIC, M.; HOWARD, K.; THOMPSON, D. K.; WARFILED, S. K.; INDER, T. E. Redution in cerebellar volumes in preterm infants: relationship to white matter injury and neurodevelopment. Pediatric Research, Vol. 60, p. 97-102, 2006.

SILVA, F. P. S.; ROCHA, N. A. C.; TUDELLA, E. Tamanho e rigidez dos objetos influenciam os ajustes proximais e distais do alcance de crianças? Revista Brasileira Fisioterapia, Vol. 15, n. 1, p. 37-44, 2011.

THELEN, E.; FISHER, D. M. Newborn stepping: an explanation for a disappearing reflex. Develop. Psychol. Vol. 18, p.760-775, 1982.

THELEN, E.; KELSO, J. A. S.; FOGEL, J. A. S. Self-organizing systems and infent motor development. Develop. Rev. Vol. 7, p.39-65, 1987.

THELEN, E. Motor development: a new synthesis. Am. Psychology, Vol. 50, n. 2, p. 79-95, 1995.

THELEN, E; CORBETTA, D.; SPENCER, J.P. Development of reaching during the first year: Role of movement speed. Journal Experimental Psychology Human Percept Perform, Vol. 22, p.1059-1076, 1996.

TOLEDO, A. M. \& TUDELLA, E. The development of reaching behavior in low-risk preterm infants. Infant Behavior Development, Vol. 31, p. 398-407, 2008.

TOLEDO, A. M.; SOARES, D. A.; TUDELLA, E. Proximal and Distal Adjustments of Reaching Behavior in Preterm Infants. Journal of Motor Behavior, Vol. 43, n. 2, 2011. 
TOLEDO, A. M.; SOARES, D. A.; TUDELLA, E. Additional Weight Influences the Reaching Behavior of Low-Risk Preterm Infants. Journal of Motor Behavior, Vol. 44, n. 3, 2012.

TRONCHIN, D. M. R.;TSUNECHIR, M. A. PREMATUROS DE MUITO BAIXO PESO: do nascimento ao primeiro ano de vida. RevistaGaúcha de Enfermagem, Vol. 28, p. 79-88, 2007.

TRONICK, E.Z., FETTERS, L., OLSON, K.L., CHEN, Y. Similar and functionally typical kinematic reaching parameters in 7- and 15-month-old in utero cocaineexposed and unexposed infants. Developmental Psychobiology, Vol. 44, p.168-175, 2004.

TURVEY, M. T.; FITCH, H. L.; TULLER, B. The Bernstein perspective: II. The concept of muscle or coordinative structure. In: Kelson, J. A. S. (ed.) Human motor behavior: an introduction, Hillsdale, LEA, p.239-251, 1982.

USER MANUAL, Qualisys Track Manger, 2011.Disponível em: http://fy.chalmers.se/ f7xiz/TIF081C/QTM-usermanual.pdf>. Acessado em janeiro de 2015.

VanHAASTERT, I. C.; VRIES, L. S.; HELDERS, P. J.; JONGMANS, M. J. Earlygross motor development of preterm infants according to the Alberta Infant Motor Scale. The Jornal of pediatrics. Vol. 149, p.617-622, 2006.

VOLPE, J. J. Cerebellum of the Premature Infant: Rapidly Developing, Vulnerable, Clinically Important. Journal of Child Neurology, Vol. 24, n. 9, 2009.

WATKINS, S.;JONSSON-FUNK, M.; BROOKHART, M. A.; ROSENBERG, S. A.; O’SHEA, T. M.; DANIELS, J. Preschool Motor Skills Following Physical and Occupational Therapy Services Among Non-Disabled Very Low Birth Weight Children. Matern Child Health, Vol. 18, p. 821-828, 2014.

WANG, L.; WANG, Y.; WANG, S.; HUANG, C. Using the Alberta Infant Motor Scale to early identify very low-birth-weight infants with cystic periventricular leukomalacia. Brain \& Development, Vol. 35, p. 32-37, 2013. 
WANG, T.; HOWE, T.; LIN, K.; HSU, Y. Hand function and its prognostic factors of very low birth weight preterm children up to a corrected age of 24 months. Research in Developmental Disabilities, Vol. 35, p. 322-329, 2014.ZHOU, H.; HUOSHENG, H.; HARRIS, N. Application of wearable inertial sensors in stroke rehabilitation. Engineering in Medicine and Biology. P. 1-4, Shanghai, China, 2005.

ZWICKER, J. G.; YOON, S. W.; MACKAY, M.; PETRIE-THOMAS, J.; ROGERS, M.; SYNNES, A. R. Perinatal and neonatal predictors of developmental coordination disorder in very low birthweight children. ArchDisChild, Vol. 98, p.118-122, 2013. 
ANEXOS 


\title{
ANEXO 1 - Termo de Consentimento Livre e Esclarecido
}

\section{TERMO DE CONSENTIMENTO LIVRE E ESCLARECIDO}

\author{
LABORATÓRIO DO MOVIMENTO UnB \\ Departamento de Educação Física, Universidade Federal de Brasília
}

Consentimento formal de participação no estudo intitulada“Análise do alcance manual de lactentes pré-termo com baixo e muito baixo peso ao nascer"

Orientadora: Aline Martins de Toledo

$\mathrm{Eu}$, portador (a) do

$\mathrm{RG} \mathrm{n}^{\circ}$......................., residente à

$\mathrm{n}^{\circ}$ bairro: na cidade de

telefone: responsável pelo (a) menor

autorizo a participação de meu (minha) filho (a) na pesquisa "Análise do alcance manual de lactentes pré-termo com baixo e muito baixo peso ao nascer", sob orientação da $\operatorname{Prof}^{\mathrm{a}} \operatorname{Dr}^{\mathrm{a}}$ Aline Martins de Toledo.

\section{Objetivo do estudo:}

A referida pesquisa tem como objetivoverificarcomo ocorre a trajetória do alcance manual em lactentes com baixo peso e prematuros, na idade de 6 meses de vida.

\section{Explicação do procedimento:}

Estou ciente de que na avaliação serei submetida a um questionário acerca dos meus dados gestacionais, dados do nascimento de meu (minha) filho (a) e seus dados atuais de condições de saúde e de comportamento motor. Em seguida, meu (minha) filho (a) será sentado em uma cadeira inclinada a $50^{\circ}$ e sucederão a apresentação a meu (minha) filho (a) de um objeto para analisar se ele realiza o comportamento de alcance manual. Todo este procedimento será filmado por 7 câmeras filmadoras colocadas em tripés.

\section{Beneficios previstos:}

Participando deste estudo, estarei ajudando na descoberta de novos procedimentos que poderão auxiliar as habilidades manuais, e isto trará benefícios para a compreensão acerca do desenvolvimento de bebês e poderá ajudar na orientação das mães sobre como estimular seu (sua) filho (a).

\section{Potenciais riscos e incômodos:}

Fui informado de que o experimento não trará nenhum risco para a saúde de meu (minha) filho (a) e que a identidade dele (a) ou minha não serão reveladas.

\section{Seguro saúde ou de vida:}


Eu entendo que não existe nenhum tipo de seguro de saúde ou de vida que possa vir a me beneficiar em função de minha participação neste estudo.

\section{Liberdade de participação:}

A minha participação neste estudo é voluntária. É meu direito interromper a participação de meu (minha) filho (a) a qualquer momento sem que isto incorra em qualquer penalidade ou prejuízo. Também entendo que a pesquisadora tem o direito de excluir do estudo o (a) meu (minha) filho (a) a qualquer momento.

\section{Sigilo de identidade:}

As informações obtidas nas filmagens deste estudo serão mantidas em sigilo e não poderão ser consultadas por pessoas leigas sem a minha autorização oficial. Estas informações só poderão ser utilizadas para fins estatísticos, científicos ou didáticos, desde que fique resguardada a minha privacidade.

A responsável por este estudo me explicou das necessidades da pesquisa e se prontificou a responder todas as questões sobre o experimento.

Eu estou de acordo com a participação de meu (minha) filho (a) no estudo de livre e espontânea vontade e entendo a relevância dele. Julgo que é meu direito manter uma cópia deste consentimento.

Para questões relacionadas a este estudo, contate:

Aline Toledo - (61) 81199028

Assinatura da mãe ou responsável legal*

Assinatura do pesquisador
Nome por extenso

Nome por extensor

Brasília, de de

(*) Responsável Legal:

Idade:

Grau de parentesco:

Endereço:

Cidade/Estado:

CEP:

Telefones:

RG: CPF: 
ANEXO 2 - Escala AIMS (Alberta Infant Motor Scale)

AIMS - Parte 1

\section{ALBERTA INFANT : MOTOR SCALE : Record Booklet :}

Name

Identification Number

Examiner

Place of Assessment

\begin{tabular}{|l|l|l|l|}
\hline & $\begin{array}{c}\text { Previous Items } \\
\text { Credited }\end{array}$ & $\begin{array}{c}\text { Items Credited } \\
\text { in Window }\end{array}$ & $\begin{array}{c}\text { Subscale } \\
\text { Score }\end{array}$ \\
\hline Prone & & & \\
\hline Supine & & & \\
\hline Sit & & & \\
\hline Stand & & & \\
\hline
\end{tabular}

Total Score

Percentile

Date of Assessment $1 / 1 /$
Date of Birth $/$ / /
Chronological Age
Corrected Age

Corrected Age

Year Month Day

Comments/Recommendations 
AIMS - Parte 2

\section{Alberta Infant Motor Scale}

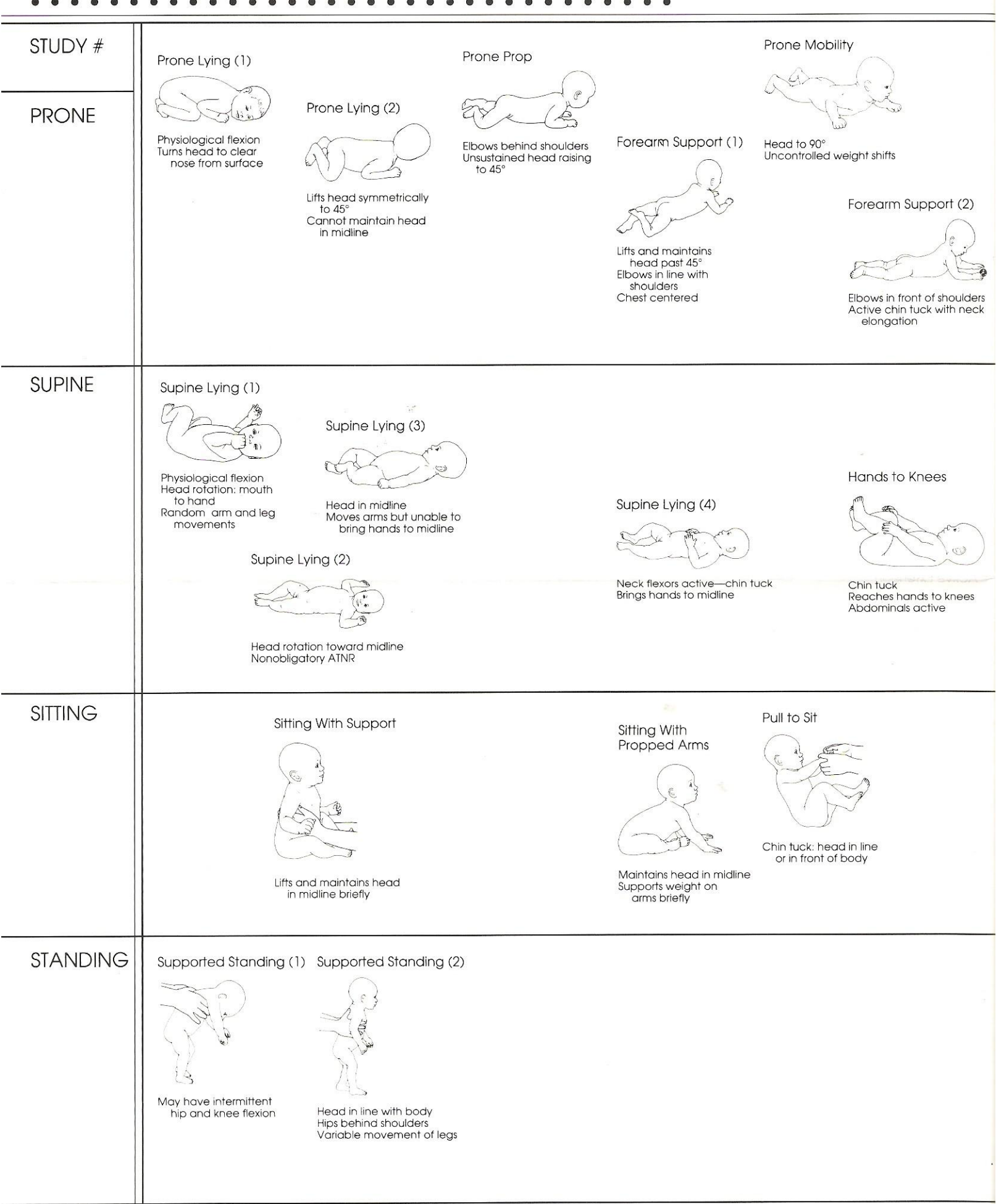


AIMS - Parte 3

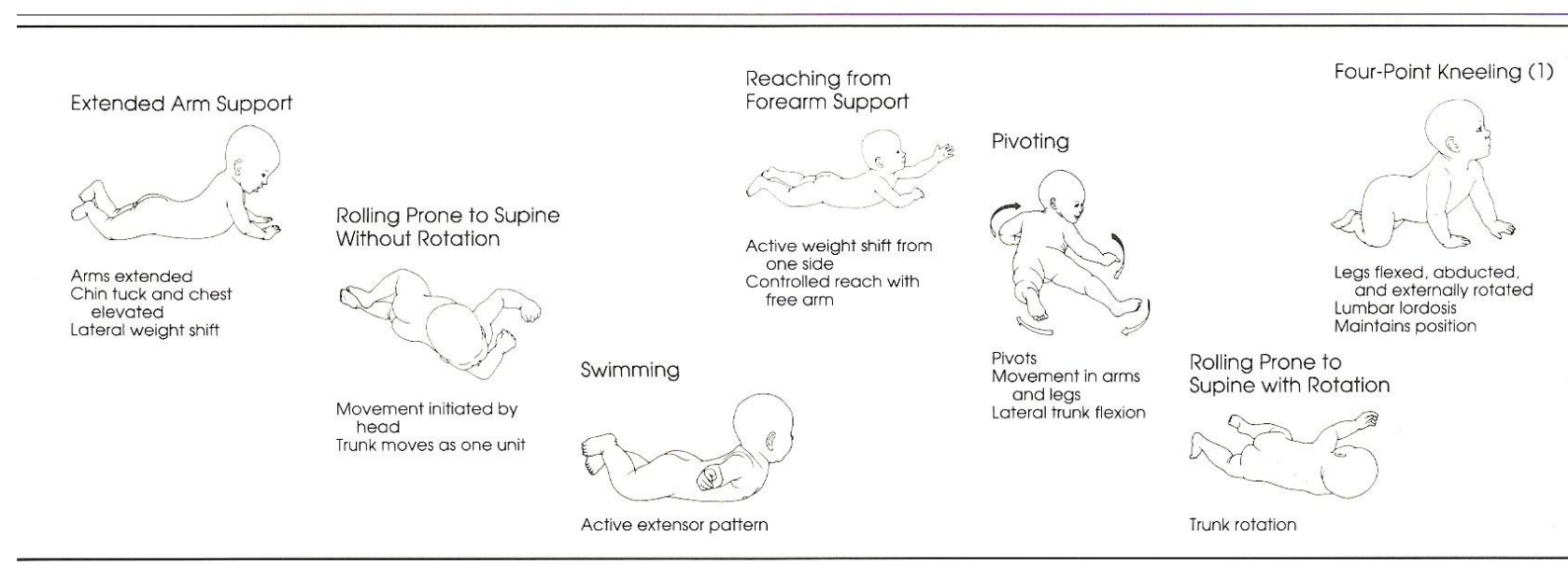

Hands to Feet

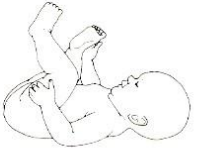

Can maintain legs in

mid-range
Pelvic mobility present

Active Extension

Rolling Supine to Prone

Without Rotation

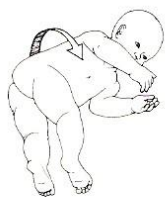

Lateral head righting

Trunk moves as one un
Rolling Supine to Prone with Rotation

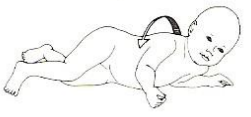

Trunk rotation

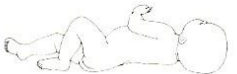

Pushes into extension

with legs

\begin{tabular}{|c|c|c|c|c|c|}
\hline $\begin{array}{l}\text { Scapular adduction } \\
\text { and humeral } \\
\text { extension } \\
\text { Cannot maintain position }\end{array}$ & $\begin{array}{l}\text { Thoracic spine extended } \\
\text { Head movements free } \\
\text { from trunk: propped } \\
\text { on extended arms }\end{array}$ & $\begin{array}{l}\text { Unsustained } \\
\text { Sitting Without } \\
\text { Arm Support } \\
\text { Cannot be left alone } \\
\text { in sitting indefinitely }\end{array}$ & $\begin{array}{l}\text { Weight shift forward, } \\
\text { backward, or sideways } \\
\text { Cannot be left alone } \\
\text { in sitting }\end{array}$ & $\begin{array}{l}\text { Sitting Without } \\
\text { Arm Support (1) } \\
\text { Arms move away } \\
\text { from body } \\
\text { Can play with a toy } \\
\text { Can be lett alone } \\
\text { in sitting }\end{array}$ & $\begin{array}{l}\text { Sits incependently } \\
\text { Reaches for toy with } \\
\text { trunk rotation }\end{array}$ \\
\hline
\end{tabular}

Supported Standing (3)

$\therefore$

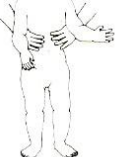

Hips in line with shoulders

variable movements of legs 
AIMS - Parte 4

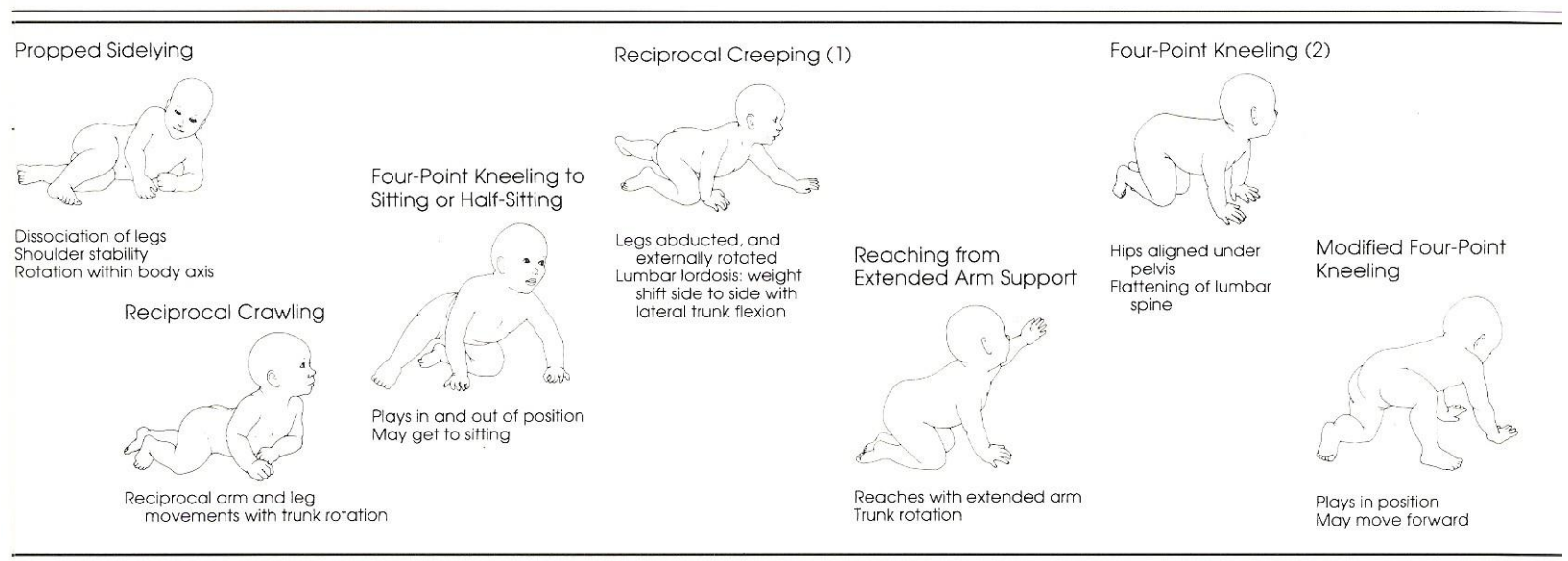

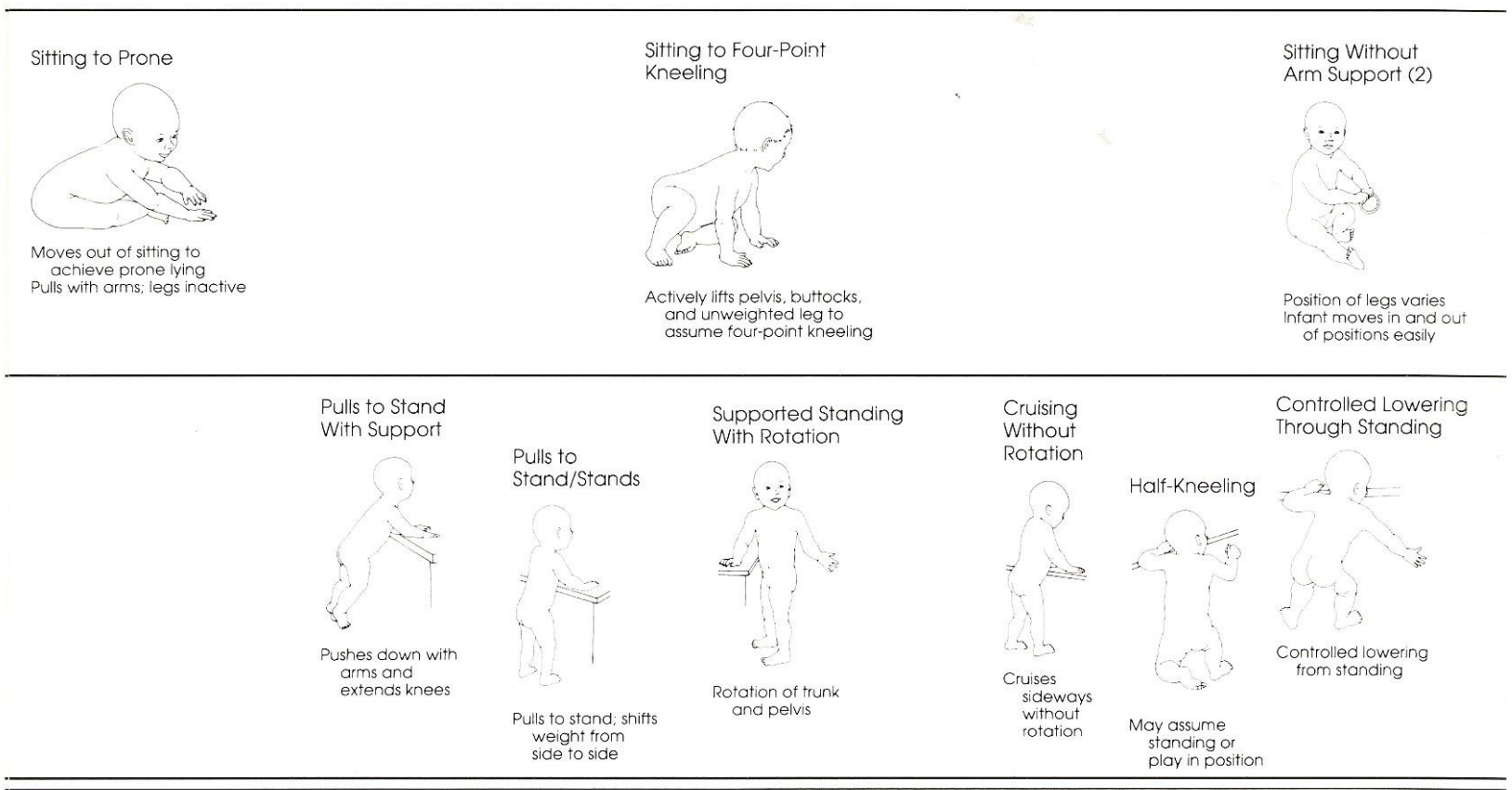


AIMS - Parte 5

Reciprocal Creeping (2)

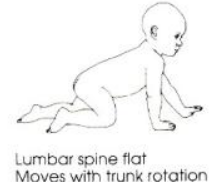

Lumbar spine flat
Moves with trunk rotation

Cruising With
Rotation
Cruises with rotation


AIMS - Parte 6

Percentile Ranks

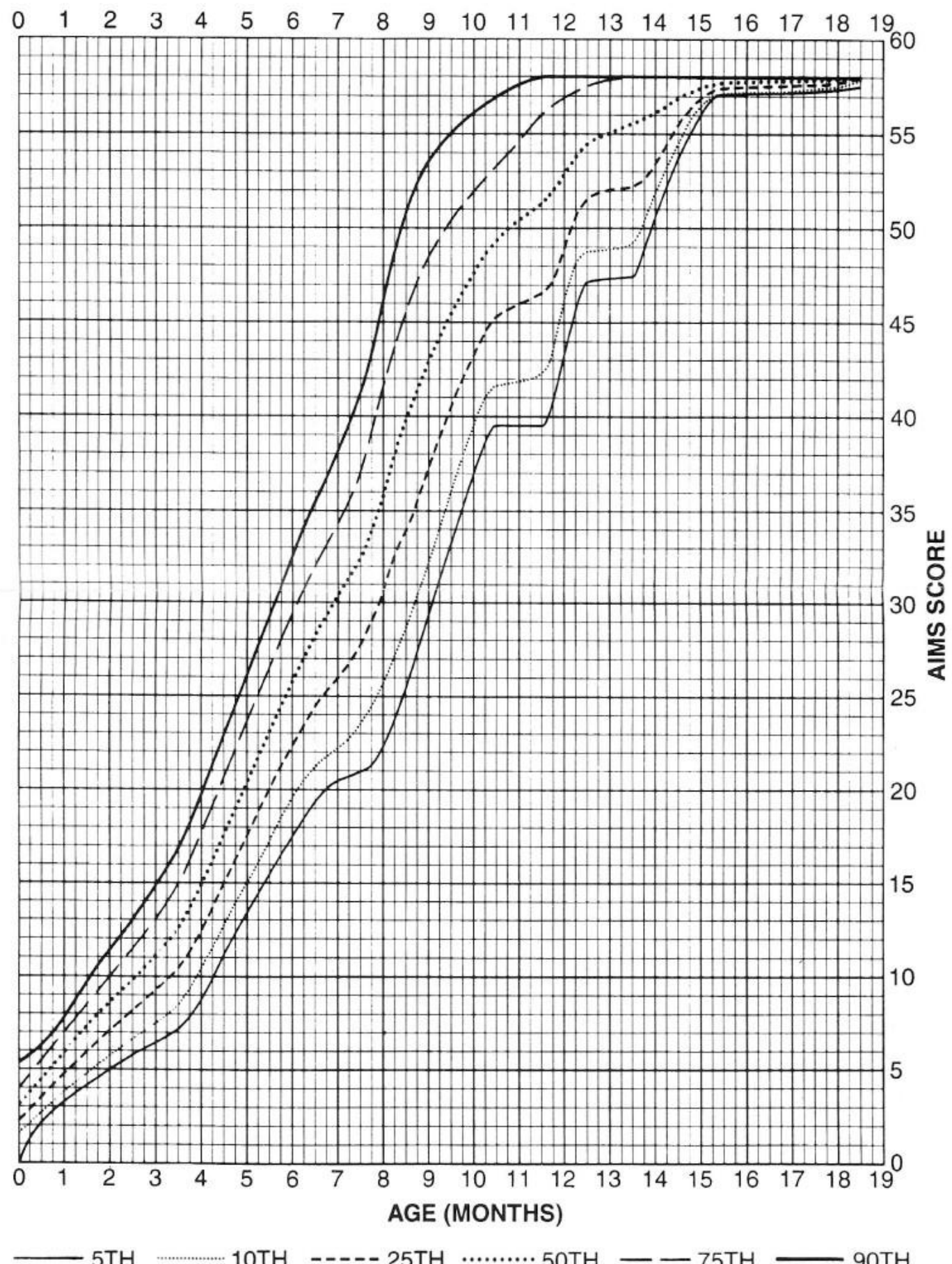




\section{ANEXO 3 - Aprovaçao do Comitê de ética em Pesquisa}

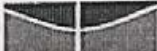 \\ Universidade de Brasilia \\ Faculdade de Ciencias da Saúde \\ Comitè de Ética em Pesquisa - CEP/FS \\ PROCESSO DE ANÁLISE DE PROJETO DE PESQUISA}

\section{Registro do Projeto no CIP: 064/12}

Titulo do Projeto: "Influència do peso adicional na ativação muscular e na cinemática do alcance de lactentes prematuros com baixo peso ao nascer".

Pesquisadora Responsivel: Aline Martins de Toledo Data de Entrada: 16/05/12

Com base na Resolução 196/96. do CNS/MS. que regulamenta a ética em pesquisa com seres humanos. o Comitê de Ética em Pesquisa com Seres Humanos da Faculdade de Cièncias da Saúde da Universidade de Brasilia, após análise dos aspectos éticos e do contexto técnico-cientifico, resolveu APROVAR o projeto 064/12 com o titulo: "Influência do peso adicional na ativação muscular e na cinemática do alcance de lactentes prematuros com baixo peso ao nascer". analisado na $5^{\circ}$ Reunião Ordinária, realizada no dia 12 de junho de 2012.

A pesquisadora responsável fiea, desde já, notifieada da obrigatoriedade da apresentação de um relatório semestral e relatório final sucinto e objetivo sobre o desenvolvimento do Projeto, no prazo de 1 (um) ano a contar da presente data (item VII.13 da Resolução 196/96).

Brasilia, 26 de outubro de 2012.
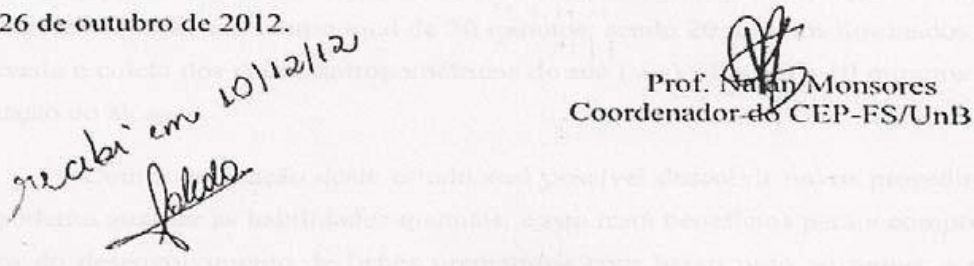

Comite de Ética em Pesquisa com Seres Humanos - Faculdade de Ciências da Saúde Telefone: (61)-3107-1947 Email cepts@unb - 
APÊNDICE 


\section{APÊNDICE A}

$\mathbf{N}^{\mathbf{0}}$ :

Protocolo para Coletas de Dados das Mães e Lactentes

Grupo: ( ) a termo ( ) pré-termo

1 - DADOS PESSOAIS

Nome do

bebê:.

Sexo: ( ) M ( ) F Cor:

Idade Corrigida:...

Data de nascimento:.....................

IdadeGestacional:

Endereço.

Bairro:

Fone:

Nome da mãe:

Idade:

Data de Nascimento:.........................

Grau de escolaridade:....

Profissão:.

Estado Civil:

2- DADOS GESTACIONAIS

$\mathbf{N}^{\mathbf{o}}$ de gestações: ( ) $1^{\circ}$ ( ) $2^{\circ}$ ( ) $3^{\circ}$ ( ) + de 3

Doenças da mãe: ( ) Não ( ) Anemia ( ) Sífilis ( ) Diabete ( )

Toxoplasmose ( ) Febre ( ) Rubéola ( )

outras:.....

Anormalidades na gravidez:

( ) Não ( ) Hemorragias ( ) Hipertensão ( ) Hipotensão ( ) Edema ( ) Síndrome de

HELP ( ) Diabétes ( ) Infecções

()Outras:....

Ingestão de tóxicos:

( ) Não ( ) Fumo ( ) Alcoolismo ( )

Outros:

Ingestão de medicamentos:

( ) Não ( )Tranqüilizantes ( ) Vitaminas ( )

Outros:

Exposição ao RX: ( ) Sim ( ) Não Mês gestação:

Desnutrição e/ou maus tratos: ( ) Sim ( ) Não

Época gestação:.

3 - DADOS AO NASCIMENTO

Tipo de parto: ( ) Espontâneo ( ) Induzido ( ) Fórceps ( ) Cesariana

Cordão Umbilical: ( ) Normal ( ) Circular ( ) Nó

Alguma

intercorrência:.

4 - DADOS PÓS-NATAL 
Idade gestacional:

Estatura:

(semanas). Peso Nascimento:

(g)

Apgar: 1' 5 , .cm

Problemas respiratórios:

a) Doença respiratória necessitando tratamento com surfactante: Sim ( ) Não ( )

b) Ventilação Mecânica: Sim ( ) Não ( ) Tempo:

c) Pneumotórax: Sim ( ) Não ( )

d) Persistência do canal arterial: $\operatorname{Sim}(\quad$ ) Não ( )

e) Ataques de apnéia: Sim ( ) Não ( )

f)Desconforto respiratório síndrome - Doença da membrana hialina:

$\operatorname{Sim}($ ) Não ( )

Asfixia leve ou grave no momento ou logo após o nascimento: ( )

Leve ( ) Grave ( ) No parto ( ) Após o nascimento ( )

Atraso do crescimento intra-uterino: ( )

Hemorragia intra ou periventricular: ( ) Grau:

Hipoglicemia: ( )

Hiperbilirrubinemia: ( ) Duração:..................dias

Infecções: bacterianas ( ) fúngicas ( ) parasitárias ( ) virais ( )

Convulsões neonatais: ( )

Leucomalácia peri-vetricular: ( )

Medicamentos:

Alimentação: ( ) amamentação - tempo:

( ) mamadeira

5 - DADOS DO TESTE

Data do Teste : .....................

- Horário da última mamada: Horário que acordou:

- Está com algum problema de saúde: ( ) sim ( ) não

- Estado comportamental: ( ) alerta ativo ( ) alerta inativo

- Horário do início do teste: Término do teste:

Quem passa a maior parte do tempo com o bebê?

Brinca freqüentemente com o bebê: ( ) Sim ( ) Não

Qual o brinquedo preferido?

Consegue alcançar o brinquedo sozinho? ( )Sim ( ) Não ( ) 